\title{
WestVirginiaUniversity
}

THE RESEARCH REPOSITORY @ WVU

Graduate Theses, Dissertations, and Problem Reports

2002

\section{Instructional alternative for underprepared students}

Deborah A. Thomas

West Virginia University

Follow this and additional works at: https://researchrepository.wvu.edu/etd

\section{Recommended Citation}

Thomas, Deborah A., "Instructional alternative for underprepared students" (2002). Graduate Theses, Dissertations, and Problem Reports. 2456.

https://researchrepository.wvu.edu/etd/2456

This Dissertation is protected by copyright and/or related rights. It has been brought to you by the The Research Repository @ WVU with permission from the rights-holder(s). You are free to use this Dissertation in any way that is permitted by the copyright and related rights legislation that applies to your use. For other uses you must obtain permission from the rights-holder(s) directly, unless additional rights are indicated by a Creative Commons license in the record and/ or on the work itself. This Dissertation has been accepted for inclusion in WVU Graduate Theses, Dissertations, and Problem Reports collection by an authorized administrator of The Research Repository @ WVU.

For more information, please contact researchrepository@mail.wvu.edu. 


\title{
Instructional Alternative for Underprepared Students
}

\author{
Deborah A. Thomas
}

Dissertation submitted to the College of Human Resources and Education at West Virginia University in partial fulfillment of the requirements for the degree of

\section{Doctor of Education \\ In}

Educational Psychology

Daniel Hursh, Ph.D., Chair

Thomas Lombardi, Ph. D.

Roy Moxley, Ph. D.

Neal Shambaugh, Ph. D.

Catherine Yura, Ed. D.

Department of Advanced Educational Studies

\author{
Morgantown, West Virginia \\ 2002
}

Keywords: Daily Drills, Underprepared College Students, Fluency Copyright 2002 Deborah A. Thomas 


\section{ABSTRACT \\ INSTRUCTIONAL ALTERNATIVE FOR UNDERPREPARED STUDENTS}

\section{Deborah A. Thomas}

This quasi-experimental study examined the use of daily drills as a supplemental instructional alternative for underprepared students enrolled in General Psychology courses at a midwestern open-admission community college. Underprepared students were defined as those students whose Nelson-Denny Reading Test score fell below community college entrance level criteria. Daily one-minute drills of course content were provided to all participants in the experimental group. Lectures, discussion, and class activities were provided to both groups. The experimental and control group were compared using retention data, reading scores, and exam scores. Although more students in the experimental group withdrew from the course, most withdrew for reasons unrelated to course performance. All students who withdrew from the control section of the course were failing the course. Although not specifically addressed, both groups demonstrated significant improvement in vocabulary, comprehension, and reading rate. For each of the five course units a set of questions was repeated on the pretest, unit exam, and posttest. In both groups, comparisons of correctly answered exam questions revealed significant improvement from the pretest to the unit exams and from the pretest to the posttest. On four of the five units, only the experimental group increased the number of correctly answered questions from the unit exam to the posttest. Anecdotal reports of student behavior suggested that the control group participated in self-initiated course-related study activities that the experimental group did not. Although there were more underprepared students in the experimental group and the control group reported additional study activities, course-related exam scores were similar between groups. The possibility that the one-minute drills may have provided an instructional tool that substituted for alternative study activities suggests the benefit of additional study of this time efficient and low cost instructional alternative for underprepared college students. 


\section{DEDICATION}

The author wishes to dedicate this document to Hazel Thomas. Because of her maternal influence, the importance of education was never questioned and always valued. 


\section{ACKNOWLEDGEMENTS}

The author wishes to acknowledge the guidance and support of the members of the doctoral committee, past and present. Dr. Lawrence Fraley provided the encouragement and challenge to apply to the educational psychology program, and served as a valued mentor. Dr. Dan Hursh generously contributed his energies to the completion of this document. Dr. Neal Shambaugh agreed to assist the effort, even though communications were only long distance. Dr. Roy Moxley and Dr. Tom Lombardi provided valuable input to the development of the prospectus.

Dr. Cathy Yura provided support, understanding, and enthusiasm that kept the process moving. These notations are only a few of the generous contributions that each have made in the evolution of this document.

The author wishes to acknowledge the encouragement provided by Mrs. Ann Crabtree who served as a valuable link to campus.

The author wishes to acknowledge the support provided by friends and colleagues at Washington State Community College. The library staff, administrators, and Opportunity Scholars staff consistently "went the extra mile" to make sure that this dream became a reality.

The author wishes to acknowledge Traci Thomas Quarrick. Her statistical skills and consistent motivation encouraged the completion of this lifelong goal.

Special thanks are extended to all friends and family who tolerated the demands of this challenge. 


\section{TABLE OF CONTENTS}

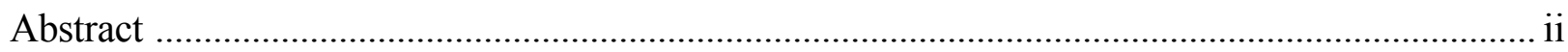

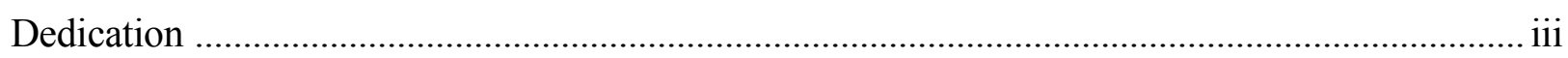

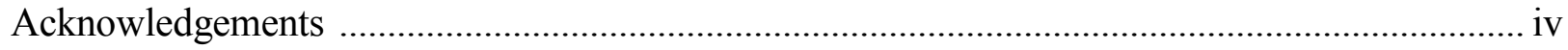

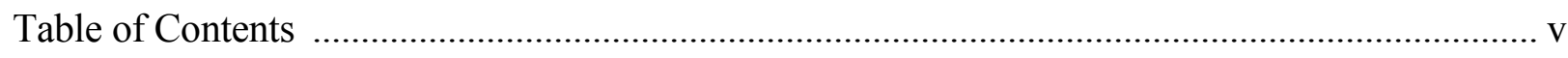

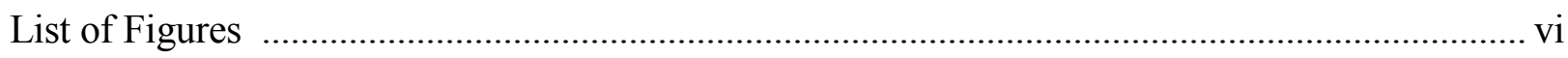

List of Tables ................................................................................................................ vii

Chapter I: Introduction and Literature Review ..................................................................... 1

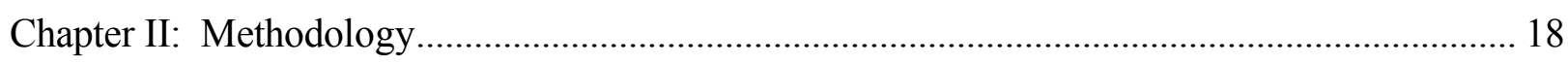

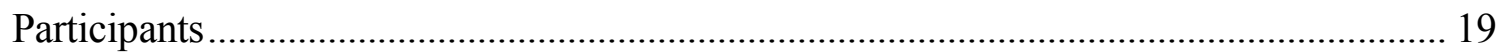

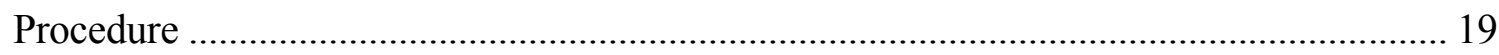

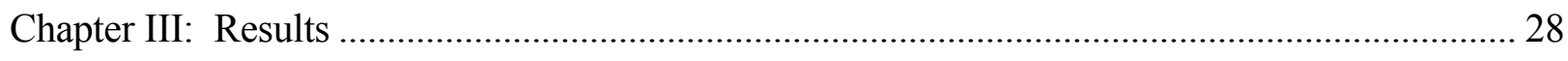

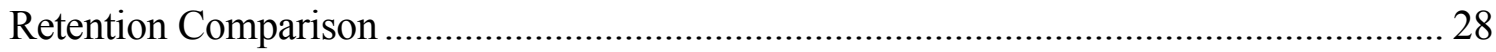

Comparison of Reading Skills..................................................................................... 30

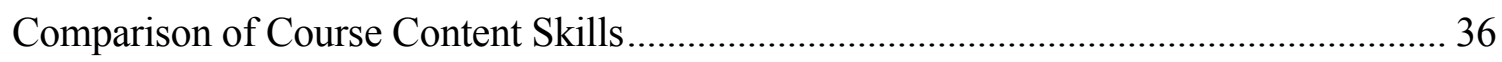

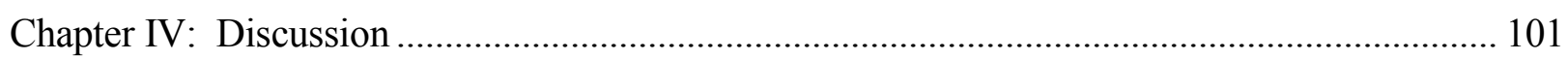

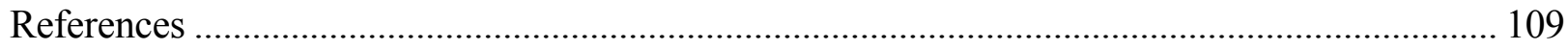

Appendix A: Research Design and Procedures.................................................................... 112

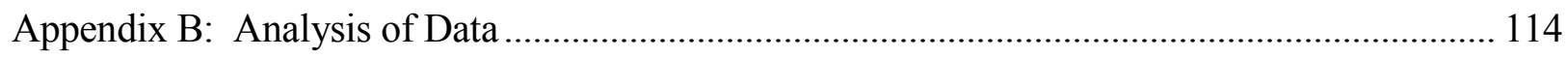

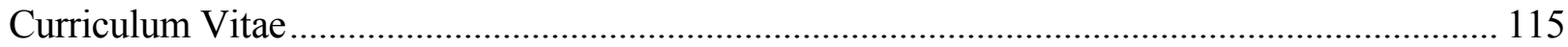




\section{LIST OF FIGURES}

Figure 1. Instructional accomplishment of skills ...................................................24

Figure 2. Progressive multiple baseline achievement test design ...................................26

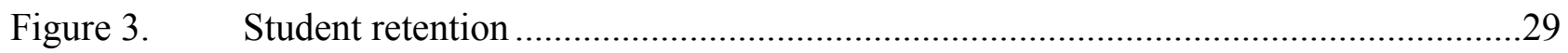

Figure 4. Percentile rank of Nelson-Denny vocabulary pretests and posttests ......................31

Figure 5. Percentile rank of Nelson-Denny comprehension pretests and posttests..................31

Figure 6. Percentile rank of Nelson-Denny total reading pretests and posttests .....................32

Figure 7. Percentile rank of Nelson-Denny reading rates .................................................33

Figure 8. Percentage increases in Nelson-Denny percentile scores ....................................34

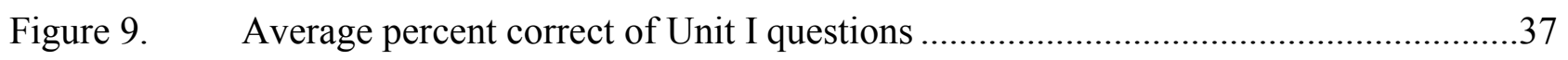

Figure 10. Average percent correct of Unit II questions ...................................................37

Figure 11. Average percent correct of Unit III questions.................................................38

Figure 12. Average percent correct of Unit IV questions ..................................................38

Figure 13. Average percent correct of Unit V questions...................................................38

Figure 14. Means comparison of Unit I questions correct .................................................42

Figure 15. Means comparison of Unit II questions correct .................................................45

Figure 16. Means comparison of Unit III questions correct................................................48

Figure 17. Means comparison of Unit IV questions correct ...........................................52

Figure 18. Means comparison of Unit V questions correct................................................55

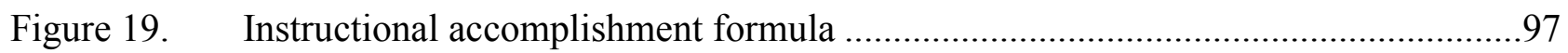

Figure 20. Progressive multiple baseline achievement test design ....................................98

Figure 21. Multiple baseline of correctly answered questions per unit.............................. 100 


\section{LIST OF TABLES}

Table 1. Sample of Daily Drill Terms and Responses from Abnormal Psychology Unit.......22

Table 2. Comparison of Differences in Pretest and Posttest Values of the Nelson-Denny ...........35

Table 3. Instructional Accomplishment of Reading Skills Measured by the Nelson-Denny ........36

Table 4. Number of Correct Test Items Per Participant on Course Content Pretest......................39

Table 5. Number of Correct Test Items Per Participant on Course Content Posttest ....................40

Table 6. Correct Test Items Per Underprepared Participant on Course Content Pretest ...............41

Table 7. Correct Test Items Per Underprepared Participant on Course Content Posttest .............41

Table 8. Means and Standard Deviations of Exam Means (Unit I, Experimental) .......................43

Table 9. Repeated Measure ANOVA (Unit I, Experimental).......................................................4

Table 10. Means and Standard Deviations of Exam Means (Unit I, Control).................................44

Table 11. Repeated Measure ANOVA (Unit I, Control) .............................................................45

Table 12. Means and Standard Deviations of Exam Means (Unit II, Experimental) ......................46

Table 13. Repeated Measure ANOVA (Unit II, Experimental) ……………………......................47

Table 14. Means and Standard Deviations of Exam Means (Unit II, Control) ................................47

Table 15. Repeated Measure ANOVA (Unit II, Control).............................................................48

Table 16. Means and Standard Deviations of Exam Means (Unit III, Experimental).....................50

Table 17. Repeated Measure ANOVA (Unit III, Experimental) ...................................................50

Table 18. Means and Standard Deviations of Exam Means (Unit III, Control) ...............................51

Table 19. Repeated Measure ANOVA (Unit III, Control) …………….........................................51

Table 20. Means and Standard Deviations of Exam Means (Unit IV, Experimental) ....................53

Table 21. Repeated Measure ANOVA (Unit IV, Experimental)..................................................53

Table 22. Means and Standard Deviations of Exam Means (Unit IV, Control) ...............................54

Table 23. Repeated Measure ANOVA (Unit IV, Control) ............................................................54

Table 24. Means and Standard Deviations of Exam Means (Unit V, Experimental)......................56

Table 25. Repeated Measure ANOVA (Unit V, Experimental) ……………………..................56

Table 26. Means and Standard Deviations of Exam Means (Unit V, Control) .................................57

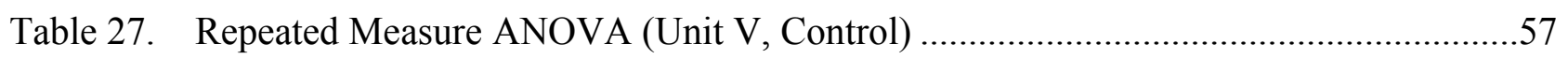

Table 28. Means and Standard Deviations of Questions Containing Drilled Terms (Unit I).........59

Table 29. ANOVA of Questions Containing Drilled Terms (Unit I, Experimental)......................60 


\section{LIST OF TABLES (CONT.)}

Table 30. ANOVA of Questions Containing Drilled Terms (Unit I, Control) ............................60

Table 31. Means and Standard Deviations of Questions Containing Applications (Unit I)..........62

Table 32. ANOVA of Questions Containing Applications (Unit I, Experimental).....................63

Table 33. ANOVA of Questions Containing Applications (Unit I, Control) .............................63

Table 34. Means and Standard Deviations of "Practice” Questions (Unit I) .............................64

Table 35. ANOVA of "Practice" Questions (Unit I, Experimental) .........................................65

Table 36. ANOVA of "Practice” Questions (Unit I, Control) ..................................................66

Table 37. Means and Standard Deviations of Questions Containing Drilled Terms (Unit II) .......67

Table 38. ANOVA of Questions Containing Drilled Terms (Unit II, Experimental) ...................68

Table 39. ANOVA of Questions Containing Drilled Terms (Unit II, Control)...........................68

Table 40. Means and Standard Deviations of Questions Containing Applications (Unit II) .........70

Table 41. ANOVA of Questions Containing Applications (Unit II, Experimental) ....................71

Table 42. ANOVA of Questions Containing Applications (Unit II, Control)...........................71

Table 43. Means and Standard Deviations of "Practice” Questions (Unit II) ...........................72

Table 44. ANOVA of "Practice” Questions (Unit II, Experimental) ......................................73

Table 45. ANOVA of "Practice” Questions (Unit II, Control) ...............................................74

Table 46. Means and Standard Deviations of Questions Containing Drilled Terms (Unit III) ......75

Table 47. ANOVA of Questions Containing Drilled Terms (Unit III, Experimental).................76

Table 48. ANOVA of Questions Containing Drilled Terms (Unit III, Control) .........................76

Table 49. Means and Standard Deviations of Questions Containing Applications (Unit III) ........78

Table 50. ANOVA of Questions Containing Applications (Unit III, Experimental) ...................79

Table 51. ANOVA of Questions Containing Applications (Unit III, Control) ...........................79

Table 52. Means and Standard Deviations of "Practice”" Questions (Unit III)...........................80

Table 53. ANOVA of "Practice” Questions (Unit III, Experimental) ......................................81

Table 54. ANOVA of "Practice” Questions (Unit III, Control) ...............................................81

Table 55. Means and Standard Deviations of Questions Containing Drilled Terms (Unit IV)......83

Table 56. ANOVA of Questions Containing Drilled Terms (Unit IV, Experimental).................84

Table 57. ANOVA of Questions Containing Drilled Terms (Unit IV, Control) ..........................84

Table 58. Means and Standard Deviations of Questions Containing Applications (Unit IV)........85

Table 59. ANOVA of Questions Containing Applications (Unit IV, Experimental) ...................86 


\section{LIST OF TABLES (CONT.)}

Table 60. ANOVA of Questions Containing Applications (Unit IV, Control) ..........................87

Table 61. Means and Standard Deviations of "Practice" Questions (Unit IV)...........................88

Table 62. ANOVA of "Practice" Questions (Unit IV, Experimental)......................................89

Table 63. ANOVA of "Practice" Questions (Unit IV, Control) ...............................................89

Table 64. Means and Standard Deviations of Questions Containing Drilled Terms (Unit V) .......90

Table 65. ANOVA of Questions Containing Drilled Terms (Unit V, Experimental)...................91

Table 66. ANOVA of Questions Containing Drilled Terms (Unit V, Control) .........................91

Table 67. Means and Standard Deviations of Questions Containing Applications (Unit V) .........93

Table 68. ANOVA of Questions Containing Applications (Unit V, Experimental) ....................94

Table 69. ANOVA of Questions Containing Applications (Unit V, Control) ...........................94

Table 70. Means and Standard Deviations of "Practice" Questions (Unit V)...........................95

Table 71. ANOVA of "Practice" Questions (Unit V, Experimental) .........................................96

Table 72. ANOVA of "Practice” Questions (Unit V, Control) ...............................................96

Table 73. Instructional Accomplishment of Course Content ................................................97 


\section{CHAPTER I: INTRODUCTION AND LITERATURE REVIEW}

While some colleges and universities continue to require that entering freshmen will have completed college preparatory courses and will have obtained minimum entrance scores on tests of basic academic skills, research has revealed that many students entering college lack basic skills (e.g., Anonymous, 1999; Foy, 1994; Levy \& Dixon, 1984; Olson, 1986; Palmer, 1984). "Underprepared college students are students with basic deficiencies in academic skills necessary for the satisfactory completion of college-level course work" (Zhao, 1999, p. 3).

Boylan, Bonham, and White (1999) stated, "Practically every college and university in the United States provides some sort of service for students who are not quite ready to take a particular test, or enroll in a particular major" (p.87). The National Center for Education Statistics (NCES), as cited in Phipps (1998), found that "78 percent of higher education institutions that enrolled freshmen offered at least one remedial reading, writing, or mathematics course" (p.6). All community colleges included in the survey were found to offer remedial classes. The NCES study focused on community colleges, because they represent the highest number of underprepared students. This author is employed at a community college where underprepared students represent a large proportion of freshmen classes annually (Crandell, 1999).

Boylan and White's study (1999) reported that remedial classes in reading, writing, and arithmetic began at the University of Wisconsin in 1849. According to Hennessey (1990), the trend of college entrants lacking skills has existed for at least one hundred years, but recently the problem has become evident nationally. The transition between high school and college, or the workplace and college, has revealed skill deficits among college freshmen. If students with basic skill deficits are to be accepted into college, these deficits must be remedied in order to increase the likelihood of student success and retention in higher education, and to avoid the degradation in university academic standards that would be necessary to accommodate such unskilled students.

Significantly, state and federal funding has been based on the number of students enrolled. In response to increasingly severe economic pressures, the competition for students has become fierce. The skill deficiencies tend to inhibit student success and lower retention rates, 
unless the institutions tacitly encourage concealed moves to lower academic standards (Fraley, 1998; Foy, 1994).

Costrell (1998) stated,

The presence of large numbers of remedial students inevitably creates pressures to reduce standards in the non-remedial classes in which they enroll. When faculty face a wider variation in preparation of those in the same class, this makes it difficult to maintain the standards that would best serve the middle and top students. Some faculty will resist the pressure to relax standards, but others will not. This can be exacerbated when resources are allocated among departments in part on the basis of enrollments. Faculty are then under heightened pressure to adjust standards to the lower average quality of students admitted, in order to maintain the department's enrollments and its claim on university resources (paragraph 27).

If students are not retained, per capita funding could be reduced, posing a threat to the financial stability of the institution. As college officials debate campus financial needs, developmental or remedial education has become a tool of survival, not just for students, but for the colleges. It is no longer enough to attract students; colleges have to keep them. Yet, there remains a controversy regarding who is responsible for remediating students, or training them more effectively prior to college.

Lazarick (1997) noted that the Florida legislature passed a law that required students who failed remedial courses to pay the full cost to take the course a second time. This effort was apparently based on the view that students and high schools should bear the responsibility for students arriving at college underprepared. Not surprisingly, college educators did not support the law, because it effected enrollment and subsequently, funding. On the other hand, the general public supported the measure, suggesting that taxpayers are not enthusiastic about paying for repeated attempts for students to acquire basic skills.

Adelman (1996) indicated "the extent of a student's need for remediation is inversely related to his or her eventual completion of a degree" (paragraph 8). However, Hebel (1999) referenced Community College of Denver data that suggested that underprepared students who successfully completed remedial classes were more likely to graduate or transfer, than those who 
did not require remediation. Data are inconsistent about the success of underprepared students, but data are clear about their presence on higher education campuses.

Some apparently successful remediation practices are not universally included within college curricula. An anonymous author published in Change (1999) asserted that policy-makers and educators debate about remedial programs, but "too little is known about the content and delivery of remedial education nationwide or the features of successful programs for the underprepared" (p.57). Between the debates about the responsibility for the problem and confusion about remediation program outcomes, lies the basic question of what can be done to train and retain effectively these underprepared students. This study was designed to explore one educational alternative to address the academic needs of these students.

The number of developmental or remedial classes has increased on college campuses, and the search for more effective teaching strategies of basic skills has continued (Adelman, 1996; Anonymous, 1999; Boylan, 1999; Gose, 1997; Lazarick, 1997). Within a limited time frame, the skill development classes have the arduous task of readying students for college course work.

To attack the problem of basic skills deficiency on the college level, specific courses have been developed that address the problem (Anonymous, 1999; Napoli \& Hiltner, 1993), basic skills instruction has been included within college level classes (Beneke, 1991; Palmer, 1984, p. 22), outsourcing has been attempted (Phipps, 1988), and contracts have been signed with tutoring companies (Gose, 1997). The reports on the effectiveness of remedial courses have been as varied as the approaches used (Hennessey, 1990; Napoli \& Hiltner, 1993; Palmer, 1984).

Evidence has not been conclusive about the effectiveness of tutoring companies (Breneman \& Haarlow, 1999; Gose, 1997; Phipps, 1998). Kaplan Educational Center and Sylvan Learning systems have been contracted by several colleges to teach remedial skills. The financial investment has been significant, but "there's little evidence to suggest whether the companies' approaches are effective with college-level remediation" (Gose, 1997, paragraph 37).

Courses in various subject matters that incorporate basic skills development have provided mixed results (Beneke, 1991; Palmer, 1984; McDade \& Goggins, 1993). According to Phipps (1998), outsourcing efforts such as contracting remedial services to private providers and remedial courses provided by private vendors have not yet provided evidence of success, either financially or academically. 
Added to the confusion is the fact that students with skill deficits have not always enrolled in available remedial classes. At the open admission community college in which this author is employed, $69 \%$ of the 301-student cohort in the fall of 1997 were advised to enroll in one or more developmental studies courses, based on their performance on the initial placement test. The percentage of students for whom remediation was recommended that actually enrolled in the recommended classes included math-77\%, composition-73\%, and reading 56\% (Crandell, 1999).

On some open admission campuses, including the one cited, there is no required skill demonstration for entry into introductory college classes; students merely have to enroll. As a result, students could be enrolled simultaneously in a remedial reading class and a course that requires college-level reading, such as psychology. Remedial classes frequently do not carry college credit, so students sometimes opt not to take them at all (Crandell, 1999). Students may reach the erroneous conclusion that because they have been accepted into college, they must already have the skills to succeed. Perhaps a more accurate conclusion would be that they are in college because they have the funding to attend.

Unfortunately, some students are not aware that open admission colleges, by policy or mission, accept every student who applies. Because some of the students have experienced limited success in public schools, they are surprised that they can attend college. This may contribute to their beliefs that remediation is not necessary to succeed in the community college setting, except in subject areas where they are aware of skill deficits. It is noted in the Crandell (1999) report that more students opt to enroll in remedial math classes than other subjects are. Perhaps this reflects a stronger recognition of math skill deficits than in other subject areas. The low enrollment in reading may reflect confusion about the necessity of higher-level reading skills to succeed in higher education classes.

Many introductory courses in higher education are described as survey courses, that is, courses that introduce the student to the field of study. Courses such as psychology, sociology, and history, are included in the curricula on most campuses, and, for many majors, are general education requirements. General education courses are included in the program requirements for successful completion of certificates and degrees, including those considered terminal technical degrees such as an associate degree in auto/diesel repair. 
Within community colleges, general education courses are offered in "science, social science, humanities, and communication" (Cohen, 1988, p. 2). The focus of these courses is an acquisition of a basic behavioral repertoire that allows the successful student to "think critically, develop values, understand traditions, respect diverse cultures and opinions, and most important, put that knowledge to use" (Cohen, 1988, p. 1). General education courses provide opportunities for students in all majors to experience instruction and exposure to subjects outside of their interest areas.

General education courses are traditionally taught in a classroom format, with the underlying assumption that students have read and studied outside of the classroom. It is logical to assume that students' deficiencies in study skills and reading may prevent academic success in such settings. Hennessey (1990) concluded "students who voluntarily enrolled in and completed a reading improvement course succeeded at a higher rate and persisted longer than students who did not complete the course or avoided it" (p. 119).

Without successful remedial intervention among the underprepared students, introductory courses become challenging experiences for students and instructors. Foy (1994) indicated that "the entire undergraduate educational program is affected...[and] may create a negative climate in the classroom with students sharing the frustration and feeling that the instructor is demanding of them abilities which they do not possess" (p. 276). Additionally, the reading skills of students and the reading levels that are found in college level books do not match (Levy \& Dixon, 1984; Olson, 1986), decreasing the likelihood of student success in courses that rely on textbooks to teach.

On the campus where this study was conducted, psychology is a general education course that is required for every major. Informal observations of students attempting the course have revealed that students with underprepared reading skills frequently withdraw from the course or receive a low course grade. Attempts to require a prerequisite reading level were thwarted by the campus practice of allowing students to waive prerequisite requirements, without advisor approval. The course in which this study was conducted has included in the syllabus the following prerequisite statement: It is strongly recommended that students have completed the College Reading course or that its completion was deemed unnecessary based on the reading section of the COMPASS test [campus placement test]. However, underprepared students 
continue to enroll in general psychology, and many remain in the class after receiving the syllabus. The students in this study represented such a population.

Collectively, all of these factors illustrate the necessity of finding more effective methods to address the needs of underprepared students. Lindsley (1992) stated, "Effective educational methods are available" (p. 21). He described the methods as those that were "mostly behavioral, structured, fast paced, and require a high proportion of regular practice" (p. 21). It is recalled that the acquisition of basic skills in elementary settings followed a similar instructional format. Elementary school students accurately engaged in such skill-building practices as computing multiplication problems, alphabetizing words, and producing writing samples within the constraints of timed drills. The basic skill deficiencies of college students appear to lend themselves to drills, as well.

After heavy utilization during elementary school, this author recalls an absence of timed drills during subsequent educational endeavors. Notable exceptions in academia include business courses like typing and shorthand, where the attainment of accuracy is not enough, because fluency is also required. In courses like typing and shorthand, fluency is demonstrated and measured by the number of correct words typed per minute. Students must demonstrate accuracy and speed at a predefined level, in order for their performance to be deemed appropriate. The old adage of "practice makes perfect" seems to have been limited to certain subject areas and athletics. McDade and Goggans (1993) stated that "the difference between a professional and an amateur is frequency of preferred responses" (p.292).

By the time students reach college, instructional practices suggest that the development of additional academic skills does not require the same level of proficiency. Demonstrations of fluency are seldom required when students perform higher-level skills. While no teacher would expect an elementary student to multiply by three digits prior to learning basic multiplication tables, students in open admission colleges are not required to demonstrate fluent reading skills or study skills before admission to college courses that require them. Frequent failure would seem an inevitable and predictable outcome for students who are allowed to proceed without those basic skills. As retention of students is becoming an economic necessity of colleges, the practices by which those seemingly inevitable failures are avoided warrant scrutiny.

A promising supplement to current teaching practices may be found within the Precision Teaching movement. According to Lindsley (1992), "Precision teaching came from free-operant 
conditioning laboratories to classrooms in 1965. Essentially, it is applying free-operant conditioning's rate of response and standard slope cumulative recording tactics to classroom teaching and research" (p.54). "Precision teaching is basing educational decisions on changes in continuous self-monitored performance frequencies displayed on standard celeration charts (Lindsley, 1992, p. 51).

Skinner (as cited by Binder and Watkins, 1990, p. 76) indicated that the "rate of responding appears to be the only datum which varies significantly and in the expected direction under conditions which are relevant to the learning process". Nonetheless, Binder and Watkins reported that the practice of measuring rate has not been as common as the practice of measuring accuracy. Binder (1993) indicated that "when Skinner built his first teaching machines, and others followed with application of behavioral principles to education and training, rate measures were generally dropped in favor of more conventional percentage correct or accuracy-only assessments" (p. 8). Binder attributed this pattern to the educational practice of evaluating accuracy and ignoring time (p.8).

Lindsley's work has revisited and retained the practice of measuring rate. Binder and Watkins (1990) gave Lindsley credit for defining "the first simple measure of learning in the literature: celeration (either a multiplicative acceleration of behavior frequency; or a dividing deceleration of behavior frequency per celeration period, e.g., per week)" (p. 78).

Binder and Watkins (1990) summarized the philosophy, development, and strategies of precision teaching. The methods have been demonstrated successfully in academic and business settings, with no indication that the age of the learner affected the outcomes. Precision teaching requires an individual to reach accurate levels of performance within timed sessions. This accurate and rapid demonstration of skills has been described as fluent behavior. Daily practices or drills are recorded on a celeration chart that indicates the rate of correct responses and monitors trends in rates of responding. Standard celeration charts are semi-log, equal ratio line graphs that are specially constructed to deal with certain subtle characteristics of skill acquisition, so that the resulting graphic representation of progress more accurately accommodates certain differentials that inhere in the behavior change process that is taking place (Pennypacker, Koenig, \& Lindsley, 1972).

Haughton (1972), cited in Binder (1993), "encouraged teachers to use brief daily samples (often one minute in duration) of correct and incorrect academic response rates to make decisions 
about students' progress" (p. 9). Because the response trends could be identified clearly, accurate predictions of future performance could be made. When a learner has not exhibited the projected behaviors, adjustments can be made to instruction immediately.

Binder (1988) stated, "The true definition of mastery is fluency, a combination of accuracy (or quality) plus speed which ensures that students will be able to perform easily in the presence of distraction, will be able to retain newly-learned skills and knowledge, and will be able to apply what they've learned to acquire new skills or to real-life situations. Fluency is 'second nature' knowledge, near-automatic performance, the ability to perform without hesitation. In short, fluency is true mastery" (p. 12).

Binder and Watkins (1990) addressed three key elements of the precision teaching philosophy. They indicated "Lindsley taught Precision Teachers to assume that learners respond in lawful ways to environmental variables and that if learners behave in an undesirable way it is the responsibility of teachers to alter those variables until they produce the desired result" ( $\mathrm{p}$. 78). In other words, teachers have the responsibility to alter the learning environment to facilitate the learning experiences of students.

The fact that increasing numbers of underprepared students are attending open admission community colleges should prompt changes in the learning environment to address their needs in appropriate ways. Unfortunately, the needs may be addressed in inappropriate ways such as reducing the standards and allowing these students to continue without basic skills. Additional remedial classes will not improve the situation, if the methodologies are not accountable.

Binder and Watkins (1990) emphasized that "daily measurement of performance" (p.78) has been an ongoing critical element of precision teaching. This scheme of measurement allows the learner and the teacher to assess performance and make immediate necessary changes. The third prescribed element requires that the learner record the daily performance. This practice allows students to come under stimulus control of their own behavioral trends and to participate in the plans for changes in the arrangements for their own instruction.

During the past thirty years precision teaching has been found to be an effective teaching practice in various academic settings. One of the most renowned programs, the Morningside Academy in Seattle, Washington, has included precision teaching in its outstanding and successful teaching operations. Precision teaching represents one facet in the multifaceted Morningside program of instruction. The Morningside Academy combines several databased 
methodologies that provide the students an individualized method of instruction across academic subjects. The focus of the program is "effective teaching to establish key component skills and their underlying tool elements to fluency" (Johnson \& Layng, 1992, p. 1476).

Johnson and Layng (1992) stated that "accurate performance needs to become quick, easy and automatic to be (a) useful, (b) remembered, and (c) applied" (p. 1476). The Morningside Model consists of four steps toward mastery of the subject areas; "establishing (accuracy building), remembering (fluency building), enduring (endurance building), and applying (new environments, formats, more complex skills)" (p. 1477). The application of these four steps to an individual's learning depends on that student's historical learning pattern and current academic skills.

Johnson and Layng (1992) found that "some learners can begin fluency building simultaneously with accuracy training, others need to be fully accurate before they can profitably build rate, and still others are between the two extremes" (p. 1479). This program allows a student and teacher jointly to identify the pattern of learning that works best and approach tasks with those steps. "The steps in the model may need to be rigorously programmed for some learners, whereas others profit from a less rigorous sequence” (Johnson \& Layng, 1992, p. 1479).

Binder (1993) reported "students must achieve certain minimum rates of correct responding on prerequisite skills or knowledge tasks in order to progress smoothly through subsequent applications of those skills and knowledge" (p.9). These prerequisite and basic skills are sometimes called "tool skills" (McDade and Goggans, 1993; Johnson and Layng, 1992). These skills provide the basis for subsequent skill development. Performance of a skill is not adequate. Even accurate performance will not provide an adequate basis for later progress. Instead, these researchers suggest that designated rates of performance on tool skills must be reached in order for the student to be prepared adequately for higher-level skill development.

Binder (1993) stated, "Early Precision Teachers derived the instructional principle that in order to acquire and smoothly attain competence on a given composite skill or knowledge task, one must achieve both accuracy and speed on its components or prerequisites" (p. 9). This principle was discovered in education following extensive research, but has always been a widely accepted assumption within the world of sports. Swimmers, ice skaters, skiers, golfers, et cetera must attain accuracy and speed on basic skills, before they are considered to be experts. There is no question that sports celebrities continue to practice basic skills in order to maintain 
their levels of expertise. Why would educational skills require less practice or expertise on basic skills?

"Decades of research and application suggest that Precision Teaching and Direct Instruction in regular and special classrooms may be capable of eliminating America's current 'basic skills crisis,' if broadly adopted" (Binder, 1990, p.75). Unfortunately, the existence of the technology has not prompted its use, and increased skill deficits on the postsecondary level have become the rule, instead of the exception (Lazarick, 1997).

One might assume that more effective methods to overcome basic skill deficits are not used because practicing teachers are unaware of their existence. Perhaps teacher education programs are not including these methodologies in their curricula. However, teachers who do have the precision teaching instruction do not necessarily engage in these practices.

Daly and Cooper (1993) conducted a study to determine if inservice and preservice teachers with training in precision teaching actually used precision teaching techniques within their classrooms. Preservice and inservice teachers who had received precision teaching instruction completed a follow-up survey, after returning to the classroom. It seemed apparent that the standard celeration charts were not an integral part of their teaching practices-a major concern for the researchers (p. 324-325). Both groups reported that "precision teaching offered effective classroom instructional application" (p. 323). While many reported the use of portions of precision teaching techniques across various subject areas, the use of standard celeration charts was low and inconsistent. The standard celeration charts were not used to make instructional decisions, but in general, the teachers indicated their positive regard for the use of drills and frequency counts within their instruction. Of concern to the authors was the relative absence of effective charting, and subsequently, an absence of instructional decisions based on the data. The standard celeration charts appeared to confuse the teachers, in addition to their perception of insufficient time to complete them. While the instructional methods were considered feasible, the charting seemed prohibitive.

The Morningside Model of Generative Instruction integrates instruction and fluency in its teaching approach. Although effectively used with children and adults, the approach with adult learners will be the focus of this review. Johnson and Layng (1992) reported examples of program success with adults enrolled in a Job Training and Partnership Act (JTPA) program and adults enrolled at Malcolm X College in Chicago, Illinois. These learners'skills appear to 
approximate closely the skills of students within open admission community colleges, the focus of this study.

Forty percent of students entering Malcolm X College score below an eighth grade literacy standard (Johnson and Layng, 1992). Because it generally takes an extended time for these students to raise their skills to college level, many do not persevere. The Morningside Model was initiated in the summer of 1991 to address the training needs of these underprepared students. Following initial assessment, students participated in morning math programs followed by afternoon reading and study skills training. Although the training only lasted six weeks, students improved a minimum of one academic year in each subject area. Students increased their reading rates approximately 1.1 academic year for every 20 hours of practice.

After the pilot program, this procedure was repeated at Malcolm X College and continues. An average gain of two grade levels for 20 hours of instruction continues (Johnson \& Layng, 1992, p.1484). With no homework and primarily a paraprofessional staff, this program has accomplished educational strides for which others are searching. Presumably, the need for retention of similar students in many colleges would make this program a model to emulate.

The adult learners in the Morningside Academy model demonstrated similar accomplishments. The JTPA workers were permitted to attend training for two hours, five days per week, although attendance averaged 3.8 days per week (Johnson \& Layng, 1992, p. 1483). These students advanced two grades for every 24 hours of instruction. Another group of learners in a subsequent group advanced two grades per 19 hours of instruction. These results are extremely good relative to the U. S. government standard of one grade level for every 100 hours of instruction (Johnson and Layng, 1992). Clearly, the Morningside model offers a cost effective and efficient method of instruction. Like other proven models, their methods are not widely utilized.

Precision teaching techniques were used to enhance reading skills for college students enrolled in an introductory psychology class (Beneke, 1991). At the beginning of each class, experimental students read prepared readings for one minute and plotted on individual standard celeration charts the number of words per minute that were read. Following the readings, students wrote as many main ideas as they could recall from that day's reading, and recorded the number of recalled concepts. The control group read the same prepared readings for two days at the beginning of the course and for two days at the end, but did not plot their scores from those 
days on standard celeration charts. The experimental group continued the same practice throughout the course. The procedure took less than five minutes per day and resulted in a significant increase in reading and recall rates within the experimental group, compared to the students in the control group. Standard celeration charts were plotted by individual students, and class averages were charted by the instructor. The charts were not utilized to make instructional decisions, because all students were provided the same readings, regardless of previous progress.

McDade, Cunningham, Brown, Boyd, and Olander (1991) conducted two studies at the Center for Individualized Instruction at Jacksonville State University. The subjects were students enrolled in freshmen level courses where reading was not a regular part of the curriculum. The Nelson-Denny Reading Test was used for pre and post testing in the experimental and control groups. Students in the experimental groups read assigned passages for one minute daily and recorded their reading rates on standard celeration charts. In both studies, the experimental groups noted significant improvement in reading, comprehension, and reading rates. Although the study attributed its success to a combination of daily drills and use of the standard celeration chart, the charts were not used to guide or alter instruction. Instead, they seemed to serve only as a self-charting method for students. Celerations and projected performances for each student could have been accessed from the standard celeration charts, but were not reported as an integral aspect of the study.

The combination of daily practice and recordings has been proven effective in the McDade et al. (1991) and the Beneke (1991) studies, but neither confined their measurements only to the effects of daily practice. It was reported in the studies that the combination of daily practices and plotting on celeration charts was responsible for the change. McDade et al. (1991) reported "There is no question that practice-simply reading-enhances students' reading performances" (p. 28). However, the study was deemed effective because of the combined use of drills and celeration charts.

The combination of daily drills and celeration chart plottings enhanced effectiveness on reading and study skills. Perhaps the use of daily drills without celeration recordings could produce a similar effect on the dependent variables. Standard celeration charts are rather complex, and those subtleties could be lost on students who could perhaps derive a sufficient measure of reinforcement from the data displays on more traditional and more familiar equalinterval line graphs of their progress. Neither the Beneke (1991) nor McDade et al. (1991) study 
used the charts to alter instruction, so a primary purpose of standard celeration charts seems to have been ignored, yet skill improvement was reported.

If college students were provided the opportunity to experience daily drills on course material, would the training enhance performance on exams pertaining to the material? If the goal of bringing the desired responses under appropriate stimulus control could occur without the celeration charts, would teachers be more likely to use that portion of the precision teaching model? While the previous studies indicate that standard celeration charts are effective tools, teachers' reluctance to use them is of concern. Daily drills were incorporated into this study to assess their contribution to skill improvement. Because skill improvement was previously produced without the instructional advantages prompted by the standard celeration chart, efforts to duplicate the improvement warrant investigation.

Huffman (1998) examined the effects of "fluency training" (p.42) in the instruction of entry-level accounting courses at an Oklahoma University. (Within the same study Huffman studied self-efficacy [a personal judgment of one's capabilities], but those results have no relevance to this report and will not be discussed.) The experimental group received precision teaching paired with traditional classroom instruction, while the control group received only traditional instruction. He described the procedures in five steps: (1) administration of pretests to both groups; (2) provision of lecture and precision teaching for the experimental group and lecture-only for the control group for the first three chapters of course content; (3) administration of the self-efficacy scale; (4) administration of the first exam; and (5) administration of the first exam 11 weeks later to assess retention (Huffman, 1998, p. 42-43). Following the instruction of the initial three chapters of the course content, both the experimental and the control groups were provided equivalent instruction.

Huffman (1998) designed fluency training of the first three chapters of course content on computers. Students were required to interact with the data and record their performances on log sheets. Citing a study by McDade and Goggans (1993), he initially established a fluency criterion of 25 correct multiple-choice responses per minute, but altered the criterion to 20 correct responses per minute, because he determined that the original criteria were too rigid. Students in the experimental group were not required to complete usual homework assignments, as were the control students. On the first examination following fluency training, the control group performed better than the experimental group. However, the follow-up exam that was 
administered 11 weeks later revealed better performance from the experimental group than from the control group.

The data from the Huffman study were confounded by the fact that only 12 of the 64 students who completed the fluency training actually reached a level of fluency. While their scores revealed better performance than those who had not reached the defined level of fluency, their scores were only slightly better than those of the control group. However, the experimental group performed significantly better than the control group on the second posttest. The experimenter explained the results as a possible anomaly, or with the speculation that the experimental students increased their efforts as a response to their low grades.

Although these results did not support the use of fluency training within this particular subject matter (accounting), there were several variables that may have effected the outcome. Students in the control group were required to complete and submit study questions to the instructor for the three chapters with which the experimental group received fluency training. Because students self-selected their placements in the designated groups by virtue of their schedules, it was impossible to make certain that the groups represented equivalent skills at the beginning of the experiment. Although the fluency training did not result in improved performance, these variables suggested a need for further study to better assess the efficacy of using these techniques in accounting classes. Perhaps noteworthy, there was no use of standard celeration charts and the course design required the student to advance to new materials before the previous materials had been mastered.

Although the standard celeration charts represent the foundation of precision teaching, there is evidence in the studies by Beneke (1991) and McDade et al. (1991) that significant learning can occur when the charts are not used for instructional direction. The assumption that they must be included appears, on some occasions, to discourage the remaining aspects of the technique from being used. In addition to allowing students to see charts of their own progress, the charted celeration data are supposed to inform a teacher about which changes are needed to enhance a student's instructional arrangement. However, a teacher untrained in the use of standard celeration charts may find the semi-log scales confusing, resulting in inaccurate interpretations or the abandonment of any practices that require use of such charts, as Daly and Cooper's (1993) results suggested. 
The present study was designed to provide students a classroom opportunity to master certain aspects of the course content through simple repeated practice of relevant skills. Drills of course-related terms were presented at the beginning of each class period, with the aim of providing students a structured opportunity to interact with the technical vocabulary of the course content. The drills served as an instructional tool and occupied one minute of classroom time.

The instructional drills shared certain features with the SAFMEDS procedure. SAFMEDS, an acronymic term coined by Ogden Lindsley is a method of providing repeated responses to terms. SAFMEDS stands for SAY ALL FAST for one MINUTE EVERY DAY after the cards are SHUFFLED. As Eshelmen (2000) described the technique, cards are prepared with a term on one side of each card and related information on the reverse side. Students are instructed to look at the term on the face of one card, orally present the related property (printed on the back of the same card), look at the back of the card only if necessary, and proceed through the remainder of the cards. Each student practices the technique every day, providing regular opportunities to interact with the terms and their definitions. The focus of the exercise is to improve the students' speed and accuracy (i.e., fluency) in demonstrating the relationship between the terms and their definitions. Students' results are self-recorded on standard celeration graphs, providing immediate feedback to the students and the instructor.

The standard celeration graphs used in the SAFMEDS procedure provide immediate feedback to the student. The number of correct responses acquired in one minute is plotted, providing a visual display of the student's acquisition of skills. Proponents of SAFMEDS strive to increase fluency of skills, because "there is evidence that fluent repertoires coincide with improved retention, endurance, and application" (Parsons, 2001, p.1).

Traditional classroom instruction on course content frequently is not enough to retain students who are deficient in reading and study skills. Research (i.e., Beneke, (1991); Haughton, (1972); Johnson and Layng, (1992); McDade et al., (1991); and Parsons, (2001)) suggests that the inclusion of precision teaching techniques is a viable methodological alternative to add to the traditional repertoire. These studies, with the exception of Beneke (1991), used precision teaching as the primary instructional approach, but they occurred outside of the traditional classroom setting. The present study is among those that have applied the procedure within classrooms. It is apparent that the procedure works, but the successful integration of precision 
teaching into traditional classrooms may increase its application and usage across subjects and age groups.

Because underprepared students frequently lack the vocabulary to effectively study the textbook, the additional exposure to terminology provided by daily drills is presumed likely to aid their efforts. Repetitions of terms, or repeated exposures to them, tend to increase the likelihood of the student responding appropriately to questions containing the terms. In fact, repeated exposure to terms is usually defined as studying with the anticipated effect of increased performance accuracy.

Colleges need instructional alternatives in order to retain students and maintain academic standards. The traditional classroom in which academic standards are enforced, has become a threat to the retention of students. Financial pressures mandate that institutions retain students, and the pressure prompts a 'trickle-down' effect. Administrators encourage professors to enroll and maintain students in classes; professors creatively find ways to keep students; and students continue to pay tuition and eventually graduate with questionable skills.

One appropriate method of keeping students in class would be to increase their basic skills. Increases in reading skills seem necessary to facilitate their learning course content, but as referenced earlier, students do not always take advantage of learning opportunities. Beneke (1991) demonstrated an increase in reading skills, while students were enrolled in a general psychology class. Beneke found that students demonstrated improved attendance while learning new reading skills. Specific reading instruction was conducted within the psychology class, but it seems that course content could be used, also. It is hypothesized that precision teaching techniques added to the traditional classroom methodology can facilitate skill acquisition and aid in the appropriate resolution of the retention problem.

McDade (1991) and Beneke (1991) attributed the success of their studies to the combination of daily practice and celeration graphing, but did not use the celeration graphs to make instructional decisions. Since the graphs were not used to make instructional decisions, it seems as though alternative reinforcers could accomplish the desired effect of providing reinforcing feedback to students. Precision teaching techniques have been available for thirty years, but used minimally. Effectiveness has not been the determining factor in its absence. Instead, teachers have experienced difficulty integrating the techniques, especially the celeration graphs, into classrooms. This study proposed the use of a SAFMEDS-like procedure for course 
content and substituted the use of equal interval, line rate graphs. If students could be retained through basic skills instruction that is integrated into course content instruction, all parties would benefit, and the institution would prosper.

Instructors have had the opportunity to utilize the existing techniques for years, but have seldom done so. This study provided an opportunity to integrate precision teaching into the classroom without using standard celeration graphs and to measure the effectiveness of brief practices. Instructors may become amenable to trying the techniques, if the methods are more easily adapted. The importance of the celeration graphs was not questioned, but the demonstration of learning without them may introduce the use of the precision teaching technology into more classrooms. Success with its easy low-cost practices may prompt teachers to learn about the advantages of precision teaching, including instructional guidance with standard celeration charts. However, the technology must get its "foot in the door" before proving its advantage, and it was believed that a demonstration of effectiveness on the college level could facilitate that effort. 


\section{CHAPTER II: METHODOLOGY}

This study was designed to evaluate the effectiveness of daily drills as an educational alternative for underprepared students. Increases in skill improve retention without requiring as much reduction in academic standards. The research questions addressed in this study include:

(1) Can retention of students improve as a result of participation in daily drills?

(2) Can daily drills of course content increase reading skills?

(3) Can daily drills of course content increase exam scores of course content?

This study was conducted at a Midwestern community college. The same instructor, who was also the experimenter, taught two sections of General Psychology. The morning class was chosen as the experimental group, and the afternoon class served as the control group. Participation in the experiment was optional and had no effect on course grading.

Because the purpose of the study was to assess the effectiveness of brief vocabulary drills on the academic performance of students in a college course, students in an experimental section of the course engaged in daily vocabulary drills during the first five minutes of each class period, followed by general class instruction. Each drill contained 29 multiple-choice items derived from course vocabulary and content. The drills were presented daily and included only terms from the segment being presented in class during the same time period. Students in a control group did not engage in such drills and instead pursued an equal interval of general class instruction and discussion on course-related issued raised by the students.

In this study the data from the daily drills were not used by the instructor to make changes in the planned course curriculum for the class as a whole or for individuals, so the use of standard celeration charts (Lindsley, 1992) by the students to track their own progress on the drills was foregone in favor of standard equal-interval graphs with which they were familiar. While the equal ratio celeration charts yield graphic data that is more sensitive to certain instructional nuances, students require special time-consuming training in how to use them. The use of familiar equal-interval graphs to chart and monitor daily progress on the drills was deemed appropriate for this study.

If effective, daily drills incorporated into normal classroom activities appeared to be an appropriate supplementary instructional methodology. To assess the effectiveness of the drills, written pretests and posttests were administered, and, in addition, a graphic display that 
incorporated pre-drill and post-drill data from the experimental group was created in a multiple baseline format.

Participants

Thirty-five students enrolled in the morning section of a General Psychology class. Thirty-four students enrolled in the afternoon section. All students agreed to participate in the instructor's research, and reported an understanding of the differences in instruction that each class would receive. The complete original groups were monitored for retention purposes, but only the participants who completed the pretest and posttest of the course content were included in the specific analysis of pre and post data. Most participants also completed the pretest and posttest of reading skills, but this was not required for inclusion in the study.

Twenty-seven students, fourteen females and thirteen males, enrolled in the morning section of a General Psychology course served as the experimental group. The mean age was 19 years- 1 month, with a range of 16 years- 7 months to 24 years- 2 months. The control group consisted of thirteen females and nine males enrolled in the afternoon section of General Psychology. The mean age of the control group was 19 years-5 months, with a range of 16 years-9 months to 39 years-1 month.

Procedure

All participants (experimental and control) were administered Form G of the NelsonDenny Reading Test at the beginning of the term, in order to assess course entry reading skills. Form $\mathrm{H}$ of the Nelson-Denny Reading Test was used as the post-test of reading skills at the completion of the course. The Nelson-Denny Reading Test publishers (2000) report, "Forms G and $\mathrm{H}$ are parallel forms that have been equated and can be used interchangeably as pretests and posttests (paragraph 19)."

The Nelson-Denny was chosen to assess reading skills because of its familiarity to educators and the frequency of its use in research. Johnson and Layng (1992) and McDade et al. (1991) used the Nelson-Denny as the reading measurement in their precision teaching research. It also serves as one of the evaluative tools in the developmental reading classes on the campus of the experiment.

Brown, Fishco, and Hanna (1993) stated, "A number of schools have conducted studies that show the Nelson-Denny can be used as a predictor of student success" (p.9). These authors cited several research studies that investigated the use of the Nelson-Denny Reading Test as a 
predictor of academic success. The cited studies utilizing college students suggested that the test adequately predicted success in an introductory psychology course (Feldt, 1988 \& Gerow and Murphy, 1980); positively correlated with the American College Testing Program (ACT) (Hawes, 1982); paired with high school grade point average could be utilized to predict college freshmen grades (Wood, 1982); and could serve as a feasible alternative to the SAT in time limited situations (Erwin, 1981).

In addition to the reading assessment, students in this study were required to complete a pretest of course content. The pretest was identical to the final exam (posttest). One hundred multiple choice test items were presented with four possible responses for each. Students used Scantron sheets to record their responses, and the Scantron sheets were graded by machine. Students were not made aware of their pretest scores from either the reading or subject matter pretest.

The course curriculum was divided into five units with five exams plus a comprehensive final exam. Five sets of drills were designed, corresponding to the units being instructed. The drill procedure administered to the experimental group required the first five minutes of class time daily. The remaining 45 minutes of class time was used for lecture, discussions, and various learning activities that typify the college classroom experience.

In addition to the exam for each course unit, pretests of later course content and posttests of previous content were also administered to both groups at the time of each unit exam. For example, at the time that the exam for Unit Two was administered, there were five questions administered from segment one and five questions administered from segment three. Unit One had only the course pretest and Unit Five had only the course posttest, because of the lack of opportunity for additional testing.

The control group was limited to 45 minutes of similar non-drill learning activities during each class session. They received instruction from the same instructor who taught the experimental group, but they were not presented the daily drills of terms. The remaining five minutes of class represented an opportunity for students to ask the instructor questions or to address issues pertinent to the class.

Because the same instructor taught each class, efforts were made to provide equivalent instruction to both the experimental and the control groups. Although it was impossible to duplicate live exchanges and discussions from one class to another, the instructor used identical 
examples to illustrate concepts and covered the same course content daily. Identical exams, quizzes, and classroom activities were provided to both groups.

At the beginning of each class, each student in the experimental group received a single piece of paper containing a one-minute drill of course-related terms and concepts. The drills contained terms pertinent only to the unit being instructed. Each drill consisted of 29 multiplechoice items. Terms were chosen from bold print items in the text and from topics presented in lectures. Four possible responses presented as options "a," "b," "c," and "d" followed each term, only one of which was correct. The order of the terms and the order of the responses were varied daily, to avoid any sequencing effect. For some terms, the responses included one correct definition and three incorrect alternatives. Response options for other terms were constructed from potential applications of the term, and/or functions of the term.

The number of drill items was determined by the space permitted on one side of a piece of paper with terms written in Times New Roman, size 12 font. To design the drill format, the experimenter used Microsoft Excel. Terms were placed in column A of the spreadsheet, and the responses were placed in columns B, C, D, or E, respectively. (See Table 1.) The placement on the spreadsheet allowed easier manipulation of the order of the terms and the sequences of the responses for each term. At least four versions of each drill were designed and presented to students. Because of the brief presentation format, it was not deemed necessary to design a separate drill for each day on which the segment drills were presented. Four versions provided variation sufficient to prevent students from learning terms by their placement on the page. Each unit represented approximately two weeks of instruction consisting of eight drill opportunities. 
Table 1

Sample of Daily Drill Terms and Responses from Abnormal Psychology Unit

\begin{tabular}{|l|l|l|l|l|}
\hline 1. dysthymic & a. catatonic & b. bipolar & $\begin{array}{l}\text { c. anxiety } \\
\text { disorder }\end{array}$ & d. depression \\
\hline 2. insanity & a. craziness & $\begin{array}{l}\text { b. abnormal } \\
\text { behavior }\end{array}$ & c. legal term & $\begin{array}{l}\text { d. psychologist } \\
\text { determined }\end{array}$ \\
\hline 3. hypnosis & a. Hippocrates & b. Mesmer & c. Gestalt & d. Ellis \\
\hline 4. sociopathic & a. antisocial & b. psychotic & $\begin{array}{l}\text { c. split } \\
\text { personality }\end{array}$ & d. depression \\
\hline
\end{tabular}

At the beginning of each daily class, each student in the experimental group was given a drill sheet and instructed to leave it facing down. The students were told to put their names and the date on the back of the page. Requiring the students to put their names and date on the paper before the timed period resulted in all students having equal time to complete the drills.

Students were instructed that the drill included 29 items and that they would have one minute to complete the page. After names were written, the instructor said, "On your mark, get set, go!" After one minute had passed, the students were instructed to stop, and were required to put their pencils down.

The students exchanged papers and graded them. The instructor orally read each of the 29 terms, and provided the appropriate responses for each. Because students were grading the papers of their peers, they were required to attend to the reading of all items, which allowed each term to gain stimulus control of each student's responding, regardless of whether or not that individual's drill had been completed. No talking was permitted during grading, so every student contacted the terms. The papers were returned to their owners, and each student plotted his/her results on an equal-interval, line, rate graph.

The equal-interval, line, rate graph was chosen because it was familiar to students and was easy to use and read, while providing a visual representation of each student's efforts. Students were required to bring the graphs to class and each day to plot their performance datum from the daily drill. Predictably, the graphs of progress served as a reinforcer of the drilling behavior, since advances in performance were readily evidenced. The purpose of the graphs in this study did not include altering the instruction based on what the graphs revealed. 
A sheet of graph paper was provided to each student in the experimental group at the beginning of the course. The students were instructed to utilize the graph in a landscape position to accommodate the plottings for each day of the quarter. On the vertical or y-axis was the number of correct responses per minute. On the horizontal or $\mathrm{x}$-axis was the identification of the course session (i.e. session 1, 2, 3, etc.).

Students plotted daily performance by identifying the course session number and the number of items correctly answered. The corresponding location on the graph was plotted with a small dot. The dots were connected for each of the plottings for each segment. Vertical lines drawn on the graph separated the five segments or units into which the course subject matter was divided.

Students were advised that plottings of drill data should reveal daily increases in value and that an absence of increases would suggest the need for additional interaction with the chapter content. Prior to each day's drills, the previous day's class average of items correct per minute was announced. The instructor expressed verbal approval of performance increases.

After the course instruction was completed for each unit, a unit exam was administered to each group. Forty-five minutes were permitted for the completion of the exams. The unit exams included items identical to those presented in the pretest and posttest, with the exception of the order of the responses. The identical items represented only a portion of the unit exams. Additional questions related to the unit were included in each exam, which the student had not seen previously on the pretest. These exams were in multiple-choice format and were graded by a Scantron machine.

During the next class session, the exams were returned to students for their review. The experimental group began that session with a one-minute drill, followed by course instruction for the next unit. The control group had no drill and immediately began course instruction for the next unit. The control group received 45 minutes of course instruction and facilitated discussion, equivalent to the instructional portion of the experimental group.

The daily drills, the feedback from the instructor regarding class performance on the previous day's drills, and the students' daily graph plottings combined to provide an alternative instructional tool. Their effects were not evaluated separately. Instead, their effectiveness was collectively measured by changes in the dependent variables. 
Several dependent variables were measured to determine the effectiveness of the intervention. Student retention (continuing to attend class as opposed to withdrawing from the course) was monitored in each class and compared between groups. It was hypothesized that when students increased their preparedness for exams by completing daily drills, a larger proportion of students would remain in the class compared with those who were not as prepared.

The Nelson-Denny Reading Test provided assessments of vocabulary, comprehension, total reading scores (vocabulary score plus comprehension score doubled), and reading rates. An analysis was conducted to determine the effects of the independent variable on each of these reading components. By comparing the pre and posttest scores obtained by students in the experimental group with those obtained by the control group, the experimenter could assess drill effectiveness on reading.

Instructional accomplishment, computed by the attained percent of possible gain analysis (Fraley, 1980), was completed for each student. The attained percent of possible gain analysis defines "instructional accomplishment" as the attained percentage of possible gain toward an established goal, where possible gain is the difference between pretest and posttest scores. (See Figure 1.)

INSTRUCTIONAL ACCOMPLISHMENT

$$
\begin{gathered}
\mathrm{I}_{\mathrm{A}}=\frac{\Delta \mathrm{B}}{\mathrm{B}_{\mathrm{C}}} \times 100 \\
\mathrm{I}_{\mathrm{A}}=\text { Instructional Accomplishment }(\%) \\
\Delta \mathrm{B}=\text { Skill level after instruction }- \text { initial skill level } \\
\mathrm{B}_{\mathrm{C}}=\text { Criterion score }- \text { initial pretest score }
\end{gathered}
$$

Figure 1. Instructional accomplishment of skills

The Nelson-Denny Reading Test (1993) established a raw score total of 97 as the grade equivalent of 13.1 (grade 13,1 month), or the first semester reading level of freshmen in college (p. 21). This raw score was established as the criterion or goal for the students in the study. Initial raw score totals of less than 97 were considered to represent underprepared reading skills. The instructional accomplishment for each underprepared student with respect to that goal, was calculated. The class average of accomplishment for underprepared students was compared 
between the experimental and control groups. It was predicted that the daily drills would increase the reading scores of students in the experimental group at a higher rate than those of the control group.

Students in both groups were administered unit exams following the instruction on each segment. The comprehensive final exam served as the second posttest following instruction. A comparison was made between the performance on exams of the experimental and control groups. Specifically, the subset of items identified from each unit that were presented on a unit pretest was compared with the same exam items on the unit exam and finally, on the final exam. For example, there were 20 questions on the pretest, unit exam, and the final exam that represented Unit One. The items were identically presented, with the exception of the order of the responses. Because the students in the experimental group had received an additional instruction procedure, the daily drills, it was hypothesized that they would demonstrate better mastery of the terms. In other words, presumably the students in the experimental group would come more completely under stimulus control of the course concepts because of their opportunities to interact more frequently with the technical terms.

After the reading pretest was administered, it was realized that the experimental group contained eleven students whose reading level was below the established level of reading skills appropriate for college-level freshmen, whereas the control group had only four students whose reading skills placed their functioning similarly in the underprepared range. Because of this difference in reading skills, an analysis of the exam performance for students with deficient reading skills versus an exam performance for students with college-level reading skills was conducted for both the control and experimental groups. It seemed likely that students with fewer entry reading skills would score lower than students with appropriate reading skills.

A progressive multiple baseline achievement test design (Miller \& Weaver, 1972) was employed to scrutinize the effectiveness of the independent variable within the experimental group. This measurement scheme is employed to reveal changes in dependent variables for a single individual or a single group, thus often eliminating the need for a control group (depending on the experimental questions). This design allowed the visualization of skill development as each segment was presented. The responses for three to five arbitrarily chosen questions from each unit were examined during the course pretest, a unit pretest, the segment exam, a unit posttest, and the final exam (posttest). (See Figure 2.) 


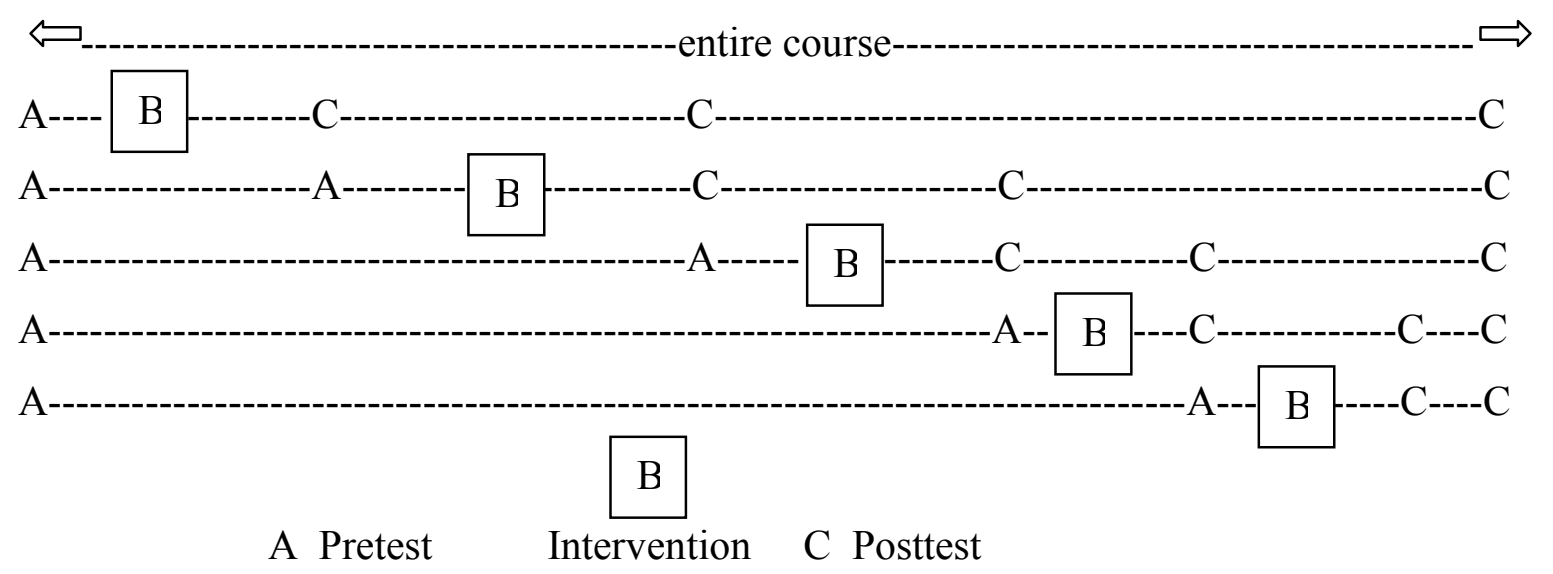

Figure 2. Progressive multiple baseline achievement test design

The pretest served as the course pretest, as well as each unit's pretest. The Unit I exam represented a posttest of test questions pertaining to that unit, and contained three questions from Unit II. These three Unit II questions on the Unit I exam served as a pretest for Unit II. Likewise, the Unit II exam included five posttest questions from Unit I and three pretest questions from Unit III. The Unit III exam included three posttest items from Unit II and five pretest questions from Unit IV. The Unit IV exam included three posttest items from Unit III and three pretest questions from Unit $\mathrm{V}$. The Unit $\mathrm{V}$ exam included three pretest items from Unit IV. The final exam served as the posttest for Unit V, as well as the entire course content. (Note that it was originally planned for each unit to have five pretest and posttest questions. It was experimenter error that resulted in some units having only three questions.)

This multiple baseline design, combined with the pre and posttests over the entire course, provided pretest measures for each instructional unit and two or three posttest measures for each instructional unit. The pre and post differences across these two classes of measures revealed the effectiveness of the instruction on each segment. However, in the experimental group the instruction included the drills plus the various classroom instructional activities. While the pretest-posttest difference across that combined instruction revealed significant gains, those gains could be attributed only to the combined instructional capacity of all included instructional activities, and the contribution of the drills to that gain could not be isolated. As the multiple baseline measure could not clearly identify the daily drills as uniquely responsible for the 
changes, the comparisons between the experimental and control groups more closely identified the effectiveness of adding the drills to the instruction. 


\section{CHAPTER III: RESULTS}

The use of one-minute daily drills on technical terms was included among the instructional activities in a college general psychology course. The daily drills provided students with additional opportunities to interact with course content, and several assumptions were made regarding their effect on learning within the course.

1) Presumably, a higher percentage of students enrolled in the experimental section of the study would complete the course than those enrolled in the control section.

2) Presumably, reading scores of students enrolled in the experimental section of the study would increase more than those of students enrolled in the control section.

3) Presumably, unit exam scores of students enrolled in the experimental section of the study would be higher than those of students enrolled in the control section.

4) Presumably, the final exam scores of students enrolled in the experimental section of the study would be higher than those of students enrolled in the control section.

\section{$\underline{\text { Retention Comparison }}$}

Thirty-five students registered for the morning section of general psychology and represented the experimental group in this study. Twenty-eight students completed the course, representing a 20 percent decline. Thirty-four students registered for the afternoon section of general psychology and served as the control group for the study. Twenty-nine students completed the course, representing a 17.2 percent decline. (See Figure 3.) 


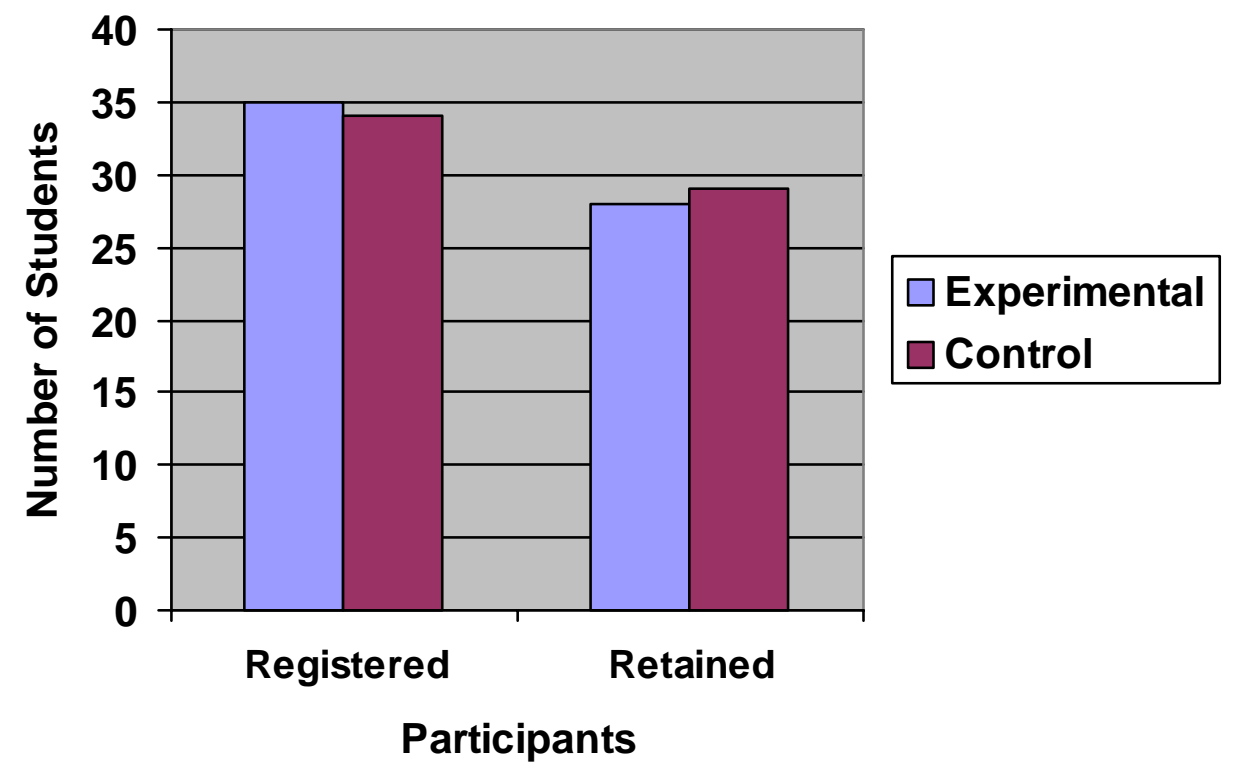

Figure 3. Student retention

Eighty percent of the students originally enrolled in the experimental group, and eightyfive percent of the students in the control group, completed the course. Two of the seven students in the experimental group were failing the course at the time they chose to withdraw from the course, while the others left because of variables unrelated to the course. Each of the five students who withdrew from the control group was failing the course at the time of the withdrawal.

Only the participants who completed the pretest and posttest of the course content were included in the specific analysis of pre and post data. Most participants also completed the pretest and posttest of reading skills, but this was not required for inclusion in the study. The complete original groups were monitored for retention purposes, but only the students who completed the pretests and posttests were included in the experimental and control groups for the study. The enrollment in either group was determined by students' schedules. The equivalence of the experimental and control groups was confirmed on the variables of gender (Chi-square $=$ $.257, \mathrm{df}=1)$ and age $($ Chi-square $=.357, \mathrm{df}=1)$. 


\section{Comparison of Reading Skills}

The Nelson-Denny Reading Test was used to assess entry and exit level reading skills in both groups. The Nelson-Denny provides an evaluation of vocabulary, comprehension, total reading, and reading rate. The test was administered to each group during regular class time. Since the test served as a pretest, it was administered during the first week of class. Some students arrived as members of the class after the pretest was administered and instruction had begun, so they did not take the pretest. Posttests were administered during the last week of the course.

The Nelson-Denny Reading Tests were scored according to the instructions on the back of the test protocols. The obtained raw scores were converted to standard scores, according to the norms provided in the Nelson-Denny Reading Test Manual (Brown, Fishco, \& Hanna, 1993, p. 21-22). The scaled score averages were computed by calculating the sum of the individual scaled scores in each group and dividing by the number of students completing the task. The percentiles for each section of the test were determined by locating the obtained scaled scores on the norms table for two-year college students and finding the corresponding percentile rank (Brown, Fishco, \& Hanna, 1993, p. 33).

The experimental group $(\mathrm{N}=27)$ demonstrated a scaled score average of 213 , representing a percentile rank of 60 on the vocabulary pretest of the Nelson-Denny Form G, while the control group $(\mathrm{N}=20)$ received a scaled score average score of 221 , with a percentile rank of 71. The vocabulary posttests (Form H of the Nelson-Denny Reading Test) revealed scaled score averages of 216 for the experimental group and 227 in the control group. These scaled score averages represented percentiles of 65 and 80 for the experimental and control groups, respectively. (See Figure 4.) 


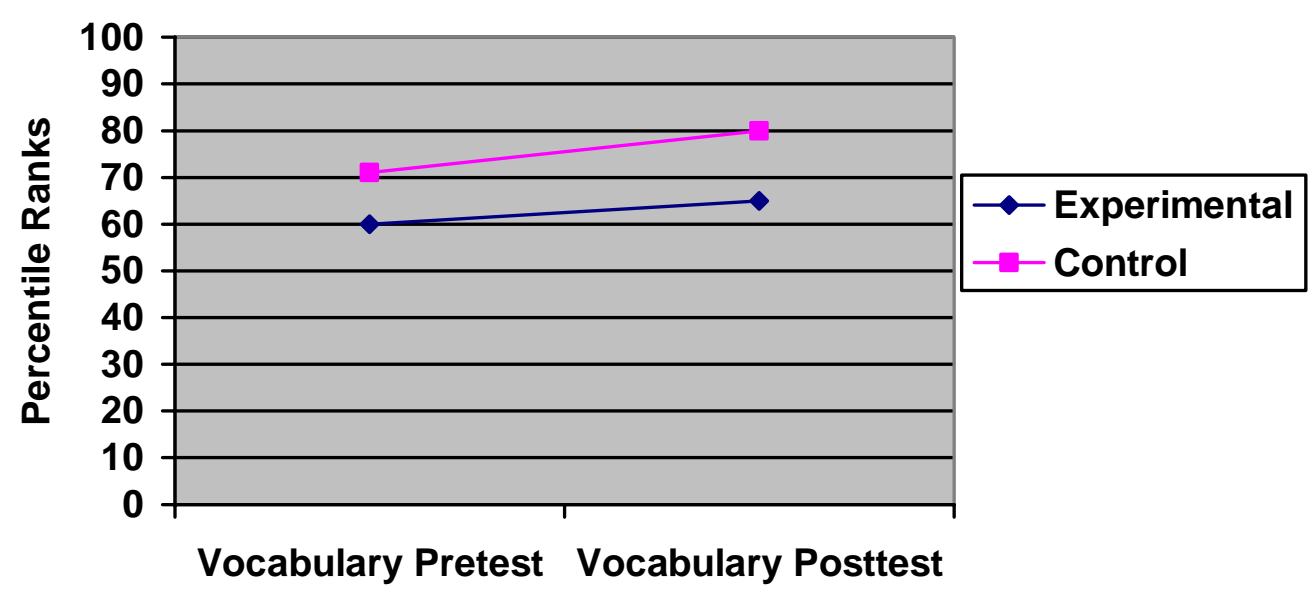

Figure 4. Percentile rank of Nelson-Denny vocabulary pretests and posttests

The comprehension pretest showed average scaled scores of 208 and 221 for the experimental and control groups, respectively. The experimental group improved to a scaled score average of 214 on the comprehension posttest. An improvement of one scaled point was noted for the control group with an average scaled score of 222. The pretest percentile rank of 52 was calculated for the experimental group, while the control group had a percentile rank of 69. Posttests showed percentiles of 60 and 70, respectively. (See Figure 5.)

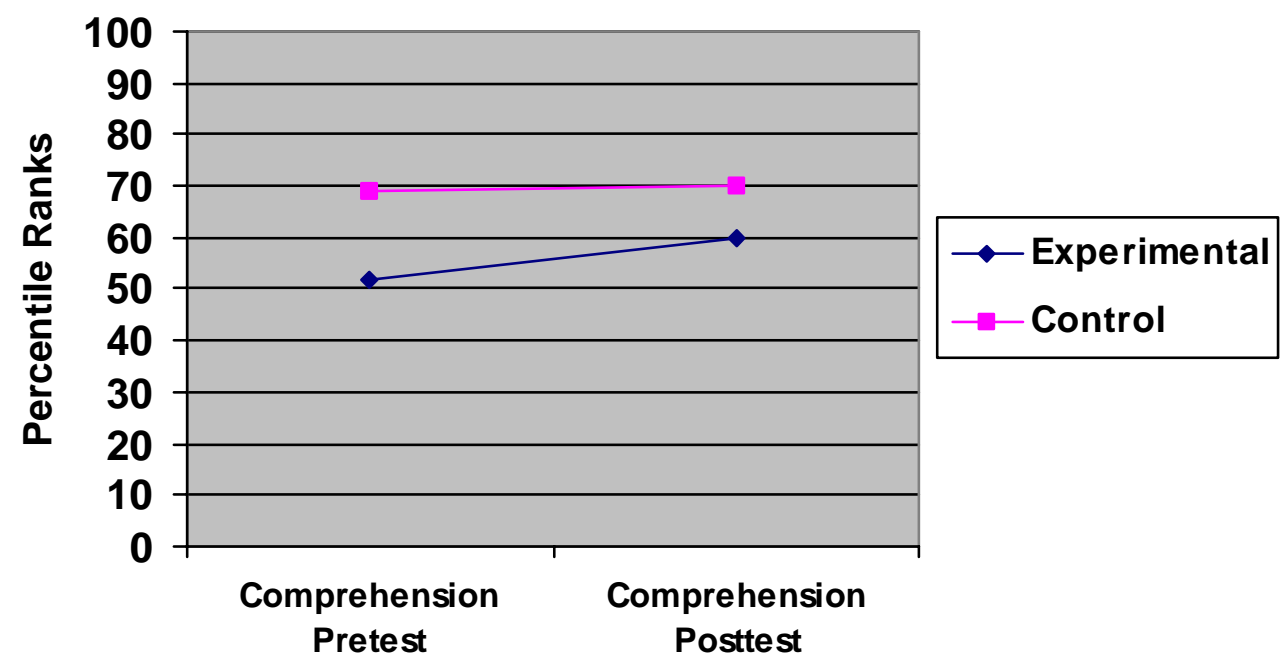

Figure 5. Percentile rank of Nelson-Denny comprehension pretests and posttests 
According to the Nelson-Denny instructions, the total reading scores were calculated by adding the vocabulary and comprehension raw test scores. The total reading scores were then converted to scaled scores and percentiles, according to the method described previously. The experimental group achieved a pretest total reading scaled score average of 211 , with a percentile rank of 57. The control group received a pretest total reading scaled score average of 222, with a percentile rank of 73. Posttests showed improvement for both groups with the experimental group's scaled score average of 216, percentile rank of 64, and the control group's scaled score average of 225, with a percentile rank of 76. (See Figure 6.)

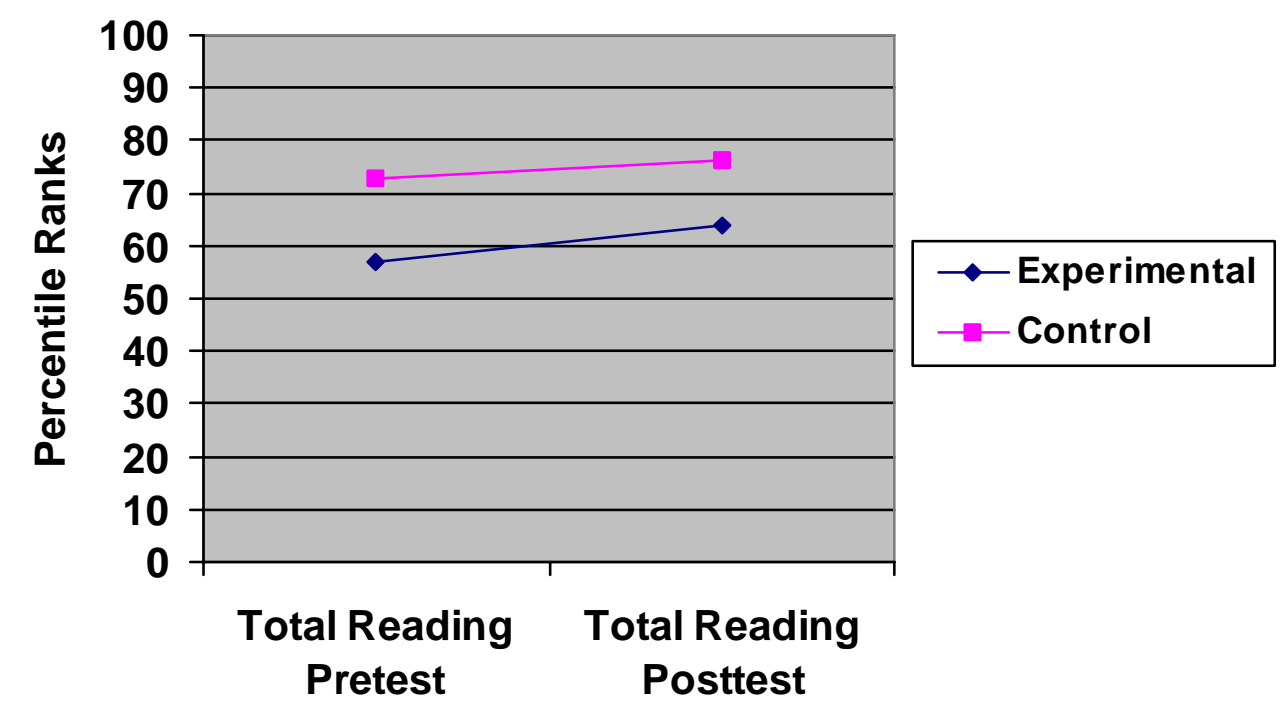

Figure 6. Percentile ranks of Nelson-Denny total reading pretests and posttests

The student determined the reading rate of the Nelson-Denny. At the beginning of the administration of the comprehension section of the test, students performed a one-minute reading. Numbers were printed on the test protocol that determined the rate of reading. At the end of one minute, the students recorded their grades and proceeded with the test. One student in the experimental group and two students in the control group erroneously recorded their scores. Their scores were not included in the calculations.

The experimental group $(\mathrm{N}=26)$ received a scaled score reading rate of 185 , with a percentile rank of 25 on the pretest. The control group $(\mathrm{N}=18)$ received a scaled score reading rate of 190, with a percentile rank of 35. Posttests for the experimental group showed a scaled 
score of 201, with a percentile rank of 50. The control group had a scaled score of 204, with a percentile rank of 59. (See Figure 7.)

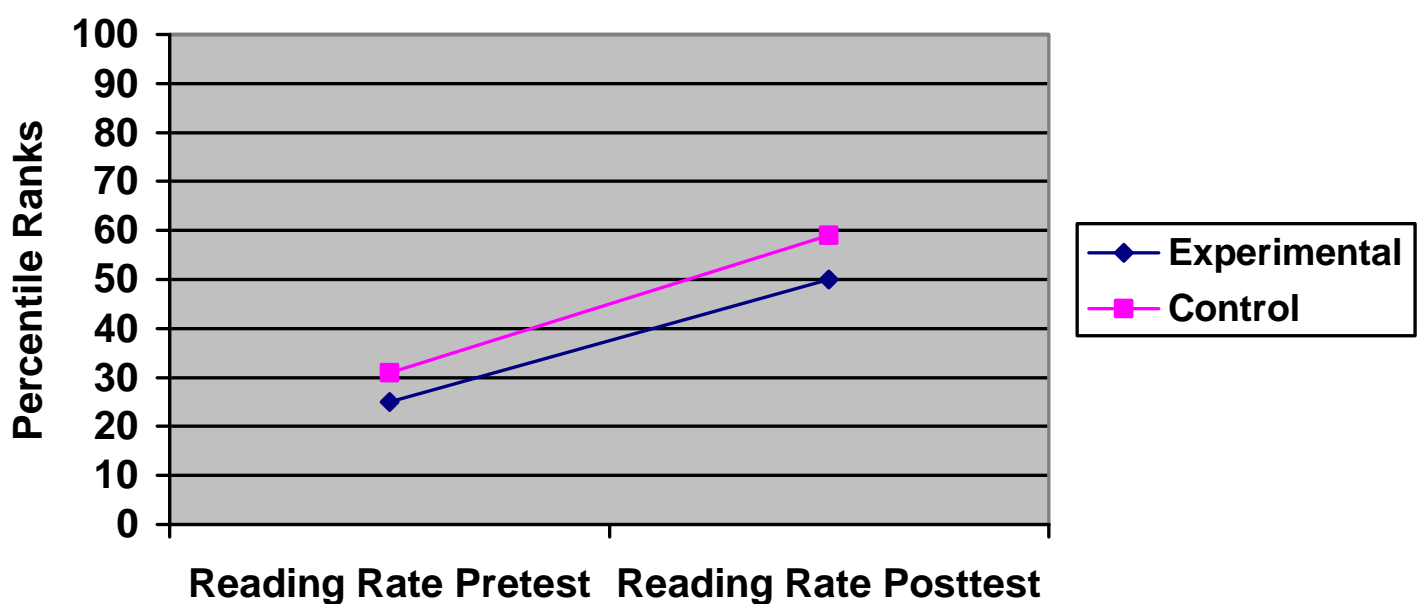

Figure 7. Percentile ranks of Nelson-Denny reading rates

Examinations of the scores revealed that the experimental group's scores were consistently lower that those scores received by the control group. Because reading is a critical component of success in a general psychology class, individual scores were reexamined to determine the number of students in each class that demonstrated skills lower than the normdetermined appropriate level for a college freshman. A raw score of 97 has been found to be the total raw score equivalent of 13 years-1 month (Brown, Fishco, \& Hanna 1993, p. 21).

Eleven of the twenty-seven students in the experimental group scored below college level. Four students in the control group scored below college level. These students were regarded as underprepared for college work. Forty-one percent of the experimental group did not have initial college level scores. Eighteen percent of the control group was underprepared. The differences in these scores suggested that the control group was better prepared for college level learning than the experimental group.

The percentage of increase in percentiles was examined to provide a closer look the effectiveness of the independent variable. Since only the experimental group received the additional instruction of the daily drills, it was hypothesized that their skills would be increased at a higher rate than those of the control group. By using the formula (posttest - pretest) / pretest 
* 100 using the percentiles in each category of the test, the percentage of increase in the percentile scores was examined. On the vocabulary portion of the Nelson-Denny, the experimental group showed a percentage increase in percentiles of $8.3 \%$ and the control group showed a percentage increase of $12.7 \%$. Comprehension skills for the experimental group increased $15.4 \%$ from the pretest to the posttest. They increased $1.4 \%$ in the control group. Total reading skills evidenced by the respective percentiles showed an increase of $12.3 \%$ for the experimental group and the control group's skills increased by $4.1 \%$. Reading rates were increased by $100 \%$ for the experimental group and $90.3 \%$ for the control group. (See Figure 8 ).

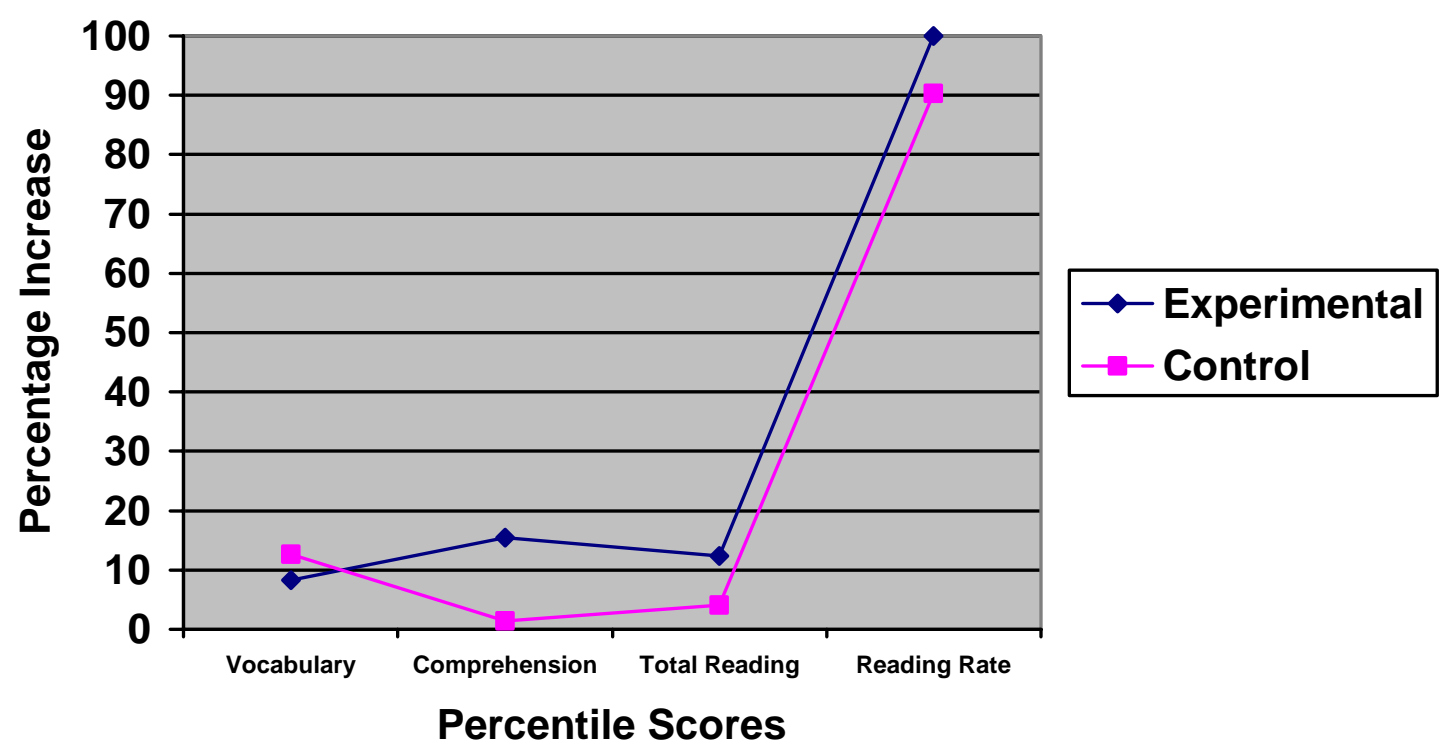

$\underline{\text { Figure 8. }}$. Percentage increases in Nelson-Denny percentile scores

In every category except vocabulary, the experimental group increased reading skills at a higher rate than the control group. These results seem to confirm the hypothesis that daily drills could be used to enhance reading skills within the confines of a general psychology class. It is noted that both groups increased their skills significantly during the quarter that data was collected, but the one-minute drills appeared to be time well spent. Although the improvements were notable, an analysis of the pretest and posttest differences revealed no statistically significant difference between the experimental and control groups. (See Table 2.) 
Table 2

Comparison of Differences in Pretest and Posttest Values of the Nelson-Denny

\begin{tabular}{lllll}
\hline & Experimental Mean & Control Mean & $t$-value & $F$-value \\
\hline Vocabulary & 5.15 & 9.05 & 1.16 & 2.91 \\
Comprehension & 6.7 & 4.8 & .65 & 1.55 \\
Total Reading & 5.04 & 6 & .31 & 1.58 \\
Reading Rate & 13.38 & 13.67 & .07 & 1.56 \\
\hline $\mathrm{p}<.05$ & & & &
\end{tabular}

Instructional accomplishment (Fraley, 1980, See Chapter Two) was calculated for underprepared students, i.e., those whose pretest total reading scores were less than 97. Most students in the experimental and control groups increased their total reading scores from the pretest to the posttest. The experimental group obtained a mean instructional accomplishment of 103.48 and a standard deviation of 111.89. The control group obtained a mean instructional accomplishment of 63.83 and a standard deviation of 119.77. The homogeneity of variance was confirmed by the F-test $(\mathrm{F}=1.15, \mathrm{p}=.376)$. A t-test of independent means was conducted and revealed no statistically significant differences between groups $(\mathrm{t}(.05,13)=.6, \mathrm{p}=.56)$. Students' scores and instructional accomplishment are presented in Table 3. 
Table 3

Instructional Accomplishment of Reading Skills Measured by the Nelson-Denny

Experimental

Control

\begin{tabular}{|l|l|l|l|l|l|l|l|}
\hline Student & Pretest & Posttest & IA * & Student & Pretest & Posttest & IA * \\
\hline 1 & 56 & 82 & 63.41 & 1 & 84 & 107 & 176.92 \\
3 & 82 & 125 & 286.67 & 2 & 74 & 102 & 121.74 \\
4 & 77 & 103 & 130 & 3 & 95 & 93 & -100 \\
5 & 87 & 108 & 210 & 4 & 67 & 84 & 56.67 \\
6 & 73 & 76 & 12.5 & & & & \\
7 & 77 & 106 & 145 & & & & \\
8 & 92 & 105 & 260 & & & & \\
9 & 70 & 87 & 62.96 & & & & \\
10 & 75 & 80 & -13.33 & & & & \\
11 & 84 & 76 & -46.15 & & & & \\
\hline
\end{tabular}

*Instructional Accomplishment

A $t$-test of independent means was used to analyze the differences in instructional accomplishment between groups. The mean of instructional accomplishment for the experimental group of 103.48 was higher than the control group mean of 63.83 , but no statistical difference existed, $t_{(.05,13)}=.6, p=.56$.

\section{Comparison of Course Content Skills}

In addition to retention and reading skills, it was predicted that course performance would be improved as a result of daily drill participation. Course exams were multiple-choice in format and included a pretest, five unit exams, and a posttest (final exam). Each unit represented an opportunity to assess the effects of the independent variable (daily drills) on the dependent variable of exam scores. Comparisons among a set of questions from the pretest, unit exam, and posttest were made.

Each unit exam contained a combination of pretest/posttest items and additional content related questions. The percent of questions correct on the course pretest, unit exam (identical questions only), and course posttest was calculated by dividing the number correct by the number of items available and multiplying by 100 (\# correct / total questions * 100). 
The following graphs represent the average performances of the control and experimental groups on each unit's pretest, unit exam, and posttest. Unit I is presented in Figure 9, Unit II is presented in Figure 10, Unit III is presented in Figure 11, Unit IV is presented in Figure 12, and Unit $\mathrm{V}$ is presented in Figure 13.

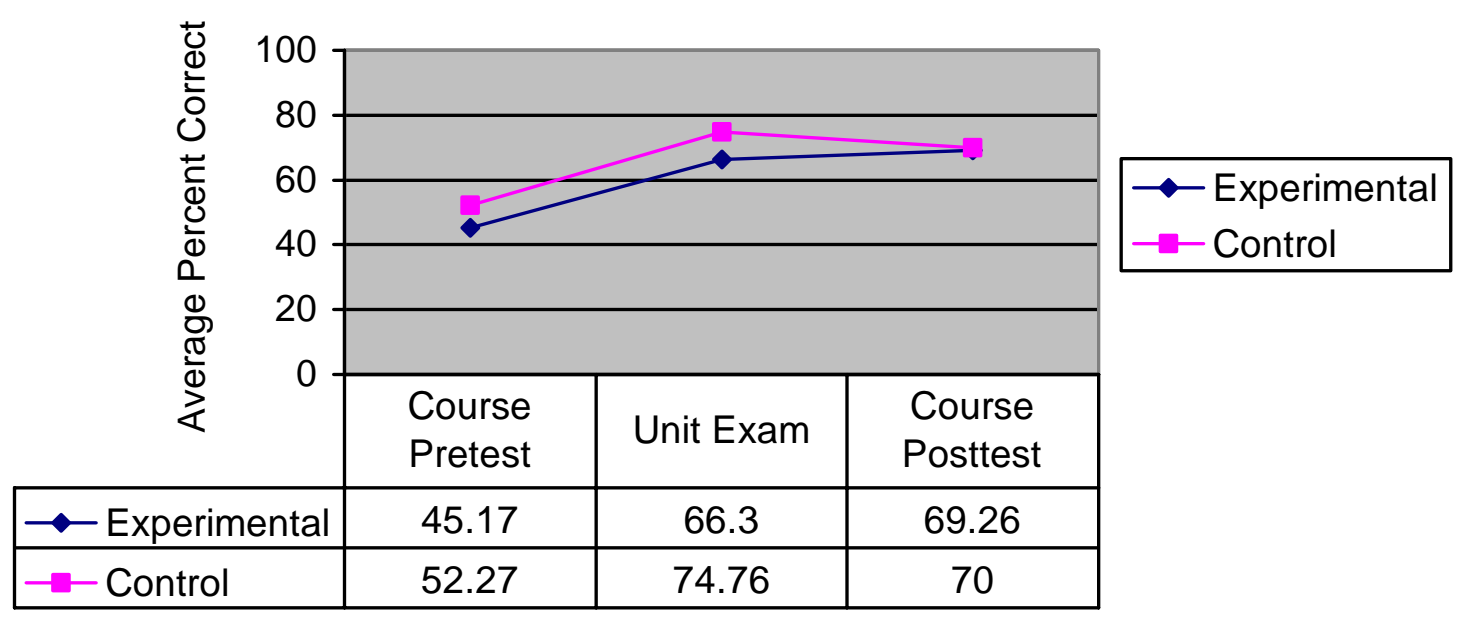

Figure 9. Average percent correct of Unit I questions

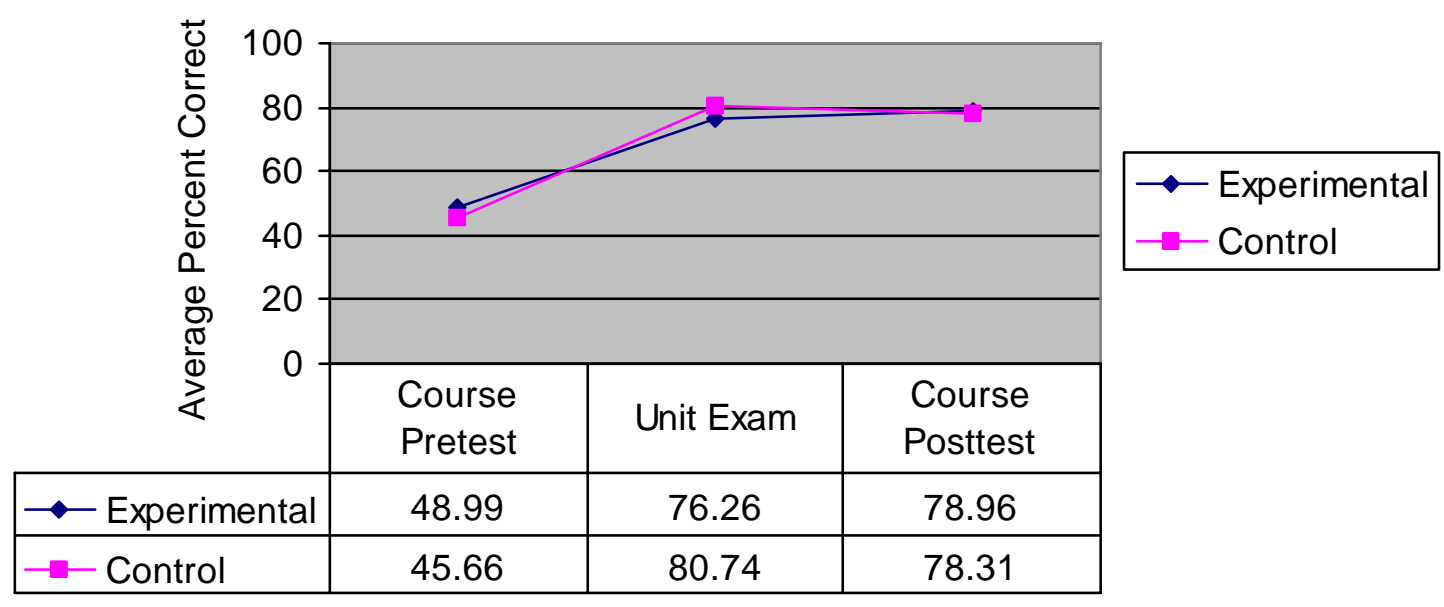

Figure 10. Average percent correct of Unit II questions 


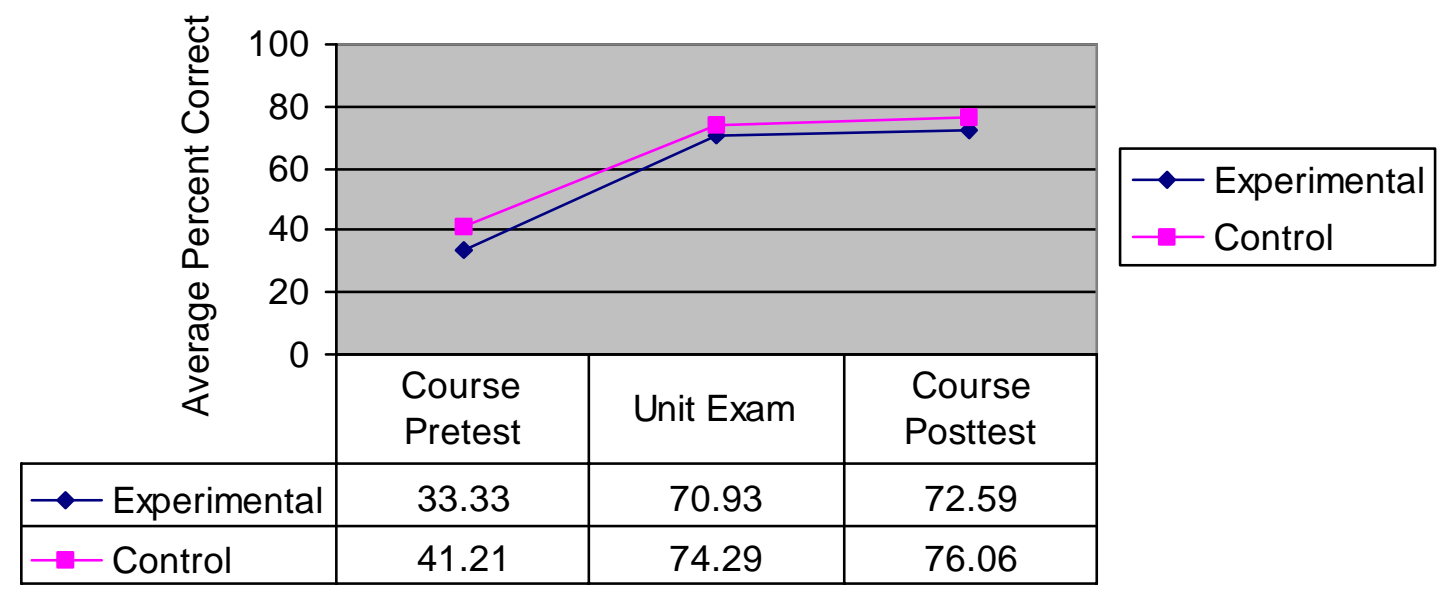

Figure 11. Average percent correct of Unit III questions

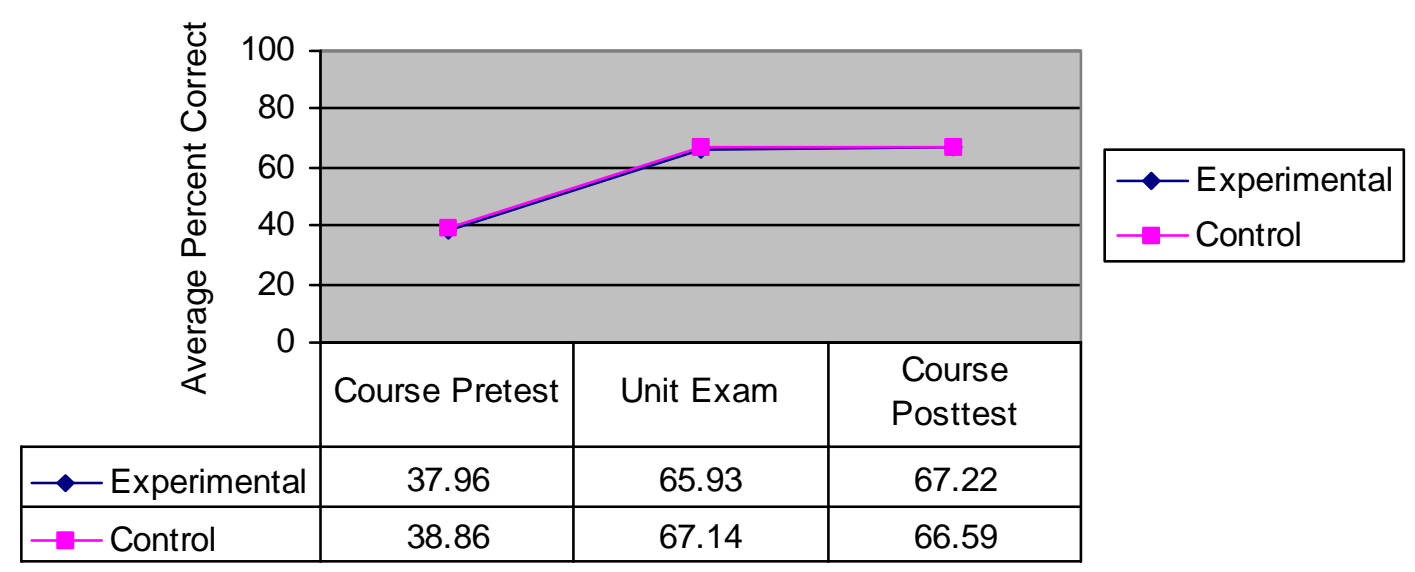

Figure 12. Average percent correct of Unit IV questions

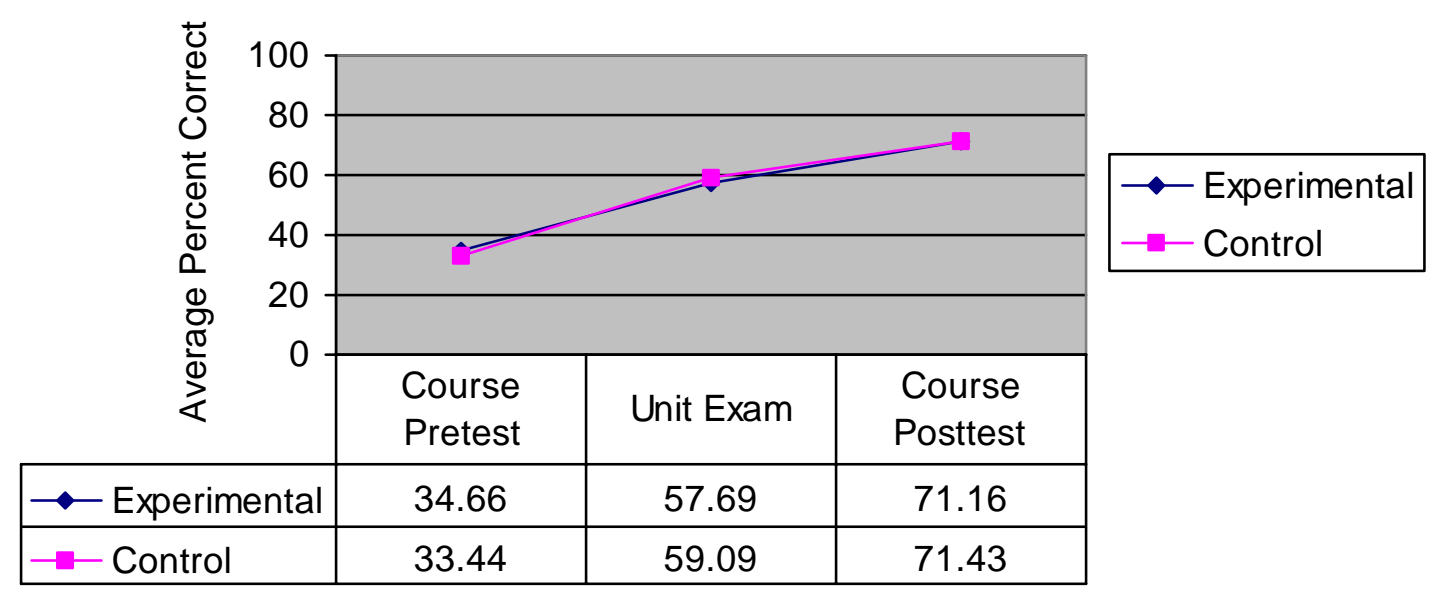

Figure 13. Average percent correct of Unit V questions 
Course content was presented in five units, each having an exam following instruction. All participants within the experimental and control groups were also administered a pretest and identical posttest consisting of 91 multiple-choice questions.

Table 3 presents the means and standard deviations by group on the pretest. The experimental group $(\mathrm{N}=27, \mathrm{SD}=7.45)$ correctly answered about 37 questions (mean $=37.33)$, while the control group $(\mathrm{N}=20)$ correctly answered almost 39 questions (mean $=38.9, \mathrm{SD}=$ 10.26).

Since the pretest measurements in the experimental group and the control group were unrelated, an independent t-test was performed. The assumption of homogeneous variances was satisfied (F-test, $\mathrm{F}=1.897, \mathrm{p}=.065)$. The pretest means were not significantly different, ( $\mathrm{t}(.05$, $45)=.61, \mathrm{p}=.547)$. See Table 4 .

Table 4

$\underline{\text { Number of Correct Test Items Per Participant on Course Content Pretest }}$

\begin{tabular}{lll}
\hline Group & Mean & SD \\
\hline Experimental & 37.33 & 7.45 \\
Control & 38.90 & 10.26 \\
\hline
\end{tabular}

Posttest performance is presented in Table 5. The experimental group $(\mathrm{N}=27)$ answered approximately the same number of questions correctly (mean $=65.52, \mathrm{SD}=12.56$ ) as the control group $(\mathrm{N}=20)$, answered (mean $=65.90, \mathrm{SD}=11.27)$. The assumption of homogeneous variances was satisfied (F-test, $F=1.24, p=.317$ ). The posttest measures were analyzed using a $\mathrm{t}$-test of independent means. The posttest means were not significantly different $(\mathrm{t}(.05,45)=.11$, $\mathrm{p}=.915$ ). 
Table 5

Number of Correct Test Items Per Participant on Course Content Posttest

\begin{tabular}{lcc}
\hline \multicolumn{1}{c}{ Group } & Mean & SD \\
\hline Experimental & 65.15 & 12.56 \\
Control & 65.90 & 11.27 \\
\hline
\end{tabular}

Because the data from pretest to posttest were related for each group, a dependent t-test was performed to analyze the differences from pretest to posttest. The mean difference between the pretest and posttest was significant for both the experimental group $(\mathrm{t}(.05,26)=12.39, \mathrm{p}=$ $.000)$ and the control group $(\mathrm{t}(.05,19)=13.14, \mathrm{p}=.000)$. The differences in scores from the pretest to posttest were almost the same for both groups.

Because the focus of this research was to assess the use of alternative instruction (daily drills) to enhance the skills of underprepared students, the pretest performance of the identified underprepared students from each group was analyzed using a t-test of independent means. Table 6 presents the means and standard deviations for each group of underprepared students on the pretest. The experimental group participants $(\mathrm{N}=11)$ correctly answered about 34 questions (mean $=33.91, \mathrm{SD}=5.34$ ), while the control group participants $(\mathrm{N}=4)$ correctly answered almost 27 questions ( mean $=27.25, \mathrm{SD}=4.72$ ).

Since the pretest measurements in the experimental group and the control group were unrelated, an independent t-test was performed. The assumption of homogeneous variances was satisfied ( $\mathrm{F}$-test, $\mathrm{F}=1.28, \mathrm{p}=.47$ ). The pretest means of the underprepared students were significantly different, $(\mathrm{t}(.05,13)=2.19, \mathrm{p}=.047)$, and the experimental group answered more questions correctly than the control group. 
Table 6

Number of Correct Test Items Per Underprepared Participant on Course Content Pretest

\begin{tabular}{lcc}
\hline \multicolumn{1}{c}{ Group } & Mean & SD \\
\hline Experimental & 33.91 & 5.34 \\
Control & 27.25 & 4.72 \\
\hline
\end{tabular}

Posttest performance of the underprepared students is presented in Table 7. The experimental group $(\mathrm{N}=11)$ answered more questions correctly (mean $=62.45, \mathrm{SD}=3.18)$ than the control group $(\mathrm{N}=4)$ answered $($ mean $=57.25, \mathrm{SD}=4.82)$.

The posttest measures were analyzed using a t-test of independent means. The assumption of homogeneous variances was satisfied (F-test, $\mathrm{F}=2.298, \mathrm{p}=.14$ ). The posttest means were not significantly different $(\mathrm{t}(.05,13)=.86, \mathrm{p}=.404)$.

Table 7

Number of Correct Test Items Per Underprepared Participant on Course Content Posttest

\begin{tabular}{lll}
\hline \multicolumn{1}{c}{ Group } & Mean & SD \\
\hline Experimental & 62.45 & 3.18 \\
Control & 57.25 & 4.82 \\
\hline
\end{tabular}

Because the data from pretest to posttest were related for each group, a dependent t-test was performed to analyze the differences from pretest to posttest. The mean difference between the pretest and posttest was significant for both the experimental group $(\mathrm{t}(.05,10)=8.9, \mathrm{p}=$ $.000)$ and the control group $(\mathrm{t}(.05,3)=11.62, \mathrm{p}=.001)$. The differences in scores from the pretest to posttest were almost the same for both groups.

The Unit I course content exam results were compared with the performances on the same items from the pretest and final exam. Specifically, Unit I contained 20 test items that were originally presented on the pretest and presented again on the posttest. A comparison of performance across opportunities is presented in Figure 14. 


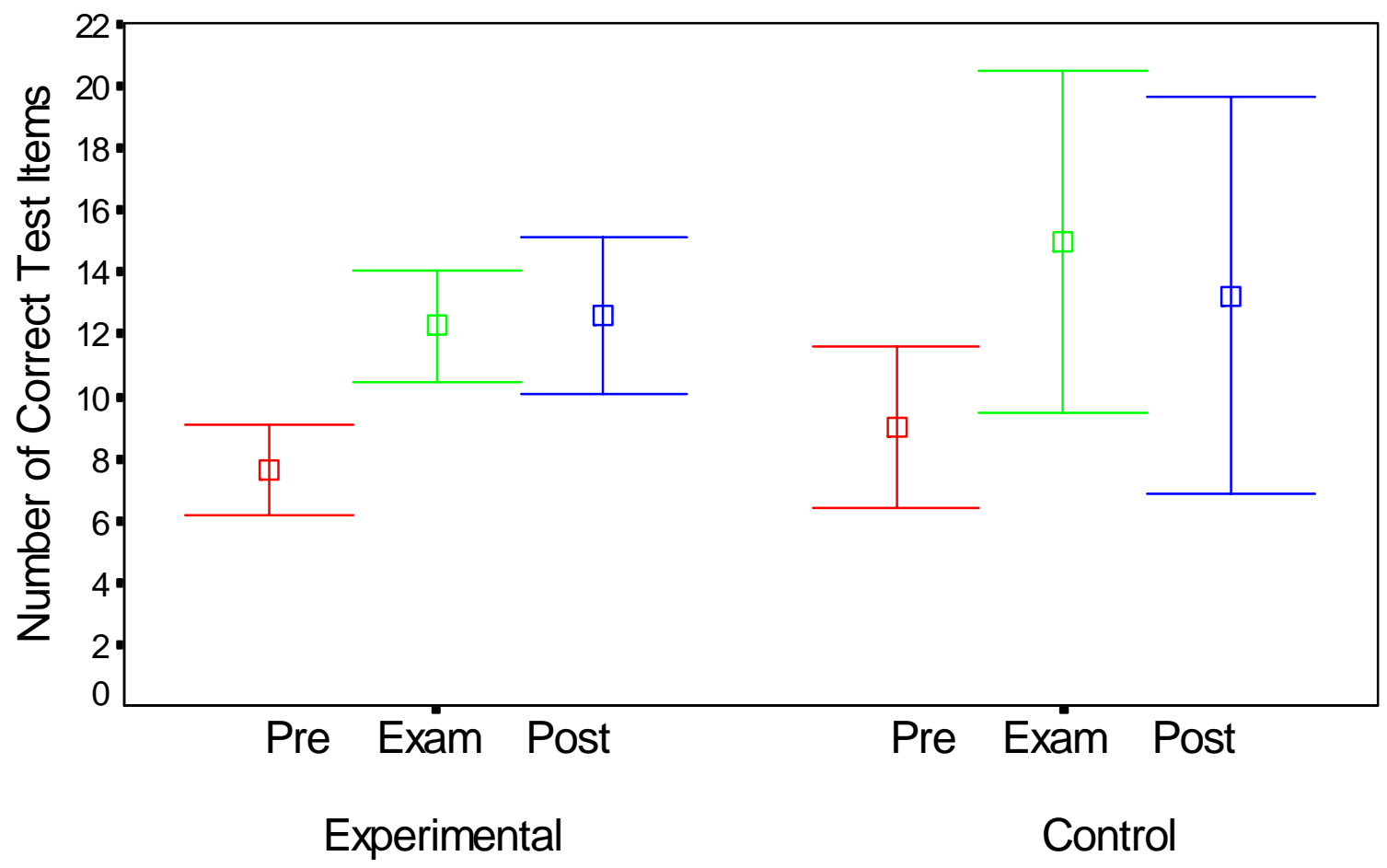

Figure 14. Means comparison of Unit I questions correct

An independent t-test comparison was performed on each set of questions, since the measurements were unrelated to each other. The pretest number of questions correctly answered by the experimental group was compared to the number of correctly answered pretest questions by the control group. The comparisons were repeated for the pertinent questions from the Unit One exam and the posttest.

On the Unit One questions from the pretest, the underprepared students of the experimental group $(\mathrm{N}=11)$ correctly answered slightly less questions (mean $=7.64, \mathrm{SD}=2.2$ ) than the underprepared students in the control group $(\mathrm{N}=4$, mean $=9.0, \mathrm{SD}=1.63)$. The assumption of homogeneous variances was satisfied (F-test, $\mathrm{F}=1.62, \mathrm{p}=.25$ ), and the means comparison revealed no statistically significant difference between groups, $t(.05,13)=1.12, p=$ .283 .

When the 20 questions were repeated on the Unit One exam, the experimental group answered fewer questions correctly (mean $=12.27, \mathrm{SD}=2.72$ ) than the control group (mean = $15, \mathrm{SD}=3.46$ ). An independent t-test was performed, and the assumption of homogeneous variances was satisfied ( $\mathrm{F}$-test, $\mathrm{F}=1.62, \mathrm{p}=.25$ ). The mean scores did not differ significantly, $\mathrm{t}$ $(.05,13)=1.6, \mathrm{p}=.133$. 
The Unit One questions on the final exam revealed that the control group (mean $=13.25$, $\mathrm{SD}=4.03)$ performed slightly better than the experimental group $($ mean $=12.63, \mathrm{SD}=3.75)$. The assumption of equal variances was satisfied ( $F$-test, $F=1.16, p=.37)$. The means were not significantly different, $\mathrm{t}(.05,13)=.28, \mathrm{p}=.787$.

Although the performances between groups revealed no significant differences, a univariate repeated measure analysis of variance was performed to analyze the differences in performance for each group across exams. There was a significant difference between the exam means of the experimental group, $\mathrm{F}(.05,2,20)=15.97, \mathrm{p}<.0001$. A post hoc analysis using Tukey's procedure $(\alpha=.05)$ revealed the mean for the unit exam was significantly higher than the pretest mean. The posttest mean was significantly higher than the pretest mean, but there was no significant difference between the unit test and the posttest means. Table 8 presents the means and standard deviations for the three exams. Table 9 presents the repeated measure analysis of variance summary for the experimental group.

Table 8

Means and Standard Deviations of Exam Means (Unit I, Experimental)

\begin{tabular}{lccc}
\hline \multicolumn{1}{c}{ Exam } & $\mathrm{N}$ & Mean & Standard Deviation \\
\hline Pretest & 11 & 7.64 & 2.20 \\
Unit I & 11 & 12.27 & 2.72 \\
Posttest & 11 & 12.64 & 3.75 \\
\hline
\end{tabular}


Table 9

Univariate Repeated Measure Analysis of Variance Summary (Unit I, Experimental)

\begin{tabular}{lcccc}
\hline \multicolumn{1}{c}{ Source of Variation } & df & Sum of Squares & Mean Square & $F$ value \\
\hline Treatment & 2 & 170.97 & 85.485 & $15.974^{*}$ \\
(between groups) & & & & \\
Residual & 20 & 107.03 & 5.352 & \\
Individual & 10 & 156.24 & & \\
(between participants) & & & & \\
$* p<0001$ & & & &
\end{tabular}

$* p<.0001$

There was a significant difference between the exam means of the control group on the questions pertaining to Unit One, $\mathrm{F}(.05,2,6)=5.21, \mathrm{p}=049$. A post hoc analysis using Tukey's procedure $(\alpha=.05)$ revealed the mean for the unit exam was significantly higher than the pretest mean. The posttest mean was not significantly higher than the pretest mean, and there was no significant difference between the unit test and the posttest means. Table 10 presents the means and standard deviations for the three exams. Table 11 presents the repeated measure analysis of variance summary.

Table 10

Means and Standard Deviations of Control Group Exam Means (Unit I, Control)

\begin{tabular}{lccc}
\hline \multicolumn{1}{c}{ Exam } & $\mathrm{N}$ & Mean & Standard Deviation \\
\hline Pretest & 4 & 9 & 1.63 \\
Unit I & 4 & 15 & 3.46 \\
Posttest & 4 & 13.25 & 4.03 \\
\hline
\end{tabular}


Table 11

Univariate Repeated Measure Analysis of Variance Summary (Unit I, Control)

\begin{tabular}{lcccc}
\hline \multicolumn{1}{c}{ Source of Variation } & df & Sum of Squares & Mean Square & $F$ value \\
\hline Treatment & 2 & 76.17 & 38.08 & $5.21^{*}$ \\
(between groups) & & & & \\
Residual & 6 & 43.83 & 7.31 & \\
Individual & 3 & 48.92 & & \\
(between participants) & & & & \\
$* p=.049$ & &
\end{tabular}

The Unit II course content exam results were compared with the performances on the same items from the pretest and final exam. Unit II contained 22 test items that were originally presented on the pretest and presented again on the posttest. A comparison of performance across opportunities is presented in Figure 15.

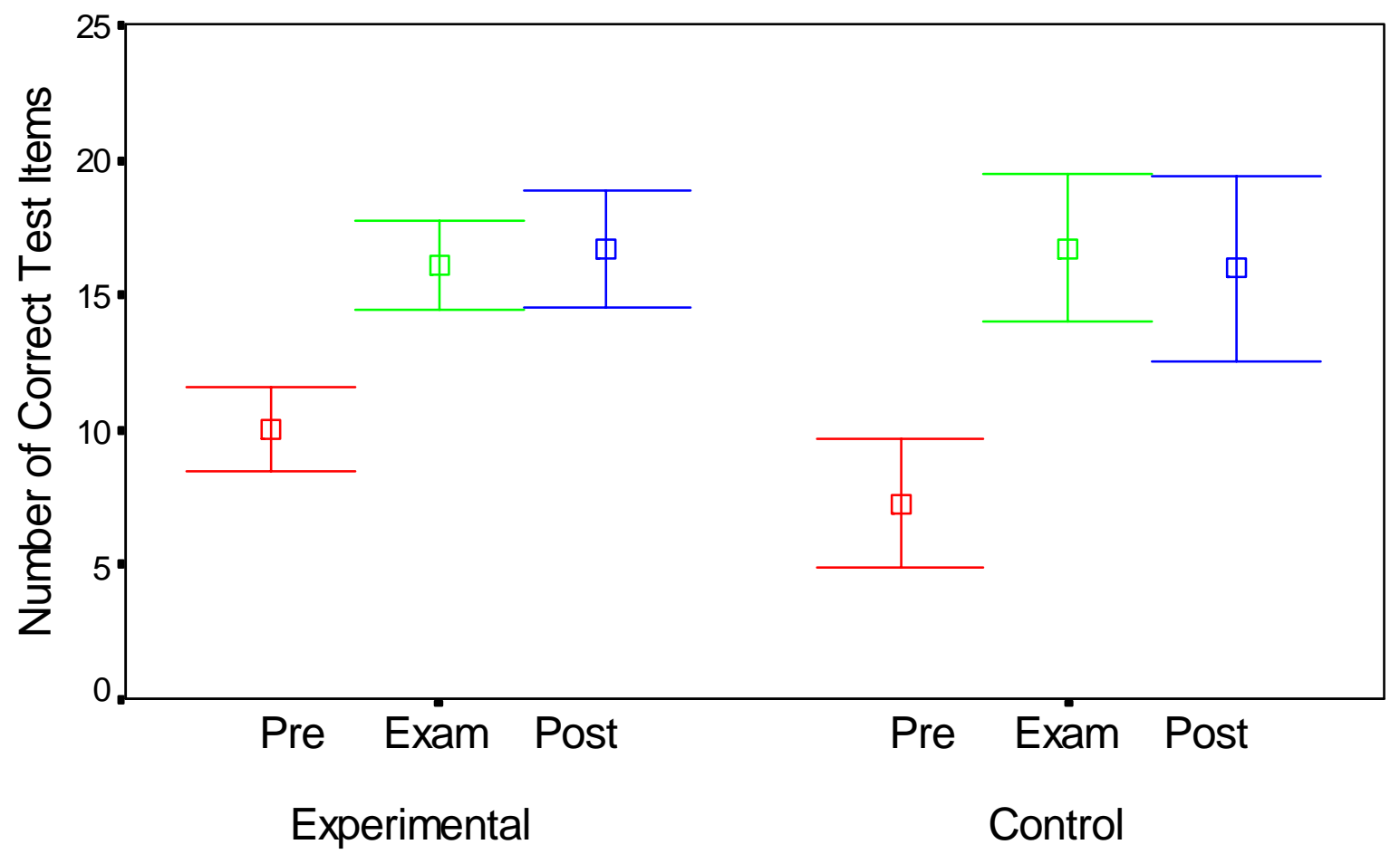

Figure 15. Means comparison of Unit II questions correct

On the Unit Two questions from the pretest, the underprepared students of the experimental group $(\mathrm{N}=11)$ correctly answered more questions (mean $=10, \mathrm{SD}=2.32)$ than the underprepared students in the control group $(\mathrm{N}=4$, mean $=7.25, \mathrm{SD}=1.5)$. The assumption of 
homogeneous variances was satisfied (F-test, $\mathrm{F}=2.39, \mathrm{p}=.256)$ and the means comparison using a t-test for independent samples revealed a statistically significant difference between groups, $\mathrm{t}(.05,13)=2.18, \mathrm{p}=.048$.

When the 22 questions were repeated on the Unit Two exam, the experimental group correctly answered almost the same number of questions (mean $=16.09, \mathrm{SD}=2.47)$ as the control group $($ mean $=16.75, \mathrm{SD}=1.71)$. The assumption of homogeneous variances was satisfied ( $F$-test, $F=2.09, p=.296$ ). The comparison of mean scores using a t-test for independent samples did not differ significantly, $\mathrm{t}(.05,13)=.49, \mathrm{p}=.634$.

The Unit Two questions on the final exam revealed that the experimental group (mean = 16.73, $\mathrm{SD}=3.26)$ performed slightly better than the control group $($ mean $=16, \mathrm{SD}=2.16)$. The assumption of equal variances was satisfied (F-test, $\mathrm{F}=2.28, \mathrm{p}=.27)$. The means were not significantly different, $\mathrm{t}(.05,13)=.41, \mathrm{p}=.689$.

A univariate repeated measure analysis of variance was performed to analyze the differences in performance for each group across exams. There was a significant difference between the exam means of the experimental group, $F(.05,2,20)=35.04, p<.0001$. A post hoc analysis using Tukey's procedure $(\alpha=.05)$ revealed the mean for the unit exam was significantly higher than the pretest mean. The posttest mean was significantly higher than the pretest mean, but there was no significant difference between the unit test and the posttest means. Table 12 presents the means and standard deviations for the three exams. Table 13 presents the repeated measure analysis of variance summary.

Table 12

Means and Standard Deviations of Experimental Group Exam Means (Unit II, Experimental)

\begin{tabular}{lccc}
\hline \multicolumn{1}{c}{ Exam } & N & Mean & Standard Deviation \\
\hline Pretest & 11 & 10 & 2.32 \\
Unit II & 11 & 16.09 & 2.47 \\
Posttest & 11 & 16.73 & 3.26 \\
\hline
\end{tabular}


Table 13

Univariate Repeated Measure Analysis of Variance Summary (Unit II, Experimental)

\begin{tabular}{lcccc}
\hline \multicolumn{1}{c}{ Source of Variation } & df & Sum of Squares & Mean Square & $F$ value \\
\hline Treatment & 2 & 303.45 & 151.73 & $35.04^{*}$ \\
(between groups) & & & & \\
Residual & 20 & 86.54 & 4.33 & \\
Individual & 10 & 134.55 & & \\
(between participants) & & & & \\
\hline
\end{tabular}

$* p<.0001$

There was a significant difference between the exam means of the control group on the questions pertaining to Unit Two, $\mathrm{F}(.05,2,6)=58.11, \mathrm{p}=.0001$. A post hoc analysis using Tukey's procedure $(\alpha=.05)$ revealed the mean for the unit exam was significantly higher than the pretest mean. The posttest mean was significantly higher than the pretest mean, but there was no significant difference between the unit test and the posttest means. Table 14 presents the means and standard deviations for the three exams. Table 15 presents the repeated measure analysis of variance summary.

Table 14

Means and Standard Deviations of Control Group Exam Means (Unit II, Control)

\begin{tabular}{lccc}
\hline \multicolumn{1}{c}{ Exam } & N & Mean & Standard Deviation \\
\hline Pretest & 4 & 7.25 & 1.5 \\
Unit II & 4 & 16.75 & 1.71 \\
Posttest & 4 & 16 & 2.16 \\
\hline
\end{tabular}


Table 15

Univariate Repeated Measure Analysis of Variance Summary (Unit II, Control)

\begin{tabular}{lcccc}
\hline \multicolumn{1}{c}{ Source of Variation } & $\mathrm{df}$ & Sum of Squares & Mean Square & $F$ value \\
\hline Treatment & 2 & 223.17 & 111.58 & $58.11^{*}$ \\
(between groups) & & & & \\
Residual & 6 & 11.5 & 1.92 & \\
Individual & 3 & 18 & & \\
(between participants) & & & & \\
$* p=.0001$ & &
\end{tabular}

The Unit III course content exam results were compared with the performances on the same items from the pretest and final exam. Unit III contained 20 test items that were originally presented on the pretest and presented again on the posttest. A comparison of performance across opportunities is presented in Figure 16.

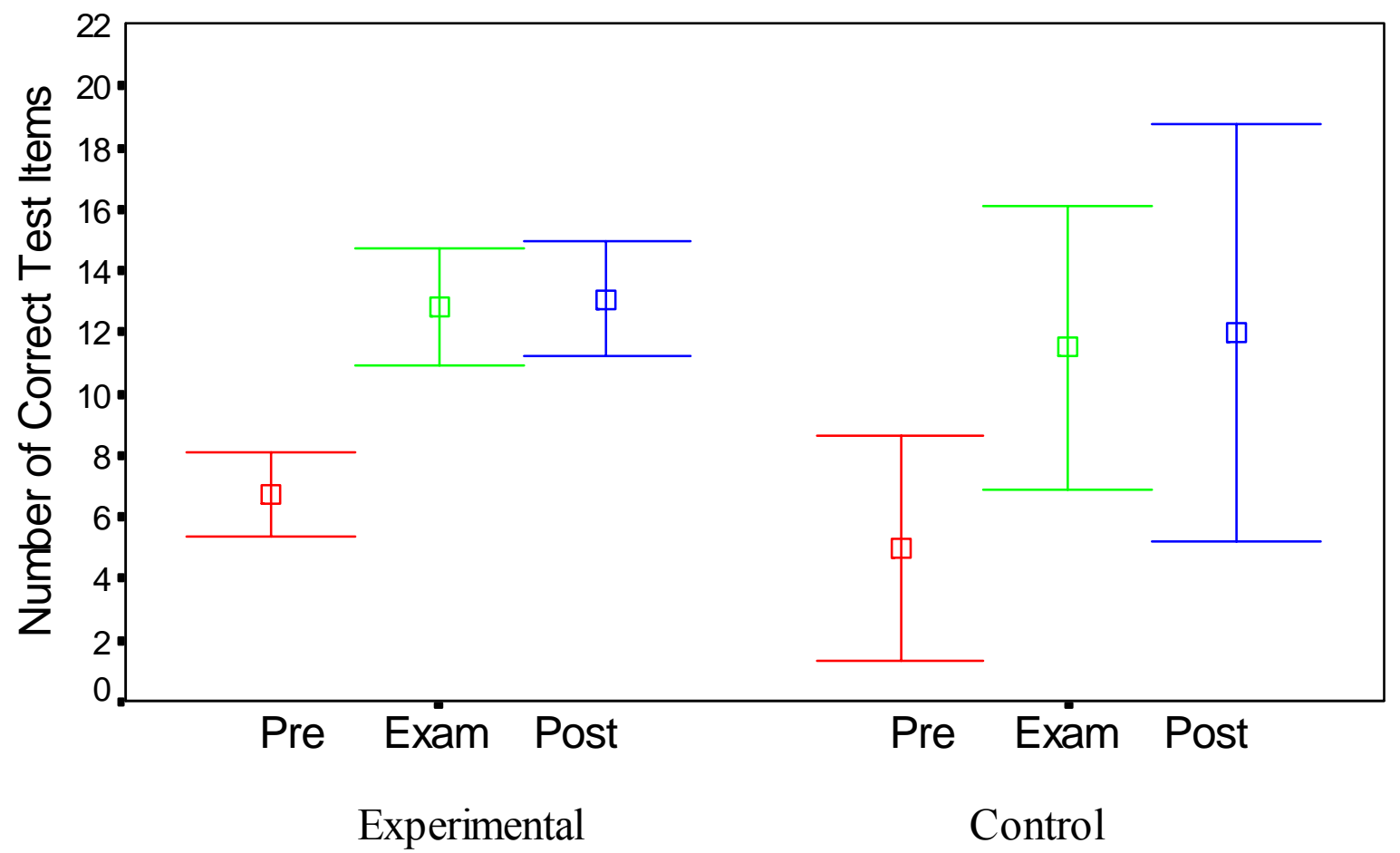

Figure 16. Means comparison of Unit III questions correct

On the Unit Three questions from the pretest, the underprepared students of the experimental group $(\mathrm{N}=11)$ correctly answered more questions (mean $=6.73, \mathrm{SD}=2.05)$ than the underprepared students in the control group $(\mathrm{N}=4$, mean $=5, \mathrm{SD}=2.31)$. The assumption 
of homogeneous variances was satisfied (F-test, $\mathrm{F}=1.27, \mathrm{p}=.337)$ and the means comparison using a t-test for independent samples revealed no statistically significant differences between groups, $\mathrm{t}(.05,13)=1.40, \mathrm{p}=.185$.

When the 20 questions were repeated on the Unit Three exam, the experimental group correctly answered slightly more questions (mean $=12.82, \mathrm{SD}=2.82)$ than the control group $($ mean $=11.5, \mathrm{SD}=2.89)$. An independent t-test was performed, and the assumption of homogeneous variances was satisfied (F-test, $F=1.05, \mathrm{p}=.413$ ). The mean scores did not differ significantly, $\mathrm{t}(.05,13)=.80, \mathrm{p}=.440$.

The Unit Three questions on the final exam revealed that the experimental group (mean $=$ $13.09, \mathrm{SD}=2.81)$ performed slightly better than the control group $($ mean $=12, \mathrm{SD}=4.24)$. The assumption of equal variances was satisfied $(F$-test, $F=2.28, p=.142)$. The means were not significantly different, $\mathrm{t}(.05,13)=.58, \mathrm{p}=.569$.

A univariate repeated measure analysis of variance was performed to analyze the differences in performance for each group across exams. There was a significant difference between the exam means of the experimental group, $F(.05,2,20)=27.23, p<.0001$. A post hoc analysis using Tukey's procedure $(\alpha=.05)$ revealed the mean for the unit exam was significantly higher than the pretest mean. The posttest mean was significantly higher than the pretest mean, but there was no significant difference between the unit test and the posttest means. Table 16 presents the means and standard deviations for the three exams. Table 17 presents the repeated measure analysis of variance summary. 
Table 16

Means and Standard Deviations of Experimental Group Exam Means (Unit III, Experimental)

\begin{tabular}{llcc}
\hline \multicolumn{1}{c}{ Exam } & $\mathrm{N}$ & Mean & Standard Deviation \\
\hline Pretest & 11 & 6.73 & 2.05 \\
Unit III & 11 & 12.82 & 2.82 \\
Posttest & 11 & 13.09 & 2.81 \\
\hline
\end{tabular}

Table 17

Univariate Repeated Measure Analysis of Variance Summary (Unit III, Experimental)

\begin{tabular}{lcccc}
\hline \multicolumn{1}{c}{ Source of Variation } & $\mathrm{df}$ & Sum of Squares & Mean Square & $F$ value \\
\hline Treatment & 2 & 284.79 & 142.39 & $27.23^{*}$ \\
(between groups) & & & & \\
Residual & 20 & 104.55 & 5.23 & \\
Individual & 10 & 96.18 & & \\
(between participants) & & & & \\
\hline$* p<.0001$ & & &
\end{tabular}

${ }^{*} p<.0001$

There was a significant difference between the exam means of the control group on the questions pertaining to Unit Three, $\mathrm{F}(.05,2,6)=25, \mathrm{p}=.001$. A post hoc analysis using Tukey's procedure $(\alpha=.05)$ revealed the mean for the unit exam was significantly higher than the pretest mean. The posttest mean was significantly higher than the pretest mean, but there was no significant difference between the unit test and the posttest means. Table 18 presents the means and standard deviations for the three exams. Table 19 presents the repeated measure analysis of variance summary. 
Table 18

Means and Standard Deviations of Control Group Exam Means (Unit III, Control)

\begin{tabular}{lccc}
\hline \multicolumn{1}{c}{ Exam } & N & Mean & Standard Deviation \\
\hline Pretest & 4 & 5 & 2.31 \\
Unit III & 4 & 11.5 & 2.89 \\
Posttest & 4 & 12 & 4.24 \\
\hline
\end{tabular}

Table 19

Univariate Repeated Measure Analysis of Variance Summary (Unit III, Control)

\begin{tabular}{lcccc}
\hline \multicolumn{1}{c}{ Source of Variation } & df & Sum of Squares & Mean Square & $F$ value \\
\hline Treatment & 2 & 122 & 61 & $25^{*}$ \\
(between groups) & & & & \\
Residual & 6 & 14.67 & 2.44 & \\
Individual & 3 & 80.33 & & \\
(between participants) & & & & \\
\hline$* p=.0001$
\end{tabular}

$* p=.0001$

The Unit IV course content exam results were compared with the performances on the same items from the pretest and final exam. Unit IV contained 15 test items that were originally presented on the pretest and presented again on the posttest. A comparison of performance across opportunities is presented in Figure 17. 


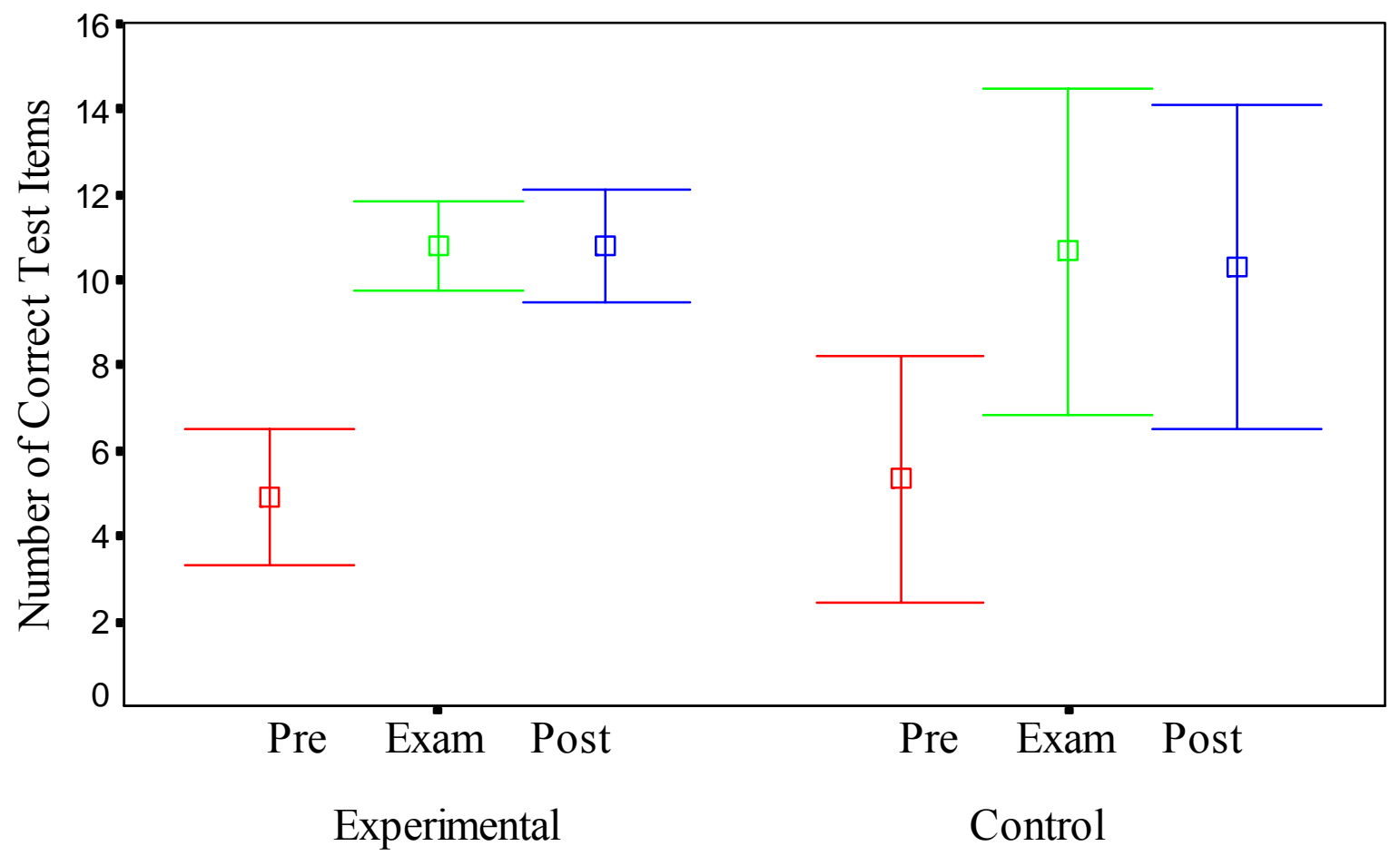

Figure 17. Means comparison of Unit IV questions correct

On the Unit Four questions from the pretest, the underprepared students of the experimental group $(\mathrm{N}=11)$ correctly answered slightly less questions (mean $=4.82, \mathrm{SD}=$ 2.136) than the underprepared students in the control group $(\mathrm{N}=4$, mean $=5.25, \mathrm{SD}=.957)$. The assumption of homogeneous variances was satisfied (F-test, $F=4.98, p=.107$ ) and the means comparison using a t-test for independent samples revealed no statistically significant difference between groups, $\mathrm{t}(.05,13)=.38, \mathrm{p}=.708$.

When the 15 questions were repeated on the Unit Four exam, the experimental group correctly answered almost the same number of questions (mean $=10.8, \mathrm{SD}=1.48$ ) as the control group (mean $=10.67, \mathrm{SD}=1.53$ ). An independent t-test was performed, and the assumption of homogeneous variances was satisfied (F-Test, $\mathrm{F}=1.068, \mathrm{p}=.384$ ). The mean scores did not differ significantly, $\mathrm{t}(.05,11)=.14, \mathrm{p}=.894$. (It is noted that one student in each group did not take the Unit Four exam.)

The Unit Four questions on the final exam revealed that the experimental group (mean = $10.45, \mathrm{SD}=2.12)$ performed slightly better than the control group (mean $=9.75, \mathrm{SD}=1.71)$. The assumption of equal variances was satisfied ( $F$-test, $F=1.54, p=.399$ ). The means were not significantly different, $\mathrm{t}(.05,13)=.59, \mathrm{p}=.562$. 
A univariate repeated measure analysis of variance was performed to analyze the differences in performance for each group across exams. Only the ten students from the experiment and the three students from the control group who took the three exams pertaining to Unit Four were included in the analyses. There was a significant difference between the exam means of the experimental group, $\mathrm{F}(.05,2,18)=36.49, \mathrm{p}<.0001$. A post hoc analysis using Tukey's procedure $(\alpha=.05)$ revealed the mean for the unit exam was significantly higher than the pretest mean. The posttest mean was significantly higher than the pretest mean, but there was no significant difference between the unit test and the posttest means. Table 20 presents the means and standard deviations for the three exams. Table 21 presents the repeated measure analysis of variance summary.

Table 20

Means and Standard Deviations of Experimental Group Exam Means (Unit IV, Experimental)

\begin{tabular}{lccc}
\hline \multicolumn{1}{c}{ Exam } & $\mathrm{N}$ & Mean & Standard Deviation \\
\hline Pretest & 10 & 4.9 & 2.23 \\
Unit IV & 10 & 10.8 & 1.48 \\
Posttest & 10 & 10.8 & 1.87 \\
\hline
\end{tabular}

Table 21

Univariate Repeated Measure Analysis of Variance Summary (Unit IV, Experimental)

\begin{tabular}{lcccc}
\hline \multicolumn{1}{c}{ Source of Variation } & df & Sum of Squares & Mean Square & $F$ value \\
\hline Treatment & 2 & 232.07 & 116.03 & $36.49^{*}$ \\
(between groups) & & & & \\
Residual & 18 & 57.27 & 3.18 & \\
Individual & 9 & 38.83 & & \\
(between participants) & & & & \\
\hline
\end{tabular}

$* p<.0001$

There was a significant difference between the exam means of the control group on the questions pertaining to Unit Four, $\mathrm{F}(.05,2,4)=28.19, \mathrm{p}=.004$. A post hoc analysis using Tukey's procedure $(\alpha=.05)$ revealed the mean for the unit exam was significantly higher than the pretest mean. The posttest mean was significantly higher than the pretest mean, but there was no significant difference between the unit test and the posttest means. Table 22 presents the 
means and standard deviations for the three exams. Table 23 presents the repeated measure analysis of variance summary.

Table 22

Means and Standard Deviations of Control Group Exam Means (Unit IV, Control)

\begin{tabular}{lccc}
\hline \multicolumn{1}{c}{ Exam } & N & Mean & Standard Deviation \\
\hline Pretest & 3 & 5.3 & 1.15 \\
Unit IV & 3 & 10.67 & 1.53 \\
Posttest & 3 & 10.33 & 1.53 \\
\hline
\end{tabular}

Table 23

Univariate Repeated Measure Analysis of Variance Summary (Unit IV, Control)

\begin{tabular}{lcccc}
\hline \multicolumn{1}{c}{ Source of Variation } & $\mathrm{df}$ & Sum of Squares & Mean Square & $F$ value \\
\hline Treatment & 2 & 122 & 26.78 & $28.19^{*}$ \\
(between groups) & & & & \\
Residual & 4 & 14.67 & 0.95 & \\
Individual & 2 & 8.22 & & \\
(between participants) & & & & \\
$*_{p} p=.0004$ & & &
\end{tabular}

The Unit V course content exam results were compared with the performances on the same items from the pretest and final exam. Unit V contained 14 test items that were originally presented on the pretest and presented again on the posttest. A comparison of performance across opportunities is presented in Figure 18. 


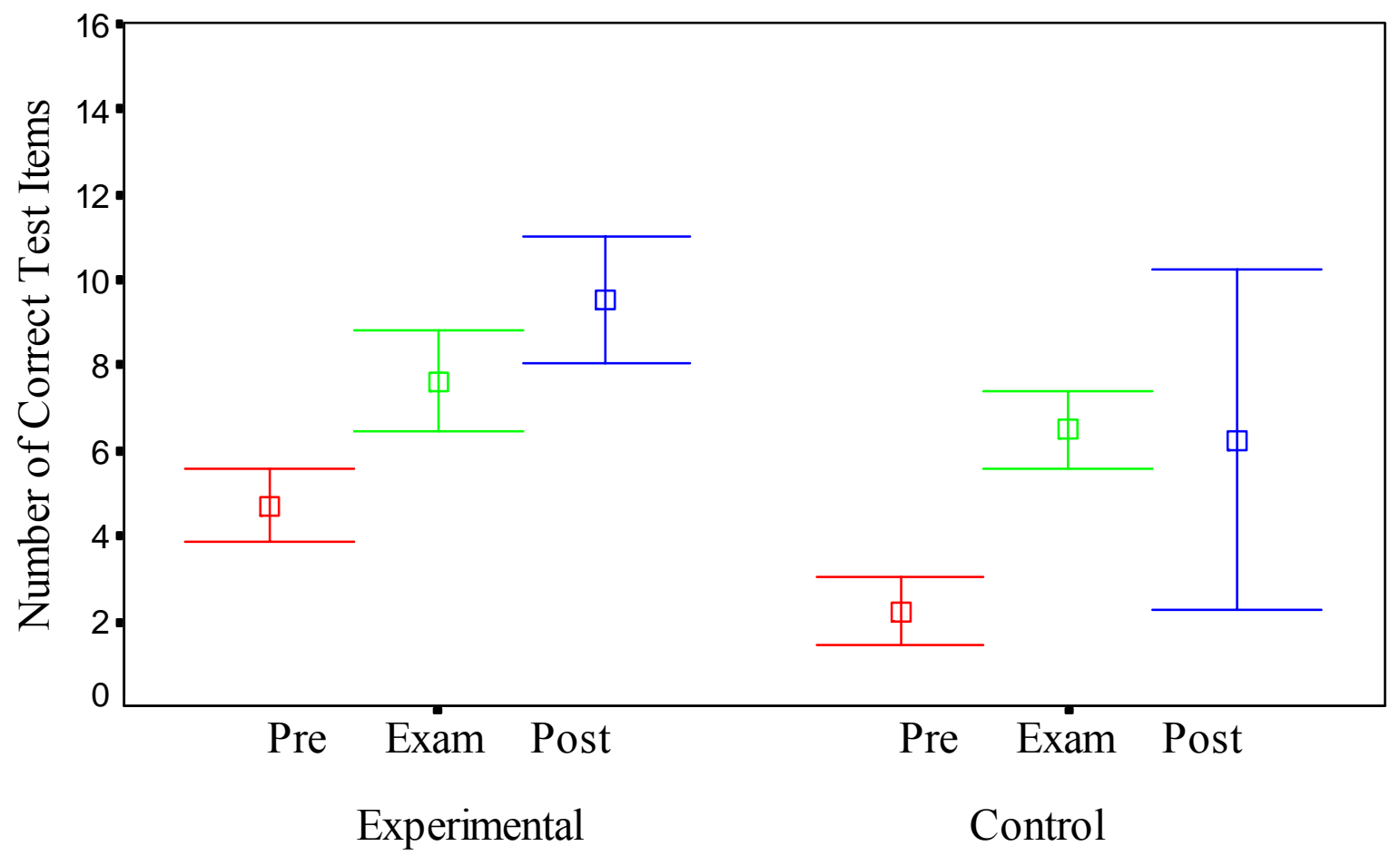

Figure 18. Means comparison of Unit $\mathrm{V}$ questions correct

On the Unit Five questions from the pretest, the underprepared students of the experimental group $(\mathrm{N}=11)$ correctly answered more questions (mean $=4.72, \mathrm{SD}=1.272)$ than the underprepared students in the control group $(\mathrm{N}=4$, mean $=2.25, \mathrm{SD}=.5)$. The assumption of homogeneous variances was satisfied (F-test, $F=6.48, p=.076$ ) and the means comparison using a t-test for independent samples revealed a statistically significant difference between groups, $\mathrm{t}(.05,13)=3.72, \mathrm{p}=.003$.

When the 14 questions were repeated on the Unit Five exam, the experimental group correctly answered slightly more questions (mean $=7.64, \mathrm{SD}=1.75$ ) as the control group (mean $=6.5, \mathrm{SD}=.577)$. The assumption of homogeneous variances was not satisfied (F-test, $\mathrm{F}=9.19$, $\mathrm{p}=.047$ ) indicating that the variances between groups were not equal. The mean scores did not differ significantly, $\mathrm{t}(.05,13)=1.25, \mathrm{p}=.234$, but may not be a valid representation of the scores since the variances were not equal.

The Unit Five questions on the final exam revealed that the experimental group (mean = $9.55, \mathrm{SD}=2.21)$ performed better than the control group (mean $=6.25, \mathrm{SD}=2.5$ ). The assumption of equal variances was satisfied ( $F$-test, $F=1.28, p=.334$ ). The means were significantly different, $\mathrm{t}(.05,13)=2.48, \mathrm{p}=.028$. 
A univariate repeated measure analysis of variance was performed to analyze the differences in performance for each group across exams. There was a significant difference between the exam means of the experimental group, $F(.05,2,20)=38.32, p<.0001$. A post hoc analysis using Tukey's procedure $(\alpha=.05)$ revealed the mean for the unit exam was significantly higher than the pretest mean. The posttest mean was significantly higher than the pretest mean, and there was a significant difference between the unit test and the posttest means. Table 24 presents the means and standard deviations for the three exams. Table 25 presents the repeated measure analysis of variance summary.

Table 24

Means and Standard Deviations of Experimental Group Exam Means (Unit V, Experimental)

\begin{tabular}{llcc}
\hline \multicolumn{1}{c}{ Exam } & $\mathrm{N}$ & Mean & Standard Deviation \\
\hline Pretest & 11 & 4.73 & 1.27 \\
Unit V & 11 & 7.64 & 1.75 \\
Posttest & 11 & 9.55 & 2.21 \\
\hline
\end{tabular}

Table 25

Univariate Repeated Measure Analysis of Variance Summary (Unit V, Experimental)

\begin{tabular}{lcccc}
\hline \multicolumn{1}{c}{ Source of Variation } & df & Sum of Squares & Mean Square & $F$ value \\
\hline Treatment & 2 & 129.52 & 64.76 & $38.32^{*}$ \\
(between groups) & & & & \\
Residual & 20 & 33.81 & 1.69 & \\
Individual & 10 & 61.64 & & \\
(between participants) & & & & \\
${ }^{*} p<.0001$ & & &
\end{tabular}

There was a significant difference between the exam means of the control group on the questions pertaining to Unit Five, $\mathrm{F}(.05,2,6)=10.94, \mathrm{p}=.009$. A post hoc analysis using Tukey's procedure $(\alpha=.05)$ revealed the mean for the unit exam was significantly higher than the pretest mean. The posttest mean was significantly higher than the pretest mean, but there was no significant difference between the unit test and the posttest means. Table 26 presents the means and standard deviations for the three exams. Table 27 presents the repeated measure analysis of variance summary. 
Table 26

Means and Standard Deviations of Control Group Exam Means (Unit V, Control)

\begin{tabular}{lccc}
\hline \multicolumn{1}{c}{ Exam } & N & Mean & Standard Deviation \\
\hline Pretest & 4 & 2.25 & .50 \\
Unit V & 4 & 6.5 & .58 \\
Posttest & 4 & 6.25 & 2.5 \\
\hline
\end{tabular}

Table 27

Univariate Repeated Measure Analysis of Variance Summary (Unit V, Control)

\begin{tabular}{lcccc}
\hline \multicolumn{1}{c}{ Source of Variation } & $\mathrm{df}$ & Sum of Squares & Mean Square & $F$ value \\
\hline Treatment & 2 & 45.5 & 22.75 & $10.94^{*}$ \\
(between groups) & & & & \\
Residual & 6 & 12.5 & 2.08 & \\
Individual & 3 & 8 & & \\
(between participants) & & & & \\
\hline
\end{tabular}

$* p=.0009$

A content analysis of exam questions which were repeated on the pretest, unit exams and posttest was completed. For each unit's content, there were exam questions that were not represented on the daily drills practiced by the experimental group, i.e. the drilled terms were not utilized in the questions. The exam questions that did not pertain to the daily drills were eliminated from the analysis. Remaining questions included those that required "application" of the drilled terms or those that required content "related" to the drilled terms.

To be included as a question that required "application" of a drilled term, the exam question had to feature the drilled term or its definition in a new but relevant context. In other words, the exam question required the use of the term or its definition in order to provide a correct response.

The "related" questions included several different types of multiple-choice items. Included were questions that provided the drilled term or its definition as a correct response. Other "related" questions provided the drilled term or its definition as an incorrect alternative. It was assumed that additional familiarity of the terms provided by the drills would reduce the likelihood of the multiple-choice alternative of a drilled term being chosen incorrectly. 
Daily drill terms of Unit One course content were represented by eleven questions on the pretest, unit exam, and posttest. On the pretest the underprepared students in the experimental group answered slightly fewer questions correctly (mean $=3.45, \mathrm{SD}=1.13$ ) than the underprepared students in the control group (mean $=4.25, \mathrm{SD}=1.25$ ). The homogeneity of variances was established by the $\mathrm{F}$-test $(\mathrm{F}=1.224, \mathrm{p}=.351)$. An independent t-test was performed, and the analysis revealed no significant difference between pretest means, $t(.05,13)$ $=1.17, \mathrm{p}=.26$.

A comparison of the eleven Unit One exam questions containing course content that had been practiced on daily drills by the experimental group was performed. The underprepared students of the control group answered more questions correctly (mean $=8.5, \mathrm{SD}=1.29$ ) than the underprepared students of the experimental group (mean $=7.09, \mathrm{SD}=1.87$ ). Homogeneous performances were evidenced, (F-test, $F=2.11, \mathrm{p}=.293$ ). The independent $\mathrm{t}$-test analysis revealed no statistical significance between Unit One exam means, $\mathrm{t}(.05,13)=1.38, \mathrm{p}=.19$.

Unit One questions containing drilled items represented on the final exam (posttest) were compared. The experimental group and the control group obtained identical means on the posttest measure $($ mean $=7$ ). The performances on the posttest were homogeneous (experimental group, $\mathrm{SD}=2.19$ and control group, $\mathrm{SD}=2.94)$, as measured by the $\mathrm{F}$-test $(\mathrm{F}=$ $1.8, \mathrm{p}=.211)$. The independent $\mathrm{t}$-test confirmed the equality of the means, $\mathrm{t}(.05,13)=0, \mathrm{p}=$ 1.00. Table 28 presents the means and standard deviations of the questions that represented Unit One. 
Table 28

Means and Standard Deviations of Unit One Correctly Answered Questions Containing Drilled $\underline{\text { Terms }}$

\begin{tabular}{lccc}
\hline \multicolumn{1}{c}{ Exam } & $\mathrm{N}$ & Mean & Standard Deviation \\
\hline Pretest & 11 & 3.45 & 1.13 \\
Experimental & 4 & 4.25 & 1.26 \\
Control & & & \\
Unit One Exam & 11 & 7.09 & 1.87 \\
Experimental & 4 & 8.5 & 1.29 \\
Control & & & \\
Posttest & 11 & 7 & 2.19 \\
Experimental & 4 & 7 & 2.94 \\
Control & & & \\
\hline
\end{tabular}

Although the performances between groups revealed no significant differences on the performance on Unit One questions, a univariate repeated measure analysis of variance was performed to analyze the differences in performance for each group across exams. There was a significant difference between the exam means of the experimental group, $\mathrm{F}(.05,2,20)=22.52$, $\mathrm{p}<.0001$. A post hoc analysis using Tukey's procedure $(\alpha=.05)$ revealed the mean for the unit exam was significantly higher than the pretest mean. The posttest mean was significantly higher than the pretest mean, but there was no significant difference between the unit test and the posttest means. Table 29 presents the repeated measure analysis of variance summary of correctly answered Unit One questions containing drilled terms by the experimental group. 
Table 29

Univariate Repeated Measure Analysis of Variance Summary for Unit One (Experimental)

\begin{tabular}{lcccc}
\hline \multicolumn{1}{c}{ Source of Variation } & df & Sum of Squares & Mean Square & $F$ value \\
\hline Treatment & 2 & 94.61 & 47.3 & $22.52^{*}$ \\
(between groups) & & & & \\
Residual & 20 & 42.06 & 2.1 & \\
Individual & 10 & 53.58 & & \\
(between participants) & & & & \\
\hline
\end{tabular}

$* p<.0001$

There was also a significant difference in the performances of the underprepared students in the control group on the correctly answered questions from Unit One that the experimental group had drilled, $\mathrm{F}(.05,2,6)=7.87, \mathrm{p}=.021$. A post hoc analysis using Tukey's procedure $(\alpha$ $=.05$ ) revealed the mean for the unit exam was significantly higher than the pretest mean, however unlike the experimental group, the mean for the posttest was not significantly better than the pretest. There was no significant difference between the Unit One exam and the posttest means. Table 30 shows the analysis of variance results for the control group on questions pertaining to Unit One course content.

Table 30

$\underline{\text { Univariate Repeated Measure Analysis of Variance Summary for Unit One (Control) }}$

\begin{tabular}{lcccc}
\hline \multicolumn{1}{c}{ Source of Variation } & df & Sum of Squares & Mean Square & $F$ value \\
\hline Treatment & 2 & 37.17 & 18.58 & $7.87^{*}$ \\
(between groups) & & & & \\
Residual & 6 & 14.17 & 2.36 & \\
Individual & 3 & 21.58 & & \\
(between participants) & & & & \\
$*{ }^{*} p=.021$ & &
\end{tabular}

Of the eleven questions presented on the pretest, unit exam, and posttest, six were application questions of daily drill terms. On the pretest the underprepared students in the experimental group answered slightly fewer questions correctly $($ mean $=1.73, \mathrm{SD}=1.10)$ than the underprepared students in the control group (mean $=2.25, \mathrm{SD}=.5)$. The F-test was performed and demonstrated homogeneity of variances $(\mathrm{F}=4.84, \mathrm{p}=.111)$. An independent $\mathrm{t}$ - 
test was performed, and the analysis revealed no significant difference between pretest means, $\mathrm{t}$ $(.05,13)=.9, \mathrm{p}=.38$.

A comparison of the six application questions on the Unit One exam was performed. The underprepared students of the control group answered more questions correctly (mean $=4.5$, SD $=.58)$ than the underprepared students of the experimental group (mean $=3.36, \mathrm{SD}=1.03)$. The homogeneity of variances was confirmed by the F-test $(\mathrm{F}=3.15, \mathrm{p}=.187)$. The independent $\mathrm{t}$ test analysis revealed no statistical significance between Unit One exam means, $\mathrm{t}(.05,13)=$ $2.07, \mathrm{p}=.06$.

Unit One application questions containing drilled items represented on the final exam (posttest) were compared. The experimental group and the control group answered almost the identical number of questions correctly, (experimental mean $=3.55, \mathrm{SD}=1.44$ and control mean $=3.75, \mathrm{SD}=1.71)$. The F-test confirmed the homogeneity of variances $(\mathrm{F}=1.41, \mathrm{p}=.297)$. The independent $\mathrm{t}$-test indicated no significant difference of the means, $\mathrm{t}(.05,13)=.23, \mathrm{p}=.82$. Table 31 presents the means and standard deviations of the questions that represented Unit One. 
Table 31

Means and Standard Deviations of Unit One Correctly Answered Questions Containing Drilled Terms (Application Only)

\begin{tabular}{lccc}
\hline \multicolumn{1}{c}{ Exam } & $\mathrm{N}$ & Mean & Standard Deviation \\
\hline Pretest & 11 & 1.73 & 1.10 \\
Experimental & 4 & 2.25 & 0.5 \\
Control & & & \\
Unit One Exam & 11 & 3.36 & 1.03 \\
Experimental & 4 & 4.5 & .58 \\
Control & & & 1.44 \\
Posttest & 11 & 3.55 & 1.71 \\
Experimental & 4 & 3.75 & \\
Control & & & \\
\hline
\end{tabular}

Although the performances between groups revealed no significant differences on the performance on Unit One application questions, a univariate repeated measure analysis of variance was performed to analyze the differences in performance for each group across exams. There was a significant difference between the exam means of the experimental group, F (.05, 2, $20)=10.71, p=.0007$. A post hoc analysis using Tukey's procedure $(\alpha=.05)$ revealed the mean for the unit exam was significantly higher than the pretest mean. The posttest mean was significantly higher than the pretest mean, but there was no significant difference between the unit test and the posttest means. Table 32 presents the repeated measure analysis of variance summary of correctly answered Unit One questions containing drilled terms by the experimental group. 
Table 32

Univariate Repeated Measure Analysis of Variance Summary for Unit One Applications (Experimental)

\begin{tabular}{lcccc}
\hline \multicolumn{1}{c}{ Source of Variation } & df & Sum of Squares & Mean Square & $F$ value \\
\hline Treatment & 2 & 22.06 & 11.03 & $10.71^{*}$ \\
(between groups) & & & & \\
Residual & 20 & 20.6 & 1.03 & \\
Individual & 10 & 22.85 & & \\
(between participants) & & & & \\
${ }^{*} p=.0007$ & & &
\end{tabular}

There was no significant difference in the performances of the underprepared students in the control group on the correctly answered application questions from Unit One that the experimental group had drilled, $F(.05,2,6)=3.57, p=.095$. Because there was no significant F-value, Tukey's analysis could not be completed. Table 33 shows the analysis of variance results.

Table 33

$\underline{\text { Univariate Repeated Measure Analysis of Variance Summary for Unit One Applications }}$ (Control)

\begin{tabular}{lcccc}
\hline \multicolumn{1}{c}{ Source of Variation } & df & Sum of Squares & Mean Square & $F$ value \\
\hline Treatment & 2 & 10.5 & 5.25 & $3.57^{*}$ \\
(between groups) & & & & \\
Residual & 6 & 8.83 & 1.47 & \\
Individual & 3 & 1.67 & & \\
(between participants) & & & & \\
$*{ }^{*} p=.095$ & &
\end{tabular}

Of the eleven questions presented on the pretest, unit exam, and posttest, five were "practice" questions of daily drill terms. On the pretest the underprepared students in the experimental group answered slightly fewer questions correctly (mean $=1.73, \mathrm{SD}=.79$ ) than the underprepared students in the control group (mean $=2, \mathrm{SD}=1.41)$. The homogeneity of variances was demonstrated (F-test, $\mathrm{F}=3.21, \mathrm{p}=.07$ ). An independent $\mathrm{t}$-test was performed, 
and the analysis revealed no significant difference between pretest means of "practice" questions, $\mathrm{t}(.05,13)=.48, \mathrm{p}=.64$.

A comparison of the five "practice" questions on the Unit One exam was performed. The underprepared students of the control group answered more questions correctly (mean $=4, \mathrm{SD}=$ $1.15)$ than the underprepared students of the experimental group (mean $=3.72, \mathrm{SD}=1.10)$. The variances were homogeneous ( $F$-test, $F=1.09, \mathrm{p}=.398$ ). The independent $\mathrm{t}$-test analysis revealed no statistical significance between Unit One exam means, $\mathrm{t}(.05,13)=.42, \mathrm{p}=.68$.

Unit One "practice" questions containing drilled items represented on the final exam (posttest) were compared. The experimental group and the control group answered almost the identical number of questions correctly, (experimental mean $=3.45, \mathrm{SD}=1.26$ and control mean $=3.25, \mathrm{SD}=.93)$. The homogeneity of variances was demonstrated $(\mathrm{F}$-test, $\mathrm{F}=1.84, \mathrm{p}=.337)$. The independent $\mathrm{t}$-test indicated no significant difference of the means, $\mathrm{t}(.05,13)=.34, \mathrm{p}=.74$. Table 34 presents the means and standard deviations of the questions that represented the "practice" questions from Unit One.

Table 34

Means and Standard Deviations of Unit One Correctly Answered Questions Containing Drilled $\underline{\text { Terms (Practice Only) }}$

\begin{tabular}{lccc}
\hline \multicolumn{1}{c}{ Exam } & $\mathrm{N}$ & Mean & Standard Deviation \\
\hline Pretest & 11 & 1.73 & .79 \\
Experimental & 4 & 2 & 1.41 \\
Control & & & \\
Unit One Exam & 11 & 3.72 & 1.10 \\
Experimental & 4 & 4 & 1.15 \\
Control & & & \\
Posttest & 11 & 3.45 & .93 \\
Experimental & 4 & 3.25 & 1.26 \\
Control & & & \\
\hline
\end{tabular}

Although the performances between groups revealed no significant differences on the performance on Unit One "practice" questions, a univariate repeated measure analysis of variance was performed to analyze the differences in performance for each group across exams. 
There was a significant difference between the exam means of the experimental group, F (.05, 2, $20)=18.23, p<.0001$. A post hoc analysis using Tukey's procedure $(\alpha=.05)$ revealed the mean for the unit exam was significantly higher than the pretest mean. The posttest mean was significantly higher than the pretest mean, but there was no significant difference between the unit test and the posttest means. Table 35 presents the repeated measure analysis of variance summary of correctly answered Unit One "practice" questions containing drilled terms by the experimental group.

Table 35

Univariate Repeated Measure Analysis of Variance Summary for Unit One (Experimental)

\begin{tabular}{lcccc}
\hline \multicolumn{1}{c}{ Source of Variation } & df & Sum of Squares & Mean Square & $F$ value \\
\hline Treatment & 2 & 25.88 & 12.94 & $18.23^{*}$ \\
(between groups) & & & & \\
Residual & 20 & 14.12 & 0.71 & \\
Individual & 10 & 12.97 & & \\
(between participants) & & & & \\
${ }^{*} p<.0001$ & & & &
\end{tabular}

There was also a significant difference in the performances of the underprepared students in the control group on the correctly answered "practice" questions from Unit One, F $(.05,2,6)=$ $13.16, \mathrm{p}=.006$. A post hoc analysis using Tukey's procedure $(\alpha=.05)$ revealed the mean for the unit exam was significantly higher than the pretest mean. The posttest mean was significantly higher than the pretest mean, but there was no significant difference between the unit test and the posttest means. Table 36 shows the analysis of variance results. 
Table 36

Univariate Repeated Measure Analysis of Variance Summary for Unit One (Control)

\begin{tabular}{lcccc}
\hline \multicolumn{1}{c}{ Source of Variation } & $\mathrm{df}$ & Sum of Squares & Mean Square & $F$ value \\
\hline Treatment & 2 & 8.17 & 4.08 & $13.16^{*}$ \\
(between groups) & & & & \\
Residual & 6 & 1.83 & 0.31 & \\
Individual & 3 & 12.92 & & \\
(between participants) & & & & \\
$* p=.006$ & & & &
\end{tabular}

Daily drill terms of Unit Two course content were represented by fifteen questions on the pretest, unit exam, and posttest. On the pretest the underprepared students in the experimental group answered more questions correctly (mean $=7, \mathrm{SD}=2)$ than the underprepared students in the control group $($ mean $=4.75, \mathrm{SD}=1.89)$. The homogeneity of variances was confirmed $(\mathrm{F}$ test, $\mathrm{F}=1.12, \mathrm{p}=.522$ ). An independent t-test was performed, and the analysis revealed no significant difference between pretest means, $\mathrm{t}(.05,13)=1.95, \mathrm{p}=.07$.

A comparison of the fifteen Unit Two exam questions containing course content that had been practiced on daily drills by the experimental group was performed. The underprepared students of the control group answered slightly more questions correctly (mean $=12.25, \mathrm{SD}=$ 1.71) than the underprepared students of the experimental group (mean $=11.36, \mathrm{SD}=1.75)$. Homogeneous variances were evidenced $(\mathrm{F}$-test, $\mathrm{F}=1.05, \mathrm{p}=.548)$. The independent $\mathrm{t}$-test analysis revealed no statistical significance between Unit Two exam means, $\mathrm{t}(.05,13)=0.87, \mathrm{p}$ $=.40$.

Unit Two questions containing drilled items represented on the final exam (posttest) were compared. The experimental group answered more questions correctly (mean $=11.55, \mathrm{SD}=$ $1.81)$ than the control group on the posttest measure (mean $=10.75, \mathrm{SD}=1.89)$. Homogeneity of variance was accepted ( $\mathrm{F}$-test, $\mathrm{F}=1.09, \mathrm{p}=.398$ ). The independent t-test revealed no statistical significance, $\mathrm{t}(.05,13)=0.74, \mathrm{p}=.47$. Table 37 presents the means and standard deviations of the questions that represented Unit Two. 
Table 37

Means and Standard Deviations of Unit Two Correctly Answered Questions Containing Drilled $\underline{\text { Terms }}$

\begin{tabular}{lccc}
\hline \multicolumn{1}{c}{ Exam } & $\mathrm{N}$ & Mean & Standard Deviation \\
\hline Pretest & 11 & 7 & 2 \\
Experimental & 4 & 4.75 & 1.89 \\
Control & & & \\
Unit Two Exam & 11 & 11.36 & 1.75 \\
Experimental & 4 & 12.25 & 1.71 \\
Control & & & 1.81 \\
Posttest & 11 & 11.54 & 1.89 \\
Experimental & 4 & 10.75 & \\
Control & & & \\
\hline
\end{tabular}

Although the performances between groups revealed no significant differences on the performance on Unit Two questions, a univariate repeated measure analysis of variance was performed to analyze the differences in performance for each group across exams. There was a significant difference between the exam means of the experimental group, $\mathrm{F}(.05,2,20)=38.75$, $\mathrm{p}<.0001$. A post hoc analysis using Tukey's procedure $(\alpha=.05)$ revealed the mean for the unit exam was significantly higher than the pretest mean. The posttest mean was significantly higher than the pretest mean, but there was no significant difference between the unit test and the posttest means. Table 38 presents the repeated measure analysis of variance summary of correctly answered Unit Two questions containing drilled terms by the experimental group. 
Table 38

Univariate Repeated Measure Analysis of Variance Summary for Unit Two (Experimental)

\begin{tabular}{lcccc}
\hline \multicolumn{1}{c}{ Source of Variation } & $\mathrm{df}$ & Sum of Squares & Mean Square & $F$ value \\
\hline Treatment & 2 & 145.7 & 72.85 & $38.75^{*}$ \\
(between groups) & & & & \\
Residual & 20 & 37.63 & 1.88 & \\
Individual & 10 & 65.64 & & \\
(between participants) & & & & \\
$*_{p}<.0001$ & & &
\end{tabular}

$* p<.0001$

There was also a significant difference in the performances of the underprepared students in the control group on the correctly answered questions from Unit Two, F (.05, 2, 6) = 43.45, $\mathrm{p}$ $=.0002$. A post hoc analysis using Tukey's procedure $(\alpha=.05)$ revealed the mean for the unit exam was significantly higher than the pretest mean, and the mean for the posttest was significantly better than the pretest. There was no significant difference between the Unit Two exam and the posttest means. Table 39 shows the analysis of variance results for the control group on questions pertaining to Unit Two course content.

Table 39

Univariate Repeated Measure Analysis of Variance Summary for Unit Two (Control)

\begin{tabular}{lcccc}
\hline \multicolumn{1}{c}{ Source of Variation } & $\mathrm{df}$ & Sum of Squares & Mean Square & $F$ value \\
\hline Treatment & 2 & 126 & 63 & $43.45^{*}$ \\
(between groups) & & & & \\
Residual & 6 & 8.67 & 1.45 & \\
Individual & 3 & 21.58 & & \\
(between participants) & & & & \\
${ }^{*} p=.0002$ & &
\end{tabular}

Of the fifteen questions presented on the pretest, unit exam, and posttest, three were application questions of daily drill terms. On the pretest the underprepared students of the experimental group answered slightly more questions correctly $($ mean $=1.36, \mathrm{SD}=1.03)$ than the control group $($ mean $=1.25, \mathrm{SD}=0.96)$. The F-test confirmed the homogeneity of variances $(\mathrm{F}=1.15, \mathrm{p}=.511)$. An independent t-test was performed, and the analysis revealed no significant difference between pretest means, $\mathrm{t}(.05,13)=.19, \mathrm{p}=.85$. 
A comparison of the three application questions on the Unit Two exam was performed. The underprepared students of the control group answered slightly fewer questions correctly (mean $=2, \mathrm{SD}=.82)$ than the underprepared students of the experimental group $($ mean $=2.27$, $\mathrm{SD}=1.01)$. Homogeneous variances were evidenced $(\mathrm{F}$-test, $\mathrm{F}=1.52, \mathrm{p}=.404)$. The independent $\mathrm{t}$-test analysis revealed no statistical significance between Unit Two exam means, $\mathrm{t}$ $(.05,13)=.48, \mathrm{p}=.639$.

Unit Two application questions containing drilled items represented on the final exam (posttest) were compared. The experimental group and the control group answered almost the identical number of questions correctly, (experimental mean $=2.27$, control mean $=2.25$ ). The standard deviations were similar (experimental group, $\mathrm{SD}=.90$ and control group, $\mathrm{SD}=.96$ ). The homogeneity of variances was confirmed by the F-test $(F=.745, p=.549)$. The independent t-test indicated no significant difference of the means, $\mathrm{t}(.05,13)=.04, \mathrm{p}=.97$. Table 40 presents the means and standard deviations of the questions that represented Unit Two. 
Table 40

Means and Standard Deviations of Unit Two Correctly Answered Questions Containing Drilled Terms (Application Only)

\begin{tabular}{lccc}
\hline \multicolumn{1}{c}{ Exam } & $\mathrm{N}$ & Mean & Standard Deviation \\
\hline Pretest & 11 & 1.36 & 1.03 \\
Experimental & 4 & 1.25 & .96 \\
Control & & & \\
Unit Two Exam & 11 & 2.27 & 1.01 \\
Experimental & 4 & 2 & .82 \\
Control & & & .90 \\
Posttest & 11 & 2.27 & .96 \\
Experimental & 4 & 2.25 & \\
Control & & & \\
\hline
\end{tabular}

Although the performances between groups revealed no significant differences on the performance on Unit Two application questions, a univariate repeated measure analysis of variance was performed to analyze the differences in performance for each group across exams. There was a significant difference between the exam means of the experimental group, F (.05, 2, $20)=7.57, p=.0004$. A post hoc analysis using Tukey's procedure $(\alpha=.05)$ revealed the mean for the unit exam was significantly higher than the pretest mean. The posttest mean was significantly higher than the pretest mean, but there was no significant difference between the unit test and the posttest means. Table 41 presents the repeated measure analysis of variance summary of correctly answered Unit Two questions containing drilled terms by the experimental group. 
Table 41

Univariate Repeated Measure Analysis of Variance Summary for Unit Two (Experimental)

\begin{tabular}{lcccc}
\hline \multicolumn{1}{c}{ Source of Variation } & df & Sum of Squares & Mean Square & $F$ value \\
\hline Treatment & 2 & 6.06 & 3.03 & $7.57^{*}$ \\
(between groups) & & & & \\
Residual & 20 & 7.94 & 0.4 & \\
Individual & 10 & 20.97 & & \\
(between participants) & & & & \\
${ }^{*} p=.0004$ & &
\end{tabular}

There was a significant difference in the performances of the underprepared students in the control group on the correctly answered application questions from Unit Two, F $(.05,2,6)=$ 13.5, $\mathrm{p}=.006$. A post hoc analysis using Tukey's procedure $(\alpha=.05)$ revealed the mean for the unit exam was significantly higher than the pretest mean. The posttest mean was significantly higher than the pretest mean, but there was no significant difference between the unit test and the posttest means. Table 42 shows the analysis of variance results.

Table 42

Univariate Repeated Measure Analysis of Variance Summary for Unit Two (Control)

\begin{tabular}{lcccc}
\hline \multicolumn{1}{c}{ Source of Variation } & df & Sum of Squares & Mean Square & $F$ value \\
\hline Treatment & 2 & 2.17 & 1.08 & $13.5^{*}$ \\
(between groups) & & & & \\
Residual & 6 & 0.5 & 0.08 & \\
Individual & 3 & 7 & & \\
(between participants) & & & & \\
${ }^{*} p=.006$ & &
\end{tabular}

Of the fifteen questions presented on the pretest, unit exam, and posttest, twelve were "practice" questions of daily drill terms. On the pretest the underprepared students in the experimental group answered more questions correctly $($ mean $=5.64, \mathrm{SD}=1.80)$ than the underprepared students in the control group (mean $=3.5, \mathrm{SD}=1)$. The homogeneity of variance was accepted (F-test, $\mathrm{F}=3.24, \mathrm{p}=.181$ ). An independent t-test was performed, and the analysis revealed a significant difference between pretest means of "practice" questions, $\mathrm{t}(.05,13)=$ $2.21, \mathrm{p}=.045$. 
A comparison of the twelve "practice" questions on the Unit Two exam was performed. The underprepared students of the control group answered more questions correctly (mean $=$ $10.25, \mathrm{SD}=1.5)$ than the underprepared students of the experimental group (mean $=9.09, \mathrm{SD}=$ 1.81). Homoscedasticity was accepted (F-test, $\mathrm{F}=1.46, \mathrm{p}=.419$. The independent $\mathrm{t}$-test analysis revealed no statistical significance between Unit Two exam means, $t(.05,13)=1.14, p$ $=.27$.

Unit Two "practice" questions containing drilled items represented on the final exam (posttest) were compared. The experimental group answered more questions correctly $($ mean $=$ $9.27, \mathrm{SD}=1.27)$ than the control group $($ mean $=8.5, \mathrm{SD}=1)$. The F-test verified the homogeneity of variance $(\mathrm{F}=1.27, \mathrm{p}=.472)$. The independent t-test indicated no significant difference of the means, $\mathrm{t}(.05,13)=1.09, \mathrm{p}=.296$. Table 43 presents the means and standard deviations of the questions that represented the "practice" questions from Unit Two. Table 43

Means and Standard Deviations of Unit Two Correctly Answered Questions Containing Drilled Terms (Practice Only)

\begin{tabular}{lccc}
\hline \multicolumn{1}{c}{ Exam } & $\mathrm{N}$ & Mean & Standard Deviation \\
\hline Pretest & 11 & 5.64 & 1.80 \\
Experimental & 4 & 3.5 & 1 \\
Control & & & \\
Unit Two Exam & 11 & 9.09 & 1.81 \\
Experimental & 4 & 10.25 & 1.5 \\
Control & & & 1.27 \\
Posttest & 11 & 9.27 & 1 \\
Experimental & 4 & 8.5 & \\
Control & & & \\
\hline
\end{tabular}

A univariate repeated measure analysis of variance was performed to analyze the differences in performance for each group across exams using Unit Two "practice" items. There was a significant difference between the exam means of the experimental group, $\mathrm{F}(.05,2,20)=$ $29.79, \mathrm{p}<.0001$. A post hoc analysis using Tukey's procedure $(\alpha=.05)$ revealed the mean for the unit exam was significantly higher than the pretest mean. The posttest mean was 
significantly higher than the pretest mean, but there was no significant difference between the unit test and the posttest means. Table 44 presents the repeated measure analysis of variance summaries of correctly answered Unit Two "practice" questions containing drilled terms by the experimental group.

Table 44

Univariate Repeated Measure Analysis of Variance Summary for Unit Two (Experimental)

\begin{tabular}{lcccc}
\hline \multicolumn{1}{c}{ Source of Variation } & $\mathrm{df}$ & Sum of Squares & Mean Square & $F$ value \\
\hline Treatment & 2 & 92.36 & 46.18 & $29.79^{*}$ \\
(between groups) & & & & \\
Residual & 20 & 30.97 & 1.55 & \\
Individual & 10 & 50.67 & & \\
(between participants) & & & & \\
${ }^{*} p<.0001$ & & &
\end{tabular}

There was also a significant difference in the performances of the underprepared students in the control group on the correctly answered "practice" questions from Unit Two, F $(.05,2,6)$ $=34.56, \mathrm{p}=.0005$. A post hoc analysis using Tukey's procedure $(\alpha=.05)$ revealed the mean for the unit exam was significantly higher than the pretest mean. The posttest mean was significantly higher than the pretest mean, but there was no significant difference between the unit test and the posttest means. Table 45 shows the analysis of variance results. 
Table 45

Univariate Repeated Measure Analysis of Variance Summary for Unit Two (Control)

\begin{tabular}{lcccc}
\hline \multicolumn{1}{c}{ Source of Variation } & $\mathrm{df}$ & Sum of Squares & Mean Square & $F$ value \\
\hline Treatment & 2 & 98.17 & 49.08 & $34.56^{*}$ \\
(between groups) & & & & \\
Residual & 6 & 8.5 & 1.42 & \\
Individual & 3 & 4.25 & & \\
(between participants) & & & & \\
$* p=.0005$ & & &
\end{tabular}

Daily drill terms of Unit Three course content were represented by nine questions on the pretest, unit exam, and posttest. On the pretest the underprepared students in the experimental group answered fewer items correctly than the control group (experimental mean $=2.27, \mathrm{SD}=$ 1.42 and control mean $=2.5, \mathrm{SD}=.577)$. The variances were not significantly different $(\mathrm{F}$-test, $\mathrm{F}$ $=6.06, \mathrm{p}=.083)$. An independent t-test was performed, and the analysis revealed no significant difference between pretest means, $\mathrm{t}(.05,13)=.3, \mathrm{p}=.769$.

A comparison of the nine Unit Three exam questions, containing course content that had been practiced on daily drills by the experimental group, was performed. The underprepared students of the control group answered slightly fewer questions correctly (mean $=6.67, \mathrm{SD}=$ $1.53)$ than the underprepared students of the experimental group (mean $=7.33, \mathrm{SD}=1.23)$. Homogeneous variances were evidenced (F-test, $\mathrm{F}=1.56, \mathrm{p}=.269)$. The independent $\mathrm{t}$-test analysis revealed no statistical significance between Unit Three exam means, $\mathrm{t}(.05,10)=0.77, \mathrm{p}$ $=.46$. It is noted that two students in the experimental group and one student in the control group did not take the Unit Three Exam, resulting in twelve participants' results being analyzed for the experimental group and three participants' results being analyzed for the control group.

Unit Three questions containing drilled items represented on the final exam (posttest) were compared. The experimental group answered slightly more questions correctly (mean $=$ $5.55, \mathrm{SD}=1.97)$ than the control group on the posttest measure $($ mean $=5.5, \mathrm{SD}=1.29)$. The Ftest confirmed the homogeneity of variance $(F=2.32, p=.264)$. The independent $t$-test revealed no statistical significance, $\mathrm{t}(.05,13)=.04, \mathrm{p}=.969$. Table 46 presents the means and standard deviations of the questions that represented Unit Three. 
Table 46

Means and Standard Deviations of Unit Three Correctly Answered Questions Containing Drilled Terms

\begin{tabular}{lccc}
\hline \multicolumn{1}{c}{ Exam } & $\mathrm{N}$ & Mean & Standard Deviation \\
\hline Pretest & 11 & 2.27 & 1.42 \\
Experimental & 4 & 2.5 & .58 \\
Control & & & \\
Unit Three Exam & 9 & 7.33 & 1.22 \\
Experimental & 3 & 6.67 & 1.53 \\
Control & & & \\
Posttest & 11 & 5.55 & 1.97 \\
Experimental & 4 & 5.5 & 1.29 \\
Control & & & \\
\hline
\end{tabular}

Although the performances between groups revealed no significant differences on the performance on Unit Three questions, a univariate repeated measure analysis of variance was performed to analyze the differences in performance for each group across exams. There was a significant difference between the exam means of the experimental group, $\mathrm{F}(.05,2,16)=39.62$, $\mathrm{p}<.0001$. A post hoc analysis using Tukey's procedure $(\alpha=.05)$ revealed the mean for the unit exam was significantly higher than the pretest mean. The posttest mean was significantly higher than the pretest mean, but there was no significant difference between the unit test and the posttest means. Table 47 presents the repeated measure analysis of variance summary of correctly answered Unit Three questions containing drilled terms by the experimental group. 
Table 47

Univariate Repeated Measure Analysis of Variance Summary for Unit Three (Experimental)

\begin{tabular}{lcccc}
\hline \multicolumn{1}{c}{ Source of Variation } & $\mathrm{df}$ & Sum of Squares & Mean Square & $F$ value \\
\hline Treatment & 2 & 105.41 & 52.7 & $39.62^{*}$ \\
(between groups) & & & & \\
Residual & 16 & 21.26 & 1.33 & \\
Individual & 8 & 41.63 & & \\
(between participants) & & & & \\
${ }^{*} p<.0001$ & & &
\end{tabular}

There was also a significant difference in the performances of the underprepared students in the control group on the correctly answered questions from Unit Three, $F(.05,2,4)=17.67, p$ $=.01$. A post hoc analysis using Tukey's procedure $(\alpha=.05)$ revealed the mean for the unit exam was significantly higher than the pretest mean, and the mean for the posttest was significantly better than the pretest. There was no significant difference between the Unit Three exam and the posttest means. Table 48 shows the analysis of variance results for the control group on questions pertaining to Unit Three course content.

Table 48

Univariate Repeated Measure Analysis of Variance Summary for Unit Three (Control)

\begin{tabular}{lcccc}
\hline \multicolumn{1}{c}{ Source of Variation } & df & Sum of Squares & Mean Square & $F$ value \\
\hline Treatment & 2 & 27.56 & 13.78 & $17.67^{*}$ \\
(between groups) & & & & \\
Residual & 4 & 3.11 & .78 & \\
Individual & 2 & 4.22 & & \\
(between participants) & & & & \\
$*{ }^{*} p=.01$ & & & &
\end{tabular}


Of the fifteen questions presented on the pretest, unit exam, and posttest, four were application questions of daily drill terms. On the pretest the underprepared students of the experimental group answered slightly more questions correctly (mean $=1.36, \mathrm{SD}=.809)$ than the control group (mean $=.75, \mathrm{SD}=.5)$. The $\mathrm{F}$-test confirmed homogeneity of variance $(\mathrm{F}=$ $2.62, \mathrm{p}=.232)$. An independent t-test was performed, and the analysis revealed no significant difference between pretest means, $\mathrm{t}(.05,13)=1.4, \mathrm{p}=.185$.

A comparison of the four application questions on the Unit Three exam was performed. The underprepared students of the control group answered slightly fewer questions correctly (mean $=2.67, \mathrm{SD}=.58)$ than the underprepared students of the experimental group (mean $=2.8$, $\mathrm{SD}=.92)$. Homoscedasticity was confirmed by the F-test $(\mathrm{F}=2.53, \mathrm{p}=.315)$. The independent $\mathrm{t}$-test analysis revealed no statistical significance between Unit Three exam means, $\mathrm{t}(.05,11)=$ $.23, \mathrm{p}=.82$.

Unit Three application questions containing drilled items represented on the final exam (posttest) were compared. The experimental group answered slightly more questions correctly than the control group, (experimental mean $=2.27, \mathrm{SD}=1.19$ and control mean $=2, \mathrm{SD}=.5$ ). Homogeneity of variance was accepted (F-test, $F=5.67, p=.09$ ). The independent t-test indicated no significant difference of the means, $\mathrm{t}(.05,13)=.84, \mathrm{p}=.416$. Table 49 presents the means and standard deviations of the questions that represented Unit Three. 
Table 49

Means and Standard Deviations of Unit Three Correctly Answered Questions Containing Drilled Terms (Application Only)

\begin{tabular}{lccc}
\hline \multicolumn{1}{c}{ Exam } & $\mathrm{N}$ & Mean & Standard Deviation \\
\hline Pretest & 11 & 1.36 & .81 \\
Experimental & 4 & .75 & .5 \\
Control & & & .92 \\
Unit Three Exam & 10 & 2.8 & .58 \\
Experimental & 3 & 2.67 & \\
Control & & & 1.19 \\
Posttest & 11 & 2.27 & .5 \\
Experimental & 4 & 1.75 & \\
Control & & & \\
\hline
\end{tabular}

Although the performances between groups revealed no significant differences on the performance on Unit Three application questions, a univariate repeated measure analysis of variance was performed to analyze the differences in performance for each group across exams. There was a significant difference between the exam means of the experimental group, F (.05, 2, $16)=7.57, p=.0004$. A post hoc analysis using Tukey's procedure $(\alpha=.05)$ revealed the mean for the unit exam was significantly higher than the pretest mean. The posttest mean was significantly higher than the pretest mean, but there was no significant difference between the unit test and the posttest means. Table 50 presents the repeated measure analysis of variance summary of correctly answered Unit Three questions containing drilled terms by the experimental group. 
Table 50

Univariate Repeated Measure Analysis of Variance Summary for Unit Three (Experimental)

\begin{tabular}{lcccc}
\hline \multicolumn{1}{c}{ Source of Variation } & df & Sum of Squares & Mean Square & $F$ value \\
\hline Treatment & 2 & 9.85 & 4.93 & $7.25^{*}$ \\
(between groups) & & & & \\
Residual & 16 & 10.81 & .68 & \\
Individual & 8 & 14.52 & & \\
(between participants) & & & & \\
${ }^{*} p=.006$ & &
\end{tabular}

There was a significant difference in the performances of the underprepared students in the control group on the correctly answered application questions from Unit Three, F $(.05,2,4)=$ $19.18, \mathrm{p}=.009$. A post hoc analysis using Tukey's procedure $(\alpha=.05)$ revealed the mean for the unit exam was significantly higher than the pretest mean. The posttest mean was significantly higher than the pretest mean, but there was no significant difference between the unit test and the posttest means. Table 51 shows the analysis of variance results.

Table 51

Univariate Repeated Measure Analysis of Variance Summary for Unit Three (Control)

\begin{tabular}{lcccc}
\hline \multicolumn{1}{c}{ Source of Variation } & df & Sum of Squares & Mean Square & $F$ value \\
\hline Treatment & 2 & 4.22 & 2.11 & $19.18^{*}$ \\
(between groups) & & & & \\
Residual & 4 & .45 & .11 & \\
Individual & 2 & .22 & & \\
(between participants) & & & & \\
$* p=.009$ & & &
\end{tabular}

Of the fifteen questions presented on the pretest, unit exam, and posttest, twelve were "practice" questions of daily drill terms. On the pretest the underprepared students in the experimental group answered fewer questions correctly $($ mean $=.91, \mathrm{SD}=.94)$ than the underprepared students in the control group (mean $=1.25, \mathrm{SD}=.96)$. Homogeneity of variance was accepted (F-test, $\mathrm{F}=1.03, \mathrm{p}=.421)$. An independent t-test was performed, and the analysis revealed no significant difference between pretest means of "practice" questions, $\mathrm{t}(.05,13)=$ $.62, \mathrm{p}=.55$. 
A comparison of the twelve "practice" questions on the Unit Three exam was performed. The underprepared students of the control group answered fewer questions correctly (mean $=4$, $\mathrm{SD}=1)$ than the underprepared students of the experimental group (mean $=4.44, \mathrm{SD}=.699)$. Homoscedasticity was confirmed ( $F$-test, $F=2.045, \mathrm{p}=.185)$. The independent t-test analysis revealed no statistical significance between Unit Three exam means, $\mathrm{t}(.05,11)=.8, \mathrm{p}=.45$.

Unit Three "practice" questions containing drilled items represented on the final exam (posttest) were compared. The experimental group answered slightly fewer questions correctly $($ mean $=3.27, \mathrm{SD}=1.27)$ than the control group $($ mean $=3.75, \mathrm{SD}=.957)$. The F-test confirmed the homogeneity of variance $(\mathrm{F}=1.765, \mathrm{p}=.351)$. The independent $\mathrm{t}$-test indicated no significant difference of the means, $\mathrm{t}(.05,13)=.68, \mathrm{p}=.51$. Table 52 presents the means and standard deviations of the questions that represented the "practice" questions from Unit Three. Table 52

Means and Standard Deviations of Unit Three Correctly Answered Questions Containing Drilled Terms (Practice Only)

\begin{tabular}{lccc}
\hline \multicolumn{1}{c}{ Exam } & $\mathrm{N}$ & Mean & Standard Deviation \\
\hline Pretest & 11 & .91 & .94 \\
Experimental & 4 & 1.25 & .96 \\
Control & & & \\
Unit Three Exam & 10 & 4.4 & .699 \\
Experimental & 3 & 4 & 1 \\
Control & & & 1.27 \\
Posttest & 11 & 3.27 & .96 \\
Experimental & 4 & 3.75 & \\
Control & & & \\
\hline
\end{tabular}

A univariate repeated measure analysis of variance was performed to analyze the differences in performance for each group across exams using Unit Three "practice" items. There was a significant difference between the exam means of the experimental group, F (.05, 2, $16)=51.54, \mathrm{p}<.0001$. A post hoc analysis using Tukey's procedure $(\alpha=.05)$ revealed the mean for the unit exam was significantly higher than the pretest mean. The posttest mean was significantly higher than the pretest mean, but there was no significant difference between the 
unit test and the posttest means. Table 53 presents the repeated measure analysis of variance summaries of correctly answered Unit Three "practice" questions containing drilled terms by the experimental group.

Table 53

Univariate Repeated Measure Analysis of Variance Summary for Unit Three (Experimental)

\begin{tabular}{lcccc}
\hline \multicolumn{1}{c}{ Source of Variation } & $\mathrm{df}$ & Sum of Squares & Mean Square & $F$ value \\
\hline Treatment & 2 & 62.89 & 31.44 & $51.54^{*}$ \\
(between groups) & & & & \\
Residual & 16 & 9.78 & .61 & \\
Individual & 8 & 5.33 & & \\
(between participants) & & & & \\
${ }^{*} p<.0001$ & &
\end{tabular}

There was also a significant difference in the performances of the underprepared students in the control group on the correctly answered "practice" questions from Unit Three, F $(.05,2,4)$ $=12.09, \mathrm{p}=.02$. A post hoc analysis using Tukey's procedure $(\alpha=.05)$ revealed the mean for the unit exam was significantly higher than the pretest mean. The posttest mean was significantly higher than the pretest mean, but there was no significant difference between the unit test and the posttest means. Table 54 shows the analysis of variance results.

Table 54

Univariate Repeated Measure Analysis of Variance Summary for Unit Three (Control)

\begin{tabular}{lcccc}
\hline \multicolumn{1}{c}{ Source of Variation } & df & Sum of Squares & Mean Square & $F$ value \\
\hline Treatment & 2 & 10.89 & 5.44 & $12.09^{*}$ \\
(between groups) & & & & \\
Residual & 4 & 1.78 & .45 & \\
Individual & 2 & 2.89 & & \\
(between participants) & & & & \\
${ }^{*} p=.02$ & & &
\end{tabular}

Daily drill terms of Unit Four course content were represented by seventeen questions on the pretest, unit exam, and posttest. On the pretest the underprepared students in the experimental group $($ mean $=6.27, \mathrm{SD}=1.9)$ answered more questions correctly than the control group $($ mean $=4.5, \mathrm{SD}=1.73)$. Homogeneity of variance was accepted $(\mathrm{F}$-test, $\mathrm{F}=1.21, \mathrm{p}=$ 
.491). An independent t-test was performed, and the analysis revealed no significant difference between pretest means, $\mathrm{t}(.05,13)=1.63, \mathrm{p}=.13$.

A comparison of the seventeen Unit Four exam questions, containing course content that had been practiced on daily drills by the experimental group, was performed. The underprepared students of the control group answered fewer questions correctly (mean $=9.5, \mathrm{SD}=2.08)$ than the underprepared students of the experimental group (mean $=11.18, \mathrm{SD}=1.9)$. Homogeneous variances were evidenced $(\mathrm{F}$-test, $\mathrm{F}=1.2, \mathrm{p}=.36$ ). The independent $\mathrm{t}$-test analysis revealed no statistical significance between Unit Four exam means, $\mathrm{t}(.05,13)=1.24, \mathrm{p}=.24$.

Unit Four questions containing drilled items represented on the final exam (posttest) were compared. The experimental group answered slightly more questions correctly (mean $=11.64$, $\mathrm{SD}=2.87)$ than the control group on the posttest measure (mean $=10.25, \mathrm{SD}=3.4)$. The F-test confirmed the homogeneity of variances $(F=1.4, \mathrm{p}=.299)$. The independent t-test revealed no statistical significance, $\mathrm{t}(.05,13)=0.79, \mathrm{p}=.44$. Table 55 presents the means and standard deviations of the questions that represented Unit Four. 
Table 55

Means and Standard Deviations of Unit Four Correctly Answered Questions Containing Drilled $\underline{\text { Terms }}$

\begin{tabular}{lccc}
\hline \multicolumn{1}{c}{ Exam } & $\mathrm{N}$ & Mean & Standard Deviation \\
\hline Pretest & 11 & 6.27 & 1.9 \\
Experimental & 4 & 4.5 & 1.73 \\
Control & & & \\
Unit Four Exam & 11 & 11.18 & 2.4 \\
Experimental & 4 & 9.5 & 2.08 \\
Control & & & 2.87 \\
Posttest & 11 & 11.64 & 3.4 \\
Experimental & 4 & 10.25 & \\
Control & & & \\
\hline
\end{tabular}

Although the performances between groups revealed no significant differences on the performance on Unit Four questions, a univariate repeated measure analysis of variance was performed to analyze the differences in performance for each group across exams. There was a significant difference between the exam means of the experimental group, $\mathrm{F}(.05,2,20)=19.31$, $\mathrm{p}<.0001$. A post hoc analysis using Tukey's procedure $(\alpha=.05)$ revealed the mean for the unit exam was significantly higher than the pretest mean. The posttest mean was significantly higher than the pretest mean, but there was no significant difference between the unit test and the posttest means. Table 56 presents the repeated measure analysis of variance summary of correctly answered Unit Four questions containing drilled terms by the experimental group. 
Table 56

Univariate Repeated Measure Analysis of Variance Summary for Unit Four (Experimental)

\begin{tabular}{lcccc}
\hline \multicolumn{1}{c}{ Source of Variation } & df & Sum of Squares & Mean Square & $F$ value \\
\hline Treatment & 2 & 194.61 & 97.3 & $19.31^{*}$ \\
(between groups) & & & & \\
Residual & 20 & 100.72 & 5.04 & \\
Individual & 10 & 75.64 & & \\
(between participants) & & & & \\
\hline
\end{tabular}

$* p<.0001$

There was also a significant difference in the performances of the underprepared students in the control group on the correctly answered questions from Unit Four, F $(.05,2,6)=19.84$, p $=.002$. A post hoc analysis using Tukey's procedure $(\alpha=.05)$ revealed the mean for the unit exam was significantly higher than the pretest mean, and the mean for the posttest was significantly better than the pretest. There was no significant difference between the Unit Four exam and the posttest means. Table 57 shows the analysis of variance results for the control group on questions pertaining to Unit Four course content.

Table 57

Univariate Repeated Measure Analysis of Variance Summary for Unit Four (Control)

\begin{tabular}{lcccc}
\hline \multicolumn{1}{c}{ Source of Variation } & df & Sum of Squares & Mean Square & $F$ value \\
\hline Treatment & 2 & 78.17 & 39.08 & $19.84^{*}$ \\
(between groups) & & & & \\
Residual & 6 & 11.83 & 1.97 & \\
Individual & 3 & 44.92 & & \\
(between participants) & & & & \\
\hline
\end{tabular}

$* p=.002$

Of the seventeen questions presented on the pretest, unit exam, and posttest, nine were application questions of daily drill terms. On the pretest the underprepared students of the experimental group answered slightly more questions correctly (mean $=3.18, \mathrm{SD}=1.6)$ than the control group $($ mean $=3, \mathrm{SD}=1.83)$. Homogeneity of variance was accepted $(\mathrm{F}$-test, $\mathrm{F}=1.31, \mathrm{p}$ 
$=.325)$. An independent t-test was performed, and the analysis revealed no significant difference between pretest means, $\mathrm{t}(.05,13)=.19, \mathrm{p}=.85$.

A comparison of the nine application questions on the Unit Four exam was performed. The underprepared students of the control group answered slightly fewer questions correctly (mean $=5.5, \mathrm{SD}=2.08)$ than the underprepared students of the experimental group (mean = 5.91, $\mathrm{SD}=1.45$ ). Homogeneous variance was evidenced ( $\mathrm{F}-\mathrm{test}, \mathrm{F}=2.06, \mathrm{p}=.169)$. The independent $\mathrm{t}$-test analysis revealed no statistical significance between Unit Four exam means, $\mathrm{t}$ $(.05,13)=.43, \mathrm{p}=.67$.

Unit Four application questions containing drilled items represented on the final exam (posttest) were compared. The experimental group answered almost an identical number of questions correctly as the control group, $($ experimental mean $=5.82$, control mean $=5.75)$. The homogeneity of variance (experimental group, $\mathrm{SD}=1.66$ and control group, $\mathrm{SD}=2.22$ ) was confirmed by the F-test $(\mathrm{F}=1.79, \mathrm{p}=.213)$. The independent $\mathrm{t}$-test indicated no significant difference of the means, $\mathrm{t}(.05,13)=.06, \mathrm{p}=.95$. Table 58 presents the means and standard deviations of the questions that represented Unit Four.

Table 58

Means and Standard Deviations of Unit Four Correctly Answered Questions Containing Drilled Terms (Application Only)

\begin{tabular}{lccc}
\hline \multicolumn{1}{c}{ Exam } & $\mathrm{N}$ & Mean & Standard Deviation \\
\hline Pretest & 11 & 3.18 & \\
Experimental & 4 & 3 & 1.6 \\
Control & & & 1.83 \\
Unit Four Exam & 11 & 5.91 & 1.45 \\
Experimental & 4 & 5.5 & 2.08 \\
Control & & & \\
Posttest & 11 & 5.82 & 1.66 \\
Experimental & 4 & 5.75 & 2.22 \\
Control & & & \\
\hline
\end{tabular}

Although the performances between groups revealed no significant differences on the performance on Unit Four application questions, a univariate repeated measure analysis of 
variance was performed to analyze the differences in performance for each group across exams. There was a significant difference between the exam means of the experimental group, F (.05, 2, $20)=12.39, p=.0003$. A post hoc analysis using Tukey's procedure $(\alpha=.05)$ revealed the mean for the unit exam was significantly higher than the pretest mean. The posttest mean was significantly higher than the pretest mean, but there was no significant difference between the unit test and the posttest means. Table 59 presents the repeated measure analysis of variance summary of correctly answered Unit Four questions containing drilled terms by the experimental group.

Table 59

Univariate Repeated Measure Analysis of Variance Summary for Unit Four (Experimental)

\begin{tabular}{lcccc}
\hline \multicolumn{1}{c}{ Source of Variation } & df & Sum of Squares & Mean Square & $F$ value \\
\hline Treatment & 2 & 52.79 & 26.39 & $12.39^{*}$ \\
(between groups) & & & & \\
Residual & 20 & 42.54 & 2.13 & \\
Individual & 10 & 31.64 & & \\
(between participants) & & & & \\
${ }^{*} p=.0003$ & & & &
\end{tabular}

There was a significant difference in the performances of the underprepared students in the control group on the correctly answered application questions from Unit Four, F $(.05,2,6)=$ $5.85, \mathrm{p}=.039$. A post hoc analysis using Tukey's procedure $(\alpha=.05)$ revealed no significance between the mean for the unit exam was and the pretest mean. The posttest mean was significantly higher than the pretest mean, but there was no significant difference between the unit test and the posttest means. Table 60 shows the analysis of variance results. 
Table 60

Univariate Repeated Measure Analysis of Variance Summary for Unit Four (Control)

\begin{tabular}{lcccc}
\hline \multicolumn{1}{c}{ Source of Variation } & df & Sum of Squares & Mean Square & $F$ value \\
\hline Treatment & 2 & 18.5 & 9.25 & $5.85^{*}$ \\
(between groups) & & & & \\
Residual & 6 & 9.5 & 1.58 & \\
Individual & 3 & 28.25 & & \\
(between participants) & & & & \\
\hline
\end{tabular}

$* p=.039$

Of the seventeen questions presented on the pretest, unit exam, and posttest, eight were "practice" questions of daily drill terms. On the pretest the underprepared students in the experimental group answered more questions correctly $($ mean $=3.18, \mathrm{SD}=1.54)$ than the underprepared students in the control group (mean $=1.5, \mathrm{SD}=.58)$. Homoscedasticity was accepted (F-test, $\mathrm{F}=7.05, \mathrm{p}=.067)$. An independent t-test was performed, and the analysis revealed no significant difference between pretest means of "practice" questions, $\mathrm{t}(.05,13)=$ $2.09, \mathrm{p}=.06$.

A comparison of the eight "practice" questions on the Unit Four exam was performed. The underprepared students of the control group answered fewer questions correctly (mean $=4$, $\mathrm{SD}=0)$ than the underprepared students of the experimental group (mean $=5.64, \mathrm{SD}=1.12$ ). The F-test confirmed the homogeneity of variance $(F=0, p=1)$. The independent t-test analysis revealed a statistical significance between Unit Four exam means, t $(.05,13)=2.85, \mathrm{p}=.01$.

Unit Four "practice" questions containing drilled items represented on the final exam (posttest) were compared. The experimental group answered slightly more questions correctly $($ mean $=5.64, \mathrm{SD}=1.36)$ than the control group $($ mean $=4.5, \mathrm{SD}=1.29)$. The homogeneity of variance was accepted (F-test, $\mathrm{F}=1.4, \mathrm{p}=.435)$. The independent $\mathrm{t}$-test indicated no significant difference of the means, $\mathrm{t}(.05,13)=1.45, \mathrm{p}=.17$. Table 61 presents the means and standard deviations of the questions that represented the "practice" questions from Unit Four. 
Table 61

Means and Standard Deviations of Unit Four Correctly Answered Questions Containing Drilled Terms (Practice Only)

\begin{tabular}{lccc}
\hline \multicolumn{1}{c}{ Exam } & $\mathrm{N}$ & Mean & Standard Deviation \\
\hline Pretest & 11 & 3.18 & 1.54 \\
Experimental & 4 & 1.5 & .58 \\
Control & & & \\
Unit Four Exam & 11 & 5.64 & 1.12 \\
Experimental & 4 & 4 & 0 \\
Control & & & 1.36 \\
Posttest & 11 & 5.64 & 1.29 \\
Experimental & 4 & 4.5 & \\
Control & & & \\
\hline
\end{tabular}

A univariate repeated measure analysis of variance was performed to analyze the differences in performance for each group across exams using Unit Four "practice" items. There was a significant difference between the exam means of the experimental group, $\mathrm{F}(.05,2,20)=$ $14.53, \mathrm{p}=.0001$. A post hoc analysis using Tukey's procedure $(\alpha=.05)$ revealed the mean for the unit exam was significantly higher than the pretest mean. The posttest mean was significantly higher than the pretest mean, but there was no significant difference between the unit test and the posttest means. Table 62 presents the repeated measure analysis of variance summaries of correctly answered Unit Four "practice" questions containing drilled terms by the experimental group. 
Table 62

Univariate Repeated Measure Analysis of Variance Summary for Unit Four (Experimental)

\begin{tabular}{lcccc}
\hline \multicolumn{1}{c}{ Source of Variation } & df & Sum of Squares & Mean Square & $F$ value \\
\hline Treatment & 2 & 44.18 & 22.09 & $14.53^{*}$ \\
(between groups) & & & & \\
Residual & 20 & 30.49 & 1.52 & \\
Individual & 10 & 24.24 & & \\
(between participants) & & & & \\
$* p<.0001$ & & &
\end{tabular}

$* p<.0001$

There was also a significant difference in the performances of the underprepared students in the control group on the correctly answered "practice" questions from Unit Four, F $(.05,2,6)$ $=15.42, p=.004$. A post hoc analysis using Tukey's procedure $(\alpha=.05)$ revealed the mean for the unit exam was significantly higher than the pretest mean. The posttest mean was significantly higher than the pretest mean, but there was no significant difference between the unit test and the posttest means. Table 63 shows the analysis of variance results.

Table 63

Univariate Repeated Measure Analysis of Variance Summary for Unit Four (Control)

\begin{tabular}{lcccc}
\hline \multicolumn{1}{c}{ Source of Variation } & df & Sum of Squares & Mean Square & $F$ value \\
\hline Treatment & 2 & 20.67 & 10.33 & $15.42^{*}$ \\
(between groups) & & & & \\
Residual & 6 & 4 & .67 & \\
Individual & 3 & 2 & & \\
(between participants) & & & & \\
$* p=.004$ & & &
\end{tabular}

Daily drill terms of Unit Five course content were represented by nine questions on the pretest, unit exam, and posttest. On the pretest the underprepared students in the experimental group (mean $=3.33, \mathrm{SD}=1.58)$ answered more questions correctly than the control group (mean $=2.25, \mathrm{SD}=.5)$. The variances were significantly different $(\mathrm{F}$-test, $\mathrm{F}=9.98, \mathrm{p}=.004)$. An independent t-test was performed, and the analysis revealed no significant difference between pretest means, $\mathrm{t}(.05,11)=1.31, \mathrm{p}=.22$. 
A comparison of the nine Unit Five exam questions, containing course content that had been practiced on daily drills by the experimental group, was performed. The underprepared students of the control group answered fewer questions correctly (mean $=4, \mathrm{SD}=1.83$ ) than the underprepared students of the experimental group $($ mean $=5.67, \mathrm{SD}=1.8)$. Homogeneous variances were evidenced $(\mathrm{F}$-test, $\mathrm{F}=1.03, \mathrm{p}=.43)$. The independent $\mathrm{t}$-test analysis revealed no statistical significance between Unit Five exam means, $\mathrm{t}(.05,11)=1.53, \mathrm{p}=.15$.

Unit Five questions containing drilled items represented on the final exam (posttest) were compared. The experimental group answered slightly more questions correctly (mean $=6.11$, $\mathrm{SD}=1.83)$ than the control group on the posttest measure $($ mean $=4.25, \mathrm{SD}=1.89)$.

Homogeneity of variances was accepted $(\mathrm{F}$-test, $\mathrm{F}=1.07, \mathrm{p}=.534)$. The independent $\mathrm{t}$-test revealed no statistical significance, $\mathrm{t}(.05,11)=1.67, \mathrm{p}=.12$. Table 64 presents the means and standard deviations of the questions that represented Unit Five.

Table 64

$\underline{\text { Means and Standard Deviations of Unit Five Correctly Answered Questions Containing Drilled }}$ $\underline{\text { Terms }}$

\begin{tabular}{lccc}
\hline \multicolumn{1}{c}{ Exam } & $\mathrm{N}$ & Mean & Standard Deviation \\
\hline Pretest & & & \\
Experimental & 9 & 3.33 & 1.58 \\
Control & 4 & 2.25 & .5 \\
Unit Five Exam & & & \\
Experimental & 9 & 5.67 & 1.8 \\
Control & 4 & 4 & 1.82 \\
Posttest & & & \\
Experimental & 9 & 6.11 & 1.83 \\
Control & 4 & 4.25 & 1.89 \\
\hline
\end{tabular}

Although the performances between groups revealed no significant differences on the performance on Unit Five questions, a univariate repeated measure analysis of variance was performed to analyze the differences in performance for each group across exams. There was a significant difference between the exam means of the experimental group, $\mathrm{F}(.05,2,16)=9.82$, $\mathrm{p}$ $<.002$. A post hoc analysis using Tukey's procedure $(\alpha=.05)$ revealed the mean for the unit 
exam was significantly higher than the pretest mean. The posttest mean was significantly higher than the pretest mean, but there was no significant difference between the unit test and the posttest means. Table 65 presents the repeated measure analysis of variance summary of correctly answered Unit Five questions containing drilled terms by the experimental group.

Table 65

Univariate Repeated Measure Analysis of Variance Summary for Unit Five (Experimental)

\begin{tabular}{lcccc}
\hline \multicolumn{1}{c}{ Source of Variation } & $\mathrm{df}$ & Sum of Squares & Mean Square & $F$ value \\
\hline Treatment & 2 & 40.07 & 20.04 & $9.82^{*}$ \\
(between groups) & & & & \\
Residual & 16 & 32.59 & 2.04 & \\
Individual & 8 & 40.3 & & \\
(between participants) & & & & \\
\hline
\end{tabular}

There was no significant difference in the performances of the underprepared students in the control group on the correctly answered questions from Unit Five, $F(.05,2,6)=2.28, \mathrm{p}=$ .18. Pretest, exam, and posttest scores were statistically consistent. Table 66 shows the analysis of variance results for the control group on questions pertaining to Unit Five course content. Table 66

Univariate Repeated Measure Analysis of Variance Summary for Unit Five (Control)

\begin{tabular}{lcccc}
\hline \multicolumn{1}{c}{ Source of Variation } & df & Sum of Squares & Mean Square & $F$ value \\
\hline Treatment & 2 & 9.5 & 4.75 & $2.28^{*}$ \\
(between groups) & & & & \\
Residual & 6 & 12.5 & 2.08 & \\
Individual & 3 & 9 & & \\
(between participants) & & & & \\
$*{ }^{*} p=.18$ & &
\end{tabular}

Of the nine questions presented on the pretest, unit exam, and posttest, seven were application questions of daily drill terms. On the pretest the underprepared students of the experimental group answered slightly more questions correctly $($ mean $=2.44, \mathrm{SD}=1.13)$ than the control group $($ mean $=2.25, \mathrm{SD}=.5)$. Homogeneity of variance was accepted $(\mathrm{F}$-test, $\mathrm{F}=$ 
$5.11, \mathrm{p}=.104)$. An independent $\mathrm{t}$-test was performed, and the analysis revealed no significant difference between pretest means, $\mathrm{t}(.05,11)=.32, \mathrm{p}=.755$.

A comparison of the seven application questions on the Unit Five exam was performed. The underprepared students of the control group answered fewer questions correctly (mean = $3.25, \mathrm{SD}=1.5$ ) than the underprepared students of the experimental group (mean $=4.56, \mathrm{SD}=$ 1.67). Homoscedasticity was accepted (F-test, $\mathrm{F}=1.24, \mathrm{p}=.357$ ). The independent t-test analysis revealed no statistical significance between Unit Five exam means, $t(.05,11)=1.34, p$ $=.21$.

Unit Five application questions containing drilled items represented on the final exam (posttest) were compared. The experimental group answered more questions correctly than the control group (experimental mean $=5.11, \mathrm{SD}=1.54$ and control mean $=3.25, \mathrm{SD}=1.26$ ). Homogeneity of variance was accepted (F-test, $F=1.49, \mathrm{p}=.407$ ). The independent $\mathrm{t}$-test indicated no significant difference of the means, $t(.05,13)=2.11, p=.06$. Table 67 presents the means and standard deviations of the questions that represented Unit Five. 
Table 67

Means and Standard Deviations of Unit Five Correctly Answered Questions Containing Drilled Terms (Application Only)

\begin{tabular}{lccc}
\hline \multicolumn{1}{c}{ Exam } & $\mathrm{N}$ & Mean & Standard Deviation \\
\hline Pretest & 9 & 2.44 & 1.13 \\
Experimental & 4 & 2.25 & .5 \\
Control & & & \\
Unit Five Exam & 9 & 4.56 & 1.67 \\
Experimental & 4 & 3.25 & 1.5 \\
Control & & & 1.54 \\
Posttest & 9 & 5.11 & 1.26 \\
Experimental & 4 & 3.25 & \\
Control & & & \\
\hline
\end{tabular}

Although the performances between groups revealed no significant differences on the performance on Unit Five application questions, a univariate repeated measure analysis of variance was performed to analyze the differences in performance for each group across exams. There was a significant difference between the exam means of the experimental group, F (.05, 2, $16)=10.79, \mathrm{p}=.001$. A post hoc analysis using Tukey's procedure $(\alpha=.05)$ revealed the mean for the unit exam was significantly higher than the pretest mean. The posttest mean was significantly higher than the pretest mean, but there was no significant difference between the unit test and the posttest means. Table 68 presents the repeated measure analysis of variance summary of correctly answered Unit Five questions containing drilled terms by the experimental group. 
Table 68

Univariate Repeated Measure Analysis of Variance Summary for Unit Five (Experimental)

\begin{tabular}{lcccc}
\hline \multicolumn{1}{c}{ Source of Variation } & df & Sum of Squares & Mean Square & $F$ value \\
\hline Treatment & 2 & 35.63 & 17.81 & $10.79^{*}$ \\
(between groups) & & & & \\
Residual & 16 & 26.37 & 1.65 & \\
Individual & 8 & 24.96 & & \\
(between participants) & & & & \\
${ }^{*} p=.001$ & & & &
\end{tabular}

There was no significant difference in the performances of the underprepared students in the control group on the correctly answered application questions from Unit Five, F $(.05,2,6)=$ $1, p=.422$. Table 69 shows the analysis of variance results.

Table 69

Univariate Repeated Measure Analysis of Variance Summary for Unit Five (Control)

\begin{tabular}{lcccc}
\hline \multicolumn{1}{c}{ Source of Variation } & df & Sum of Squares & Mean Square & $F$ value \\
\hline Treatment & 2 & 2.67 & 1.33 & $1^{*}$ \\
(between groups) & & & & \\
Residual & 6 & 8 & 1.33 & \\
Individual & 3 & 4.25 & & \\
(between participants) & & & & \\
$* *^{*} p=.422$ & & &
\end{tabular}

Of the nine questions presented on the pretest, unit exam, and posttest, two were "practice" questions of daily drill terms. On the pretest the underprepared students in the experimental group answered slightly more questions correctly (mean $=.89, \mathrm{SD}=.78)$ than the underprepared students in the control group (mean $=0, \mathrm{SD}=0$ ). The F-test confirmed the homogeneity of variances $(\mathrm{F}=0, \mathrm{p}=1)$. An independent t-test was performed, and the analysis revealed a significant difference between pretest means of "practice" questions, $\mathrm{t}(.05,11)=$ $2.22, \mathrm{p}=.05$.

A comparison of the two "practice" questions on the Unit Five exam was performed. The underprepared students of the control group answered fewer questions correctly (mean $=.75, \mathrm{SD}$ $=.82)$ than the underprepared students of the experimental group $($ mean $=1.11, \mathrm{SD}=.78)$. 
Homogeneity of variance was accepted $(\mathrm{F}$-test, $\mathrm{F}=1.11, \mathrm{p}=.402)$. The independent $\mathrm{t}$-test analysis revealed a statistical significance between Unit Five exam means, $\mathrm{t}(.05,11)=.84, \mathrm{p}=$ .42 .

Unit Five "practice" questions containing drilled items represented on the final exam (posttest) were compared. The groups obtained identical means (experimental group, mean $=1$, $\mathrm{SD}=1$ and control group, mean $=1, \mathrm{SD}=.82)$. Homoscedasticity was accepted (F-test, $\mathrm{F}=$ $1.49, \mathrm{p}=.407)$. The independent $\mathrm{t}$-test indicated no significant difference of the means, $\mathrm{t}(.05$, 11) $=0, p=1$. Table 70 presents the means and standard deviations of the questions that represented the "practice" questions from Unit Five.

Table 70

Means and Standard Deviations of Unit Five Correctly Answered Questions Containing Drilled $\underline{\text { Terms (Practice Only) }}$

\begin{tabular}{lccc}
\hline \multicolumn{1}{c}{ Exam } & $\mathrm{N}$ & Mean & Standard Deviation \\
\hline Pretest & 9 & .89 & .78 \\
Experimental & 4 & 0 & 0 \\
Control & & & \\
Unit Five Exam & 9 & 1.11 & .78 \\
Experimental & 4 & .75 & .5 \\
Control & & & 1 \\
Posttest & 9 & 1 & .82 \\
Experimental & 4 & 1 & \\
Control & & & \\
\hline
\end{tabular}

A univariate repeated measure analysis of variance was performed to analyze the differences in performance for each group across exams using Unit Five "practice" items. There was no significant difference between the exam means of the experimental group, $\mathrm{F}(.05,2,16)=$ $.21, \mathrm{p}=.81$. Table 71 presents the repeated measure analysis of variance summaries of correctly answered Unit Five "practice" questions containing drilled terms by the experimental group. 
Table 71

Univariate Repeated Measure Analysis of Variance Summary for Unit Five (Experimental)

\begin{tabular}{lcccc}
\hline \multicolumn{1}{c}{ Source of Variation } & $\mathrm{df}$ & Sum of Squares & Mean Square & $F$ value \\
\hline Treatment & 2 & .22 & .11 & $.21^{*}$ \\
(between groups) & & & & \\
Residual & 16 & 8.45 & .53 & \\
Individual & 8 & 9.33 & & \\
(between participants) & & & \\
$* p=.81$ & &
\end{tabular}

There was no significant difference in the performances of the underprepared students in the control group on the correctly answered "practice" questions from Unit Five, F $(.05,2,6)=$ $3.48, \mathrm{p}=.1$. Table 72 shows the analysis of variance results.

Table 72

Univariate Repeated Measure Analysis of Variance Summary for Unit Five (Control)

\begin{tabular}{lcccc}
\hline \multicolumn{1}{c}{ Source of Variation } & df & Sum of Squares & Mean Square & $F$ value \\
\hline Treatment & 2 & 2.17 & 1.08 & $3.48^{*}$ \\
(between groups) & & & & \\
Residual & 6 & 1.83 & .31 & \\
Individual & 3 & .92 & \\
(between participants) & & & \\
${ }^{*} p=.1$ & \\
$\quad$ Instructional accomplishment (Fraley, 1980) allows an analysis of each student's \\
progress toward the course criterion. (See Figure 19.)
\end{tabular}


Figure 19. Instructional accomplishment formula

$$
\begin{gathered}
\text { INSTRUCTIONAL ACCOMPLISHMENT } \\
\qquad \mathrm{I}_{\mathrm{A}}=\frac{\Delta \mathrm{B}}{\mathrm{B}_{\mathrm{C}}} \times 100 \\
\mathrm{I}_{\mathrm{A}}=\text { Instructional Accomplishment (\%) } \\
\Delta \mathrm{B}=\text { Skill level after instruction - initial skill level } \\
\mathrm{B}_{\mathrm{C}}=\text { Criterion score }- \text { initial pretest score }
\end{gathered}
$$

The criterion score used in the analysis was $70 \%$, the minimum score for a letter grade of "C" on the final exam. The mean instructional accomplishment for the experimental group was 80.26, and the standard deviation was 30.6. The mean instructional accomplishment for the control group was 70.78 , and the standard deviation was 20.8. Homogeneity of variance was accepted by the F-test $(\mathrm{F}=2.16, \mathrm{p}=.286)$. A t-test of independent means was conducted and resulted in no statistical difference between groups $(\mathrm{t}(.05,13)=.6, \mathrm{p}=.56)$. Individual pretest scores, posttest scores, and calculated instructional accomplishment are presented in Table 73.

Table 73

Instructional Accomplishment of Course Content

Experimental Control

\begin{tabular}{|l|l|l|l|l|l|l|l|}
\hline Student & Pretest & Posttest & IA * & Student & Pretest & Posttest & IA * \\
\hline 1 & 41 & 64 & 79.31 & 1 & 23 & 47 & 51.06 \\
2 & 36 & 61 & 73.53 & 2 & 26 & 54 & 63.64 \\
3 & 34 & 68 & 94.44 & 3 & 34 & 70 & 100 \\
4 & 27 & 54 & 62.79 & 4 & 32 & 58 & 68.42 \\
5 & 40 & 80 & 133.33 & & & & \\
6 & 30 & 46 & 40 & & & & \\
7 & 29 & 61 & 78.05 & & & & \\
8 & 42 & 51 & 32.14 & & & & \\
9 & 39 & 60 & 67.74 & & & & \\
10 & 38 & 73 & 109.38 & & & & \\
11 & 29 & 75 & 112.2 & & & & \\
\hline
\end{tabular}


A progressive multiple baseline achievement test design (Miller \& Weaver, 1972) was employed to scrutinize the effectiveness of the independent variable within the experimental group. This design allowed the visualization of skill development as each unit was presented. The responses for three to five arbitrarily chosen questions from each unit were examined during the course pretest, a unit pretest, the unit exam, a unit posttest, and the final exam (posttest). (See Figure 20.)

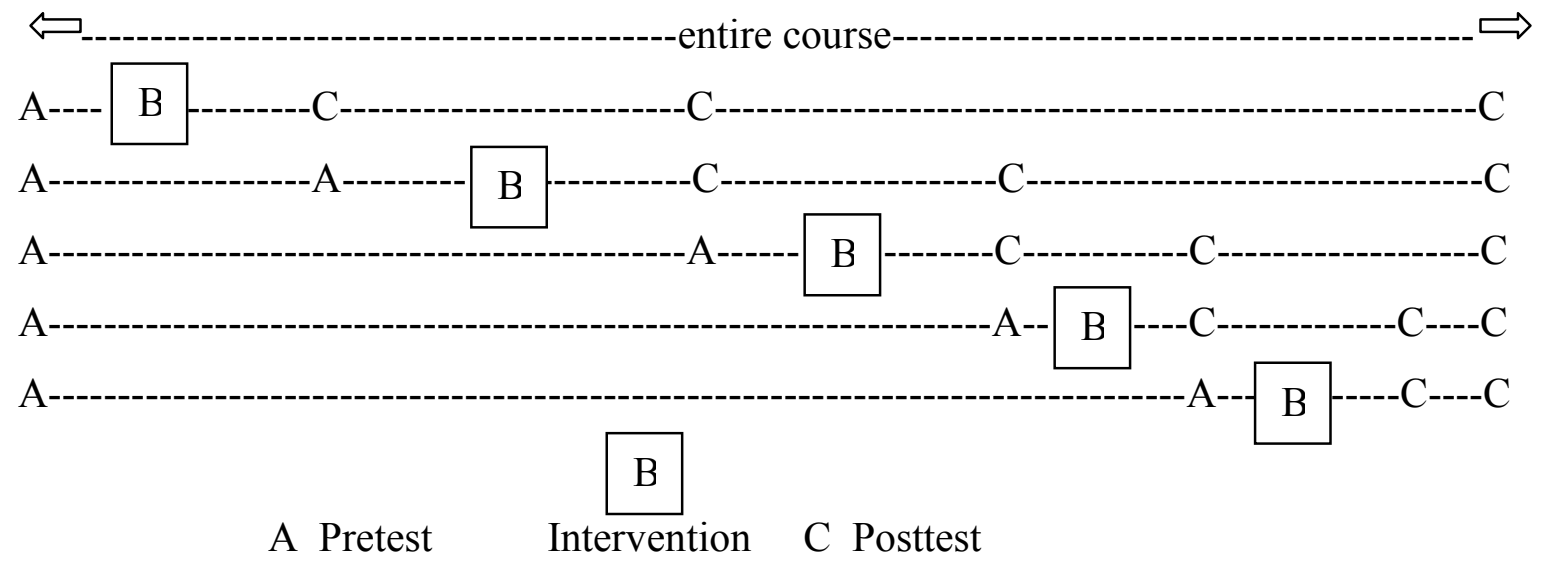

Figure 20: Progressive multiple baseline achievement test design

The pretest served as the course pretest, as well as each unit's pretest. The Unit I exam represented a posttest of test questions pertaining to that unit, and contained three questions from Unit II. These three Unit II questions on the Unit I exam served as a pretest for Unit II. Likewise, the Unit II exam included five posttest questions from Unit I and three pretest questions from Unit III. The Unit III exam included three posttest items from Unit II and five pretest questions from Unit V. The Unit IV exam included three posttest items from Unit III and three pretest questions from Unit V. The Unit V exam included three pretest items from Unit IV. The final exam served as the posttest for Unit V, as well as the entire course content. (Note that it was originally planned for each unit to have five pretest and posttest questions. It was experimenter error that resulted in some units having only three questions. Additionally, Unit V had three pretests and Unit IV had only one pretest due to experimenter error.)

This multiple baseline design, combined with the pre and posttests over the entire course, provided pretest measures for each instructional unit and two or three posttest measures for each instructional unit. The pre and post differences across these two classes of measures revealed the 
effectiveness of the instruction on each unit. However, in the experimental group the instruction included the drills plus the various classroom instructional activities.

The units are presented on separate graphs to demonstrate the changes across the course. Figure 21 presents the group average of correct responses for each of the presentations of unit questions. 


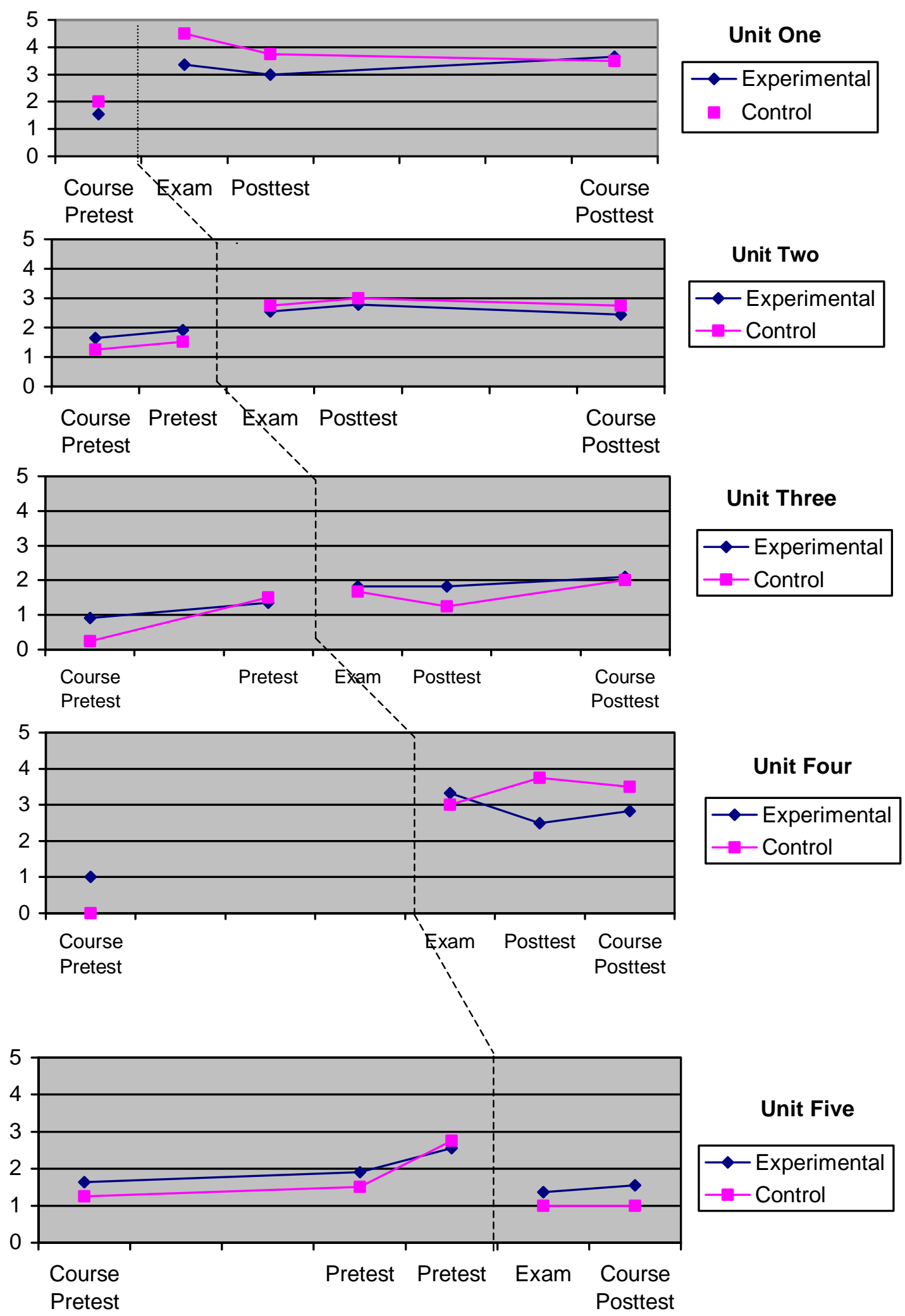

Figure 21. Multiple baseline of correctly answered questions per unit 


\section{CHAPTER IV: DISCUSSION}

This study was conducted at an open admission community college with students enrolled in an introductory general psychology course. One-minute daily drills of course content and vocabulary used in the course text were presented to students in the experimental group. Both the experimental and control groups received instruction via lecture, discussion, and class activities. It was predicted that the additional practice of terms afforded by the drills would result in an enhanced performance by the experimental group. Course retention, reading skills, and performance on course content exams were compared. (See Appendix A and Appendix B.)

Open admission community colleges serve students of varying ages and skills. Retention of students is critical to financial stability of the colleges, and is essential to the economy of the communities in which they are located. Increased retention was a predicted outcome of this study, even though it was not specifically addressed.

The comparison of course retention revealed that a higher percentage of the students in the control group completed the course, contrary to the predicted outcome. Although reviewing simply the percentages of students retained would suggest that the independent variable had no effect on retention, the students' grades at the time of their withdrawal was notable. Only two of the seven students $(28.57 \%)$ in the experimental group who withdrew from the course had failing grades. All of the five students in the control group (100\%) who withdrew were failing the course. Because five of the seven students in the experimental group withdrew for personal reasons, the effect of the drills on retention in this study is unknown and cannot be confirmed or denied. This limitation must be addressed before definitive statements advocating the usage of daily drills to enhance retention, can be made.

Future studies could address retention more directly by awarding course points for attendance in the course and participation in the study. The points gained with only a oneminute commitment daily could provide an incentive for students to remain in the course. Daily drills of course content are generally not designed to keep students enrolled in courses. However, if students find additional success by using drills to learn new skills, perhaps course retention could be improved.

The Nelson-Denny reading test was used to assess the reading skills of the participants in the study. Although reading skills were not specifically taught in the course or by the use of 
daily drills, it was predicted that the drills could enhance the reading skills of the experimental group participants. Comparisons of performance were conducted for each segment of the Nelson-Denny; vocabulary, comprehension, total reading score, and reading rate. Each segment was analyzed using the following steps; (1) conversion of raw scores to scaled scores, (2) computation of scaled score averages for each group, (3) determination of percentile representation of scaled score averages.

Palmer (1984, p. 22) proposed, "Since reading and writing are practiced in almost all academic courses, it is logical to hypothesize that coursework in all areas - not just reading and writing courses themselves - will help improve student reading and writing ability." This study confirmed that students in both groups demonstrated improved reading skills from the beginning to the end of the course. Participation in this college course appeared to have a positive effect on reading skills, even though specific reading skills were not taught. Because course participation increased reading skills, a limitation of the study in isolating the drilling effects on reading performance was noted.

The control group's initial percentile scores were higher for each measured skill than those of the experimental group. Likewise, the control group demonstrated higher skills on the posttests. Based on this comparison, the drills did not appear to have a measurable effect on reading.

Examining the percentage of skill increase from the pretest to the posttest more closely evaluated the effects of the independent variable. This measure allowed scrutiny of individual increases in performance, with respect to the initial skills of each participant. These increases were averaged and then compared. The analysis of the percentage of skill increase revealed different results than reviewing only the pretests and posttests. Comprehension, total reading scores, and reading rates revealed that the experimental group proportionally increased their scores more than the control group. The vocabulary scores demonstrated a greater increase than the control group, consistent with the earlier analysis.

The instructional accomplishment measure (Fraley, 1980) indicated that both groups progressed toward the academic goal of demonstrating college-level reading skills. Five of the eleven underprepared students in the experimental group exceeded the minimum criteria of college-level skills, as did two of the four students in the control group. Sixteen participants in the experimental group had already demonstrated expected reading skills and were considered 
"prepared" students. At the end of the course twenty-one of the twenty-seven $(77.77 \%)$ of the experimental group participants demonstrated college-level reading skills. The addition of the two previously underprepared students resulted in the control group having $90 \%$ "prepared" students.

Comparisons of performances by both groups were made for the pretest, unit exams, and posttest using the same set of questions across the three measurements. Performances on pretests, unit exams, and posttests were closely related between groups. The significance of the pretest to posttest differences for both groups suggested that course content skills greatly increased from the beginning of the course to the end, consistent with the reading skills increase. Ironically, the skills increase in both groups presented another limitation of the study because of the difficulty in isolating the effects of the drills alone.

Because the underprepared participants were the focus of the study, their performances across measures were examined. For each course content unit there was a significant difference between pretest to unit test performances, as well as pretest to posttest performances by the underprepared participants in both the experimental and the control group. The experimental group increased their scores from the unit exams to the posttest on four of the five opportunities, with the fifth score remaining the same from the unit exam to the posttest. The control group's averages decreased from the unit exam to the posttest on four of the five opportunities, and the fifth score showed an increase of performance.

The difference in the pattern of Unit Five scores might be explained by the brief time period between the unit exam and the course final - a period of only two days. A limitation of the study was the variation of time intervals between drilling procedures and the final exam. For some course content there was an eight-week interval between the drills intervention and the final exam, while the final unit had only a two-day interval. Future studies could provide assessment of test items from all units across the entire course. This assessment could provide specific data about the effects of the drills on skills acquisition, by observing the changes after each unit's presentations.

Although the differences were not statistically significant, the trend of skill increases in the experimental group suggests that the drills may have contributed to better stimulus control of the participants'responses, i.e. retention, as time lapsed. Future studies could re-evaluate 
participants after longer periods of time to determine if this trend continued following the use of daily drills.

A content analysis examined the performances of participants on test questions that contained content directly or indirectly related to the daily drills. The control group answered more Unit One questions on the pretest and unit exam than the experimental group. The posttest scores on Unit One were the same for both groups. Like Unit One, the experimental group answered slightly fewer questions correctly on the pretest of Unit Three than the control group. However, on the unit exam and posttest the experimental group answered slightly more questions correctly. The experimental group answered more questions correctly than the control group on Units Two, Four, and Five.

The number of correctly answered questions that required application of the drilled terms showed significant changes from the pretest to the unit exam and from the pretest to the posttest. On Unit One and Unit Five, the experimental group participants raised their scores from the unit exam to the posttest. Likewise, the control group participants raised their scores from the unit exam to the posttest on Unit Two and Unit Four. No consistent advantages of exposure to daily drills were evident. The response pattern to questions that required students to use drilled course content on related test items revealed little difference between groups.

The instructional accomplishment computation reflected each student's progress toward a grade of "C" $(70 \%)$ on the posttest. Seven of the eleven underprepared students $(63.63 \%)$ in the experimental group demonstrated an instructional accomplishment of greater than $70 \%$, while only one of four participants (25\%) in the control group demonstrated comparable improvement. In other words, the majority of the students in the experimental group showed $70 \%$ or better gains toward the course criterion. While only three of the eleven underprepared participants $(27.27 \%)$ in the experimental group and one of the four $(25 \%)$ underprepared participants met or exceeded the course criterion, the improvement toward the goal-indicated by the instructional accomplishment measure-was notable.

The multiple baseline test design provided a closer look at a small number of questions across multiple opportunities to respond. The analysis revealed little difference between groups. The design could not isolate the daily drills from other instructional activities, so its use was limited. The daily drills added to the instruction provided to the experimental group appeared comparable to the instruction provided to the control group. Continuous assessments of course 
content skills, as mentioned earlier, could better substantiate the effects of the drills in a more specific and precise manner.

Initial scrutiny of the study suggested little difference in performance between groups. However, some of the results suggest alternative explanations and may represent limitations of the design of the study. Although the groups satisfied the Chi-square equivalence of gender and age, they were not randomly selected and participants may have not been equivalently distributed between groups. The experimental group of 27 participants had 11 individuals underprepared in reading. The control group of 20 students had only 4 individuals underprepared in reading. It seems likely that additional behavioral differences existed related to classroom success. The absence of a statistically significant difference between groups does not negate the possibility of the existence of related, but unmeasured differences.

Due to the nature of this study, the methods of exposure and practice of course content outside of the classroom were not controlled. Anecdotal data noted by the instructor during the class sessions suggested that the control group practiced more effective study habits than the experimental group. The control group formed study groups, utilized the course website with additional learning activities, and actively competed among themselves for better test scores. The initial formation of a study group of a few students seemed to model appropriate behavior for the remaining members of the control group. Several other groups formed and informally competed with each other. Appropriate studying became socially appropriate behavior and was reinforced by better grades, as well as peer acceptance. The control group reported that the experimental group had an advantage by using the drills and did not want them to exhibit better scores.

The experimental group reported that their increases in daily drill scores elicited feelings of preparedness for exams without further study. Only one study group formed to prepare for the final, and only a few students reported the use of additional study activities. Joking among group participants about poor grades was not uncommon. Bragging about passing a test without studying was a common theme among experimental group members. Scores achieved with minimal effort appeared to reinforce repeated patterns of minimal test preparation.

From anecdotal experimenter observation, it appears that the addition of daily drills to the classroom inadvertently contributed to a learning environment that included little course preparation by participants in the experimental group. Paradoxically, the perceived advantage of 
the inclusion of drills in course instruction resulted in increased course preparation by the participants in the control group.

Assuming that these self-reports were accurate, the daily drills may have served a valuable role in the training of the experimental group. The one-minute drills may have effectively substituted for learning activities exhibited by the control group. The improvement in reading and course content evidenced between groups was equivalent, in spite of the reported lack of additional exposure to the learning materials by the experimental group. In order to effectively measure the efficacy of drills within the classroom setting, external exposure to course materials would have to be controlled. If the in-class drills presented in one minute provided similar results to hours of outside preparation, then the time was well spent.

Beneke (1991) used daily drills within psychology classes to increase reading skills. He utilized course time to increase reading skills and gave up to $12 \%$ course credit for completing the drills. The experimental group significantly increased their reading rates and comprehension. No course credit was provided to the participants in the study under discussion and the reading skill increases occurred in both groups. Both groups in the current study increased vocabulary, comprehension, total reading scores, and reading rates; the control group by completion of course activities and the experimental group by completion of daily drills and course activities. Since the drills provided additional practice of course-related content, their inclusion seemed to be a viable instructional methodology that took no class time to directly address remedial instruction. The increases in reading and course content scores for students considered underprepared for college work suggest that the continued use of daily drills be considered.

Huffman (1998) determined that a combination of course preparation outside of the classroom and fluency training increased course functioning, as evidenced by exam scores. Specifically, students who were repeating the course and were exposed to training performed better than other students. His conclusion that "fluency training may have some value to those who need remedial work to pass the class" (p. 86) was supported by the current study. The underprepared students in this study reported minimal efforts outside of the classroom, yet significant improvement was noted from pretest to posttest.

It is noted that the participants in the current study may have never actually reached a level of skill fluency via the drills, classroom instruction, and/or completion of the course. The nature of the course provided constant shifts from topic to topic, so that skill acquisition of units 
presented during the initial weeks of the course were not required for success on later unit exams. Course vocabulary changed from unit to unit. The improvement of the experimental group's scores from the unit exams to the posttest could have been related to the increase in reading skills, better retention of course content as a result of the daily drills, or both. Future studies using courses that require cumulative course content skills acquisition, such as foreign language skills could provide more evidence of the effectiveness of daily drills.

Toward the end of the course instruction, fluency of reading skills or at least improved reading skills may have been a significant contributing variable to skill acquisition. Because the exams were in multiple-choice format, improved reading skills would likely increase the probability of more successful performances. Additional study that more closely examines actual reading skills improvement could provide a more precise explanation of the behavior changes from pretest to posttest.

Johnson and Layng (1992) and McDade and Goggans (1993) addressed the concept of tool skills, i.e. minimal skills necessary to build more complex and related skills. McDade and Goggans indicated that the appropriate level of silent reading fluency is " 250 words per minute with recall of $90-100 \% "$ (p. 293). The underprepared students in the experimental group of this study demonstrated an average reading rate of 189 words per minute at the end of the course, with no demonstration of recall. Reading fluency had not been established, but reading skills had been improved. Although most educators would agree that reading is a tool skill for the development of skills in a college-level psychology class, students successfully passed the course, seemingly without reading fluency.

Daily drills of course content without mastery requirements or incentives provided an additional pedagogical tool, but did not insure inclusion of course content into students' behavioral repertoires. Johnson and Layng (1992) described their model's requirements of learning as "remembering, enduring, and applying" (p. 1478). While this course, like most college courses, required the student to recall course content and apply the content into unique contexts, success in the course did not indicate fluency of the course content. Without such fluency, it seems unlikely that retention would occur after a period of time that exposure to the course content was unavailable. Although the higher scores at the conclusion of the course were promising, additional longitudinal data are necessary to determine if the integration of course content into student repertoires occurred. 
Students' anecdotal reports and the instructor's observations indicated that daily drills provided assistance toward the completion of the course objectives in the introductory psychology class addressed in this study. Fluency of terminology was not likely accomplished, but significant acquisition of course content did occur. As course content acquisition occurred within the control group at a similar pace, the data did not definitively support the use of daily drills. However, the data suggested that the drills might have served as an appropriate supplement to instruction, especially when students reportedly did not engage in study activities outside of the classroom.

Since the pre-existence of the tool skill of reading is not a requirement for entrance into college coursework on open admission campuses, teaching methodologies that provide additional interactions with course content and increase likelihood of vocabulary growth appear to be appropriate. Daily drills are cost-effective and time-efficient supplemental instructions that may serve this function. In the absence of opportunities to establish fluent tool skill repertoires, alternative instruction techniques such as daily drills appear to provide a viable method of instruction for underprepared students. Although limitations existed in the current study (i.e., using a convenient sample with clear differences between the groups at the outset, differences that developed throughout the study favoring the control group, not assuring mastery or fluency with the drills for the experimental group, and many exam items being different in design and format from the drill items), additional studies that address the acquisition (mastery) and retention (fluency) of course content skills using daily drills within this particular population are recommended. Those future studies could continue to identify specifically the effectiveness of this instructional alternative and to answer the questions prompted by the current study. 


\section{REFERENCES}

Adelman, C. (1996). The truth about remedial work. The Chronicle of Higher Education [On-line]. Available: http://chronicle.com, Section: Opinion, A56.

Anonymous (1999). The Landscape: From remediation to acceleration: Raising the bar in developmental education. Change, 31 (1), 57-60.

Beneke, W. M. (1991). Precision teaching to enhance reading skills of introductory psychology students. Journal of Precision Teaching, VIII, 37-43.

Binder, C. (1988). Precision Teaching: Measuring and attaining exemplary academic achievement. Youth Policy 10 (7), 12-15.

Binder, C. (1993). Behavioral fluency: a new paradigm. Educational Technology, 33, October, 8-14.

Binder, C. \& Watkins, C. (1990). Precision teaching and direct instruction: measurably superior instructional technology in schools. Performance Improvement Quarterly, 3 (4), 74-96.

Boylan, H. R., Bonham, B. S., White, S. R. (1999). Developmental and remedial education in postsecondary education. New directions for higher education, 27 (4), 87-101.

Brenneman, D. W. \& Haarlow, W. (1998). Remedial education: costs and consequences. Fordham Report [on-line]. Available: http://www.edexcellence.net/library/remed.html

Breneman, D. \& Haarlow, W. (1999). Establishing the real value of remedial education. The Chronicle of Higher Education [On-line]. Available: http://chronicle.com, Section: Opinion \& Arts, B6.

Brown, J. I., Fishco, V. V., Hanna, G. (1993). Nelson-Denny Reading Test: Manual for Scoring and Interpretation. Itasca, IL; Riverside Publishing Company.

Cohen, A. M. (1988). General education and the community college. ERIC Digest. (ERIC Document No. EDD00036).

Costrell, R. M. (1998). Commentary. In Brenneman, D. W. \& Haarlow, W. (1998).

Remedial education: costs and consequences. Fordham Report [on-line]. Available: http://www.edexcellence.net/library/remed.html

Crandell, M. (1999). Student academic achievement program review report: responses to the evaluation criteria. Marietta, Ohio: Washington State Community College. 


\section{REFERENCES (CONT.)}

Daly, P. M. \& Cooper, J. O. (1993). Persuading student teachers and inservice teachers to use precision teaching after the course is over. Education and Treatment of Children, 16 (3), 316-325.

Eshlemen, J. (2000). Guidelines and considerations for SAFMEDS. SAFMEDS on the Web. Available: http://members.aol.com/standardcharter/safmeds.html

Foy, J. G. (1994). Academic standards and basic skills in higher education: empowerment of the student and the teacher. College Student Journal, 28 (3), 275-280.

Fraley, L. E. (1980). The role of measures in the contingencies on teacher behavior. In L. E. Fraley (Contrib. Ed.), Behavioral Analyses of Issues in Higher Education. Reedsville, WV: Society of the Behavioral Analysis of Culture.

Fraley, L. E. (1998). Adverse implications for university teaching concealed in economically driven policies. The Behavior Analyst, 21 (2), 289-305.

Gose, B. (1997, September 19). Tutoring companies take over remedial teaching at some colleges. The Chronicle of Higher Education [On-line]. Available: http://chronicle.com, Section: Students, A44.

Hebel, S. (1999). As need for remediation grows, 2-year colleges must fill the gap, officials agree. The Chronicle of Higher Education [On-line]. Available: http://chronicle.com, April 9, 1999.

Hennessey, J. H. (1990). At-risk community college students and a reading improvement course: a longitudinal study. Journal of Reading, 34 (2), 114-120.

Huffman, W. E. (1998). Fluency training as a pedagogical tool to improve performance of undergraduate students enrolled in the first financial accounting course at a four-year regional Oklahoma university. Unpublished doctoral dissertation, University of North Texas, Denton.

Johnson, K. \& Layng, T. V. J. (1993). Breaking the structuralist barrier: literacy and numeracy with fluency. American Psychologist, 47, 1475-1490.

Lazarick, L. (1997). Back to the basics: remedial education. Community College Journal 68 (2), 10-15.

Levy, S. A., \& Dixon, M. E. (1984). Student reading ability vs textbook readability at a community college. Educational Research Quarterly, 9 (1), 43-47. 


\section{REFERENCES (CONT.)}

Lindsley, O. R. (1992). Why aren't effective teaching tools widely adopted? Journal of Applied Behavior Analysis, 25 (1), 21-26.

Lindsley, O. R. (1992). Precision teaching: discoveries and effects. Journal of Applied Behavior Analysis, 25 (1), 51-57.

McDade, C. E., Cunningham, D. B., Brown, J. M., Boyd, B. B., \& Olander, C.P. (1991). A minute a day to enhanced reading skills. Journal of Precision Teaching, 8, 27-33.

McDade, C. E., \& Goggans, L. A. (1993). Computer-based precision learning: achieving fluency with college students. Education and Treatment of Children, 16, 3, 290-305.

Miller, I. K. \& Weaver, F. H. (1972). A multiple baseline achievement test. In G. Semb, Editor, Behavior Analysis \& Education-1972. (pp. 393-399 ). Lawrence, Kansas: Support and Development Center For Follow Through.

Napoli, A. R. \& Hiltner III, G. J. (1993). An evaluation of developmental reading instruction. Journal of Developmental Education, 17 (1), 14-20.

Olson, M. A. (1986). Reading difficulty and the community college student. Community College Review, 14, 22-30.

Palmer, J. C. (1984). Do college courses improve basic reading and writing skills? Community College Review, 12, 20-28.

Parsons, J. (2001). Celeration technologies fluency glossary of terms. [On-line]. Available: http://members.home.net/joeparsons/index.html

Pennypacker, H. S., Koenig, C. H., \& Lindsley, O. R. (1972). Handbook of the standard behavior chart. Kansas City, KS: Precision Media.

Phipps, R. (1998). College remediation: what it is, what it costs, what's at stake. Institute for Higher Education Policy. Washington, D. C.

Unknown Author. (2000). Riverside publishing: Nelson-Denny Test. Available: http://fiverpub.com/products/group/nd read indepth htm. Section: Forms.

Zhao, J. C. (1999). Factors Affecting Academic Outcomes of Underprepared Community College Students. Paper presented at the Annual Forum of the Association for Institutional Research (39 ${ }^{\text {th }}$, Seattle, WA, May 30-June 3, 1999). 
$\underline{\text { Appendix A }}$

Research Design and Procedures

\begin{tabular}{|c|c|c|}
\hline Procedures & Data & Analysis \\
\hline $\begin{array}{l}\text { Administer course content } \\
\text { pretest to both groups }\end{array}$ & $\begin{array}{l}\text { Number of test items } \\
\text { answered correctly }\end{array}$ & $\begin{array}{l}\text { Pretest-posttest comparison } \\
\text { for total group and } \\
\text { underprepared, question } \\
\text { content analysis }\end{array}$ \\
\hline $\begin{array}{l}\text { Administer Nelson-Denny } \\
\text { pretest to both groups }\end{array}$ & $\begin{array}{l}\text { Vocabulary, comprehension, } \\
\text { total reading, and reading rate }\end{array}$ & $\begin{array}{l}\text { Pretest-posttest comparison } \\
\text { for total group and } \\
\text { underprepared }\end{array}$ \\
\hline \multicolumn{3}{|l|}{$\begin{array}{l}\text { Administer daily drills for } \\
\text { Unit One }\end{array}$} \\
\hline $\begin{array}{l}\text { Administer Unit One Exam } \\
\text { and pretest for Unit Two }\end{array}$ & $\begin{array}{l}\text { Exam score following } \\
\text { intervention, Unit Two pretest }\end{array}$ & $\begin{array}{l}\text { Comparison of number correct } \\
\text { on pretest, exam, and posttest } \\
\text { of Unit One, multiple baseline } \\
\text { analysis for underprepared, } \\
\text { question content analysis }\end{array}$ \\
\hline \multicolumn{3}{|l|}{$\begin{array}{l}\text { Administer daily drills for } \\
\text { Unit Two }\end{array}$} \\
\hline $\begin{array}{l}\text { Administer Unit Two Exam } \\
\text { and pretest for Unit Three }\end{array}$ & $\begin{array}{l}\text { Exam score following } \\
\text { intervention, Unit Three } \\
\text { pretest }\end{array}$ & $\begin{array}{l}\text { Comparison of number correct } \\
\text { on pretest, exam, and posttest } \\
\text { of Unit Two, multiple baseline } \\
\text { analysis for underprepared, } \\
\text { question content analysis }\end{array}$ \\
\hline $\begin{array}{l}\text { Administer daily drills for } \\
\text { Unit Three }\end{array}$ & & \\
\hline
\end{tabular}


$\underline{\text { Appendix A (continued) }}$

\begin{tabular}{|c|c|c|}
\hline Procedures & Data & Analysis \\
\hline $\begin{array}{l}\text { Administer Unit Three Exam } \\
\text { and pretest for Unit Four }\end{array}$ & $\begin{array}{l}\text { Exam score following } \\
\text { intervention, Unit Four pretest }\end{array}$ & $\begin{array}{l}\text { Comparison of number correct } \\
\text { on pretest, exam, and posttest } \\
\text { of Unit Three, multiple } \\
\text { baseline analysis for } \\
\text { underprepared, question } \\
\text { content analysis }\end{array}$ \\
\hline \multicolumn{3}{|l|}{$\begin{array}{l}\text { Administer daily drills for } \\
\text { Unit Four }\end{array}$} \\
\hline $\begin{array}{l}\text { Administer Unit Four Exam } \\
\text { and pretest for Unit Five }\end{array}$ & $\begin{array}{l}\text { Exam score following } \\
\text { intervention, Unit Five pretest }\end{array}$ & $\begin{array}{l}\text { Comparison of number correct } \\
\text { on pretest, exam, and posttest } \\
\text { of Unit Four, multiple baseline } \\
\text { analysis for underprepared, } \\
\text { question content analysis }\end{array}$ \\
\hline \multicolumn{3}{|l|}{$\begin{array}{l}\text { Administer daily drills for } \\
\text { Unit Five }\end{array}$} \\
\hline Administer Unit Five Exam & $\begin{array}{l}\text { Exam score following } \\
\text { intervention }\end{array}$ & $\begin{array}{l}\text { Comparison of number correct } \\
\text { on pretest, exam, and posttest } \\
\text { of Unit Five for } \\
\text { underprepared, question } \\
\text { content analysis }\end{array}$ \\
\hline $\begin{array}{l}\text { Administer course content } \\
\text { posttest to both groups (final) }\end{array}$ & $\begin{array}{l}\text { Number of test items } \\
\text { answered correctly }\end{array}$ & Pretest-posttest comparison \\
\hline $\begin{array}{l}\text { Administer Nelson-Denny } \\
\text { posttest to both groups }\end{array}$ & $\begin{array}{l}\text { Vocabulary, comprehension, } \\
\text { total reading, and reading rate }\end{array}$ & Pretest-posttest comparison \\
\hline
\end{tabular}


Appendix B

$\underline{\text { Analysis of Data }}$

\begin{tabular}{|l|l|}
\hline \multicolumn{1}{|c|}{ Data compared } & \multicolumn{1}{c|}{ Analysis Procedure } \\
\hline $\begin{array}{l}\text { Pretest-posttest comparison of course content } \\
\text { (all participants) }\end{array}$ & T-test of dependent means (pretest to posttest) \\
T-test of independent means (pretests) \\
\hline Pretest-posttest comparison of Nelson Denny & Percentile ranking of vocabulary results \\
& Percentile ranking of comprehension results \\
& Percentile ranking of total reading results \\
& Percentile ranking of reading rates \\
\hline Pretest-posttest comparison of Nelson Denny & Percentage increase of percentile ranks \\
Reading Test (underprepared only) & T-test of dependent means \\
& Instructional accomplishment \\
\hline $\begin{array}{l}\text { Comparison of questions from pretest to Unit } \\
\text { Exam to posttest (all participants) }\end{array}$ & Average percentage correct \\
\hline Comparison of questions from pretest to Unit & Means comparison \\
Exam to posttest (underprepared only) & T-test of independent means (pretests) \\
& ANOVA (pretest, unit exam, posttest) \\
& Multiple baseline analysis \\
& Instructional accomplishment \\
\hline Content analysis of test questions & T-test of independent means (pretests) \\
(application and related)-(underprepared & ANOVA (pretest, unit exam, posttest) \\
only) & \\
\hline
\end{tabular}




\section{CURRICULUM VITAE}

DEBORAH THOMAS

3304 Clement Ave. • Parkersburg, WV 26104•

Home: 304-422-4964 • Work: 740-374-8716•

E-mail:dthomas@wirefire.com

EMPLOYMENT HISTORY

ASSOCIATE PROFESSOR OF PSYCHOLOGY

1996-PRESENT

WASHINGTON STATE COMMUNITY COLLEGE

MARIETTA, OH

- COORDINATES CAMPUS COURSES IN PSYCHOLOGY

- INSTRUCTS AND DESIGNS COURSES IN DEVELOPMENTAL PSYCHOLOGY, GENERAL PSYCHOLOGY, ABNORMAL PSYCHOLOGY, AND EDUCATIONAL PSYCHOLOGY

- ADVISES LIBERAL ARTS MAJORS AND SPECIAL NEEDS STUDENTS

WASHINGTON STATE COMMUNITY COLLEGE

MARIETTA, $\mathrm{OH}$

- REVIEWED AND ANALYZED DISABILITY DOCUMENTATION FOR ALL STUDENTS

- DEVELOPED AND COORDINATED ACCOMMODATIONS FOR STUDENTS WITH PHYSICAL, PSYCHIATRIC, AND LEARNING DISABILITIES

- SERVED AS CAMPUS ADVOCATE FOR STUDENTS WITH DISABILITIES

COUNSELOR AND SOCIAL WORKER (PRIVATE PRACTICE)

$1990-2000$

FRED J. KRIEG PH.D. AND ASSOCIATES VIENNA, WV

- PROVIDED INDIVIDUAL, COUPLES, GROUP, AND FAMILY COUNSELING

- CONSULTED WITH LOCAL SCHOOLS REGARDING LEARNING AND BEHAVIORAL PROBLEMS

- COORDINATED AND TRAINED PROFESSIONAL STAFF AT SHELTERED WORKSHOP TO UTILIZE MEDICAID SERVICES AND BILLING 
WESTERN DISTRICT MENTAL HEALTH CENTER

PARKERSBURG, WV

- COORDINATED MENTAL HEALTH SERVICES FOR AN EIGHT COUNTY CATCHMENT AREA

- SUPERVISED MENTAL HEALTH STAFF INCLUDING COUNSELORS, SOCIAL WORKERS, AND CASE MANAGERS

- WROTE FUNDING GRANTS FOR THE DEVELOPMENT AND CONTINUATION OF MENTAL HEALTH SERVICES

WESTERN DISTRICT MENTAL HEALTH CENTER

PARKERSBURG, WV

- PROVIDED COUNSELING AND CASE MANAGEMENT SERVICES TO MENTAL HEALTH CLIENTS

- REPRESENTED AGENCY SERVICES TO COMMUNITY SERVICE PROVIDERS AND EDUCATORS

- SERVED AS PSYCHOMETRICIAN AND CASE RECORD REVIEWERS

CENTRAL DISTRICT MENTAL HEALTH CENTER

- PROVIDED COUNSELING AND CASE MANAGEMENT SERVICES TO MENTAL HEALTH CLIENTS

- CONDUCTED PARENT TRAINING AND SELF-HELP SKILLS TRAINING WITHIN EARLY CHILDHOOD PROGRAM

- SUPERVISED STUDENTS IN CLINICAL INTERNSHIPS

EDUCATION

DOCTOR OF EDUCATION, EDUCATIONAL PSYCHOLOGY WEST VIRGINIA UNIVERSITY MORGANTOWN, WV

MASTER OF ARTS, COUNSELING AND GUIDANCE WEST VIRGINIA UNIVERSITY

MORGANTOWN, WV

BACHELOR OF ARTS, PSYCHOLOGY

\section{ADDITIONAL EXPERIENCE AND SKILLS}

- EXPERTISE IN PRESENTATION DEVELOPMENT; SAMPLE OF TOPICS INCLUDE TIME MANAGEMENT, STRESS MANAGEMENT, PARENT 
TRAINING, DIAGNOSIS AND TREATMENT OF MENTAL HEALTH DISORDERS, CLASSROOM MANAGEMENT, DISABILITY ISSUES

- UTILIZATION OF WORD PROCESSING, DATABASE, SPREADSHEET, PRESENTATION, AND STATISTICAL SOFTWARE

- DEVELOPMENT AND INSTRUCTION OF ONLINE CLASSES

- DEVELOPMENT OF DOCUMENTATION FORMATS FOR MENTAL HEALTH, DISABILITIES, AND CLASSROOM MANAGEMENT

- LICENSED AS PROFESSIONAL COUNSELOR AND CERTIFIED SOCIAL WORKER IN WEST VIRGINIA

- GRANT WRITING EXPERIENCE AND SUCCESS

- CONSULTATION OF DISABILITY ACCOMMODATIONS TO HUMAN RESOURCES PERSONNEL

- PRESENTED THEORETICAL PAPER AT ASSOCIATION OF BEHAVIOR ANALYSIS CONFERENCE 